\title{
Excavation of a Bronze Age Kerbed Cairn at Olcote, Breasclete, Near Calanais, Isle of Lewis
}

\author{
by Tim Neighbour \\ CFA Archaeology Ltd, Old Engine House, \\ Eskmills Park, Musselburgh EH21 7PQ \\ with contributions by \\ S Carter, M Church, M Johnson, \\ K McSweeney, P Milburn and G Warren
}

Scottish Archaeological Internet Report 13, 2005 www.sair.org.uk 
Published by the Society of Antiquaries of Scotland, www.socantscot.org with Historic Scotland, www.historic-scotland.gov.uk and the Council for British Archaeology, www.britarch.ac.uk

Editors John Lewis and Debra Barrie

Produced by Archetype Information Technology Ltd, www.archetype-it.com

Requests for permission to reproduce material from a SAIR report should be sent to the Director of the Society of Antiquaries of Scotland, as well as to the author, illustrator, photographer or other copyright holder.

Copyright in any of the Scottish Archaeological Internet Reports series rests with the SAIR Consortium and the individual authors.

The maps are reproduced from Ordnance Survey material with the permission of Ordnance Survey on behalf of The Controller of Her Majesty's Stationery Office, (c) Crown Copyright 2001. Any unauthorised reproduction infringes Crown copyright and may lead to prosecution or civil proceedings. Historic Scotland Licence No GD 03032G, 2002.

The consent does not extend to copying for general distribution, advertising or promotional purposes, the creation of new collective works or resale.

ISBN: 0903903814

ISSN: $1473-3803$ 


\section{Contents}

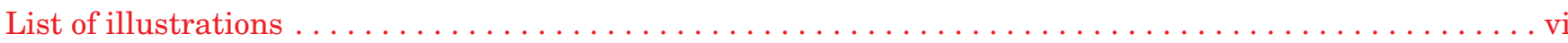

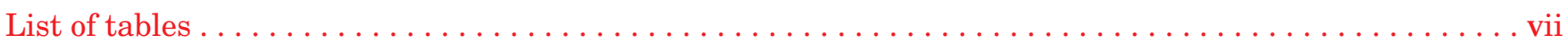

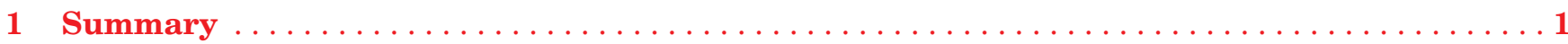

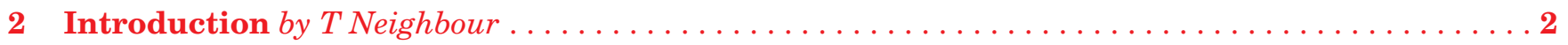

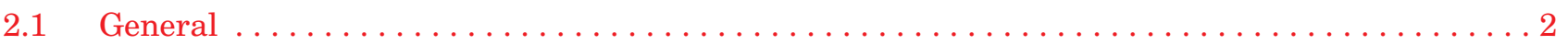

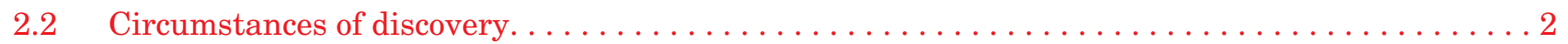

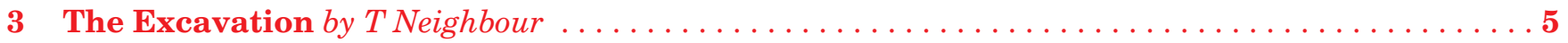

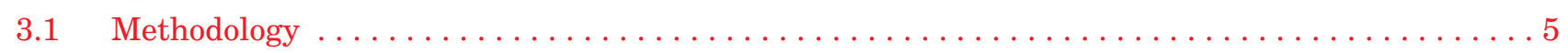

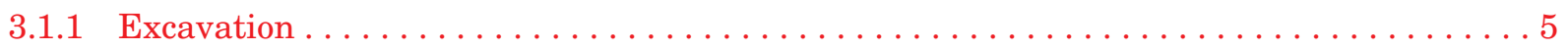

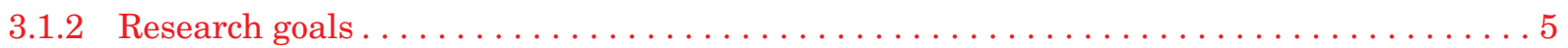

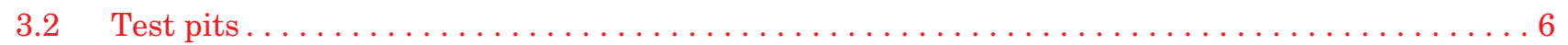

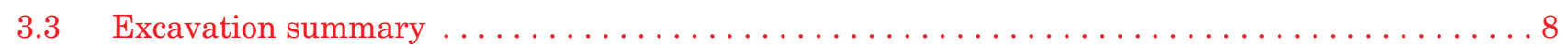

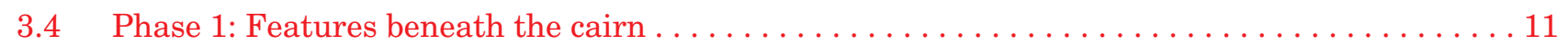

3.5 Phase 2: Cultivation marks and preparation of the ground $\ldots \ldots \ldots \ldots \ldots \ldots \ldots \ldots \ldots \ldots$

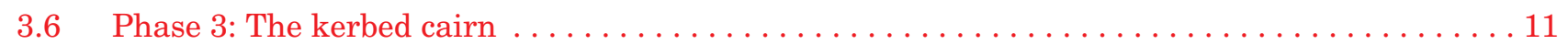

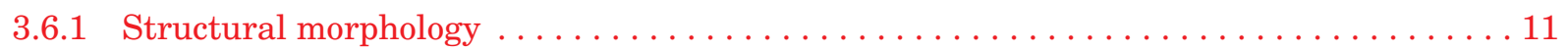

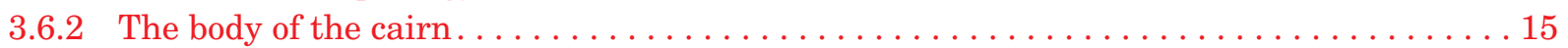

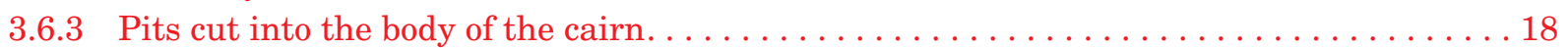

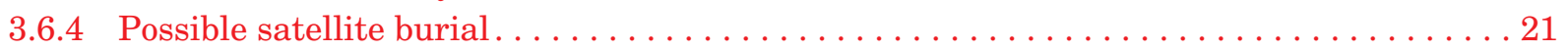

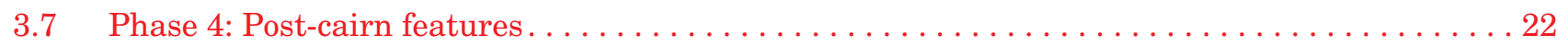

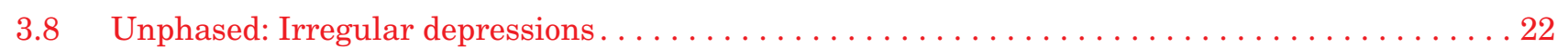

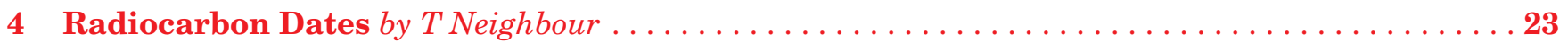

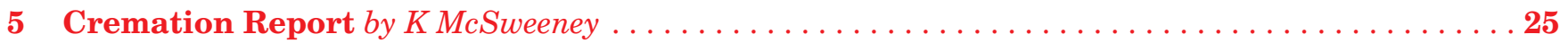

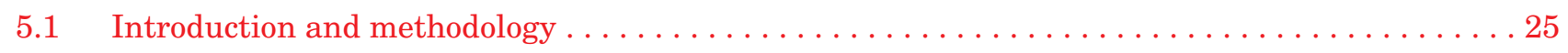

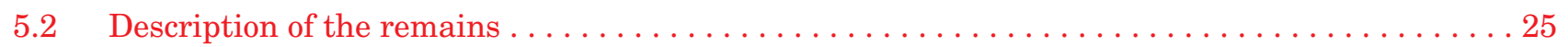

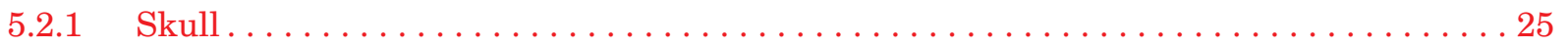

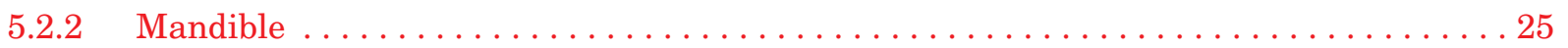

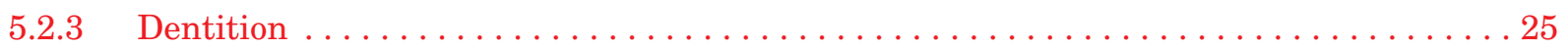

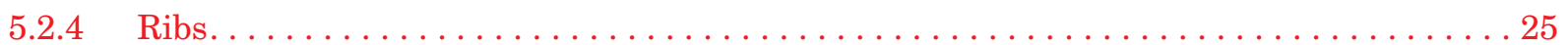

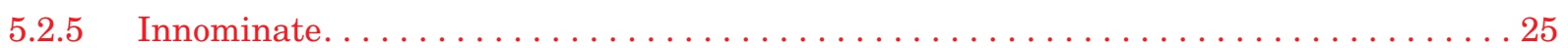

5.2 .6 Humerus . . . . . . . . . . . . . . . . . . . . . . . . . . . . . . 25

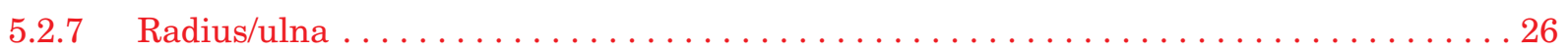

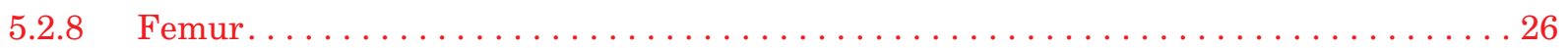

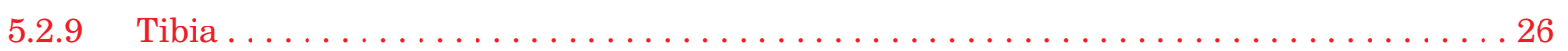

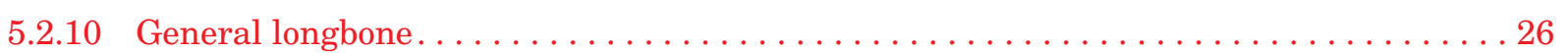

5.2 .11 Hands . . . . . . . . . . . . . . . . . . . . . . . . . . . . . 26

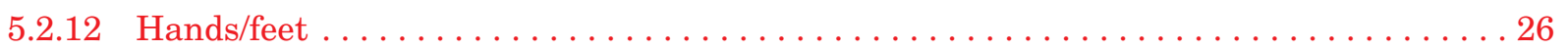

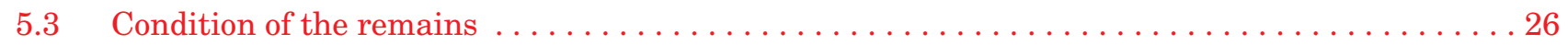

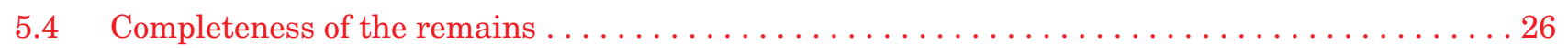




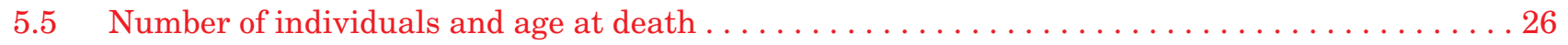

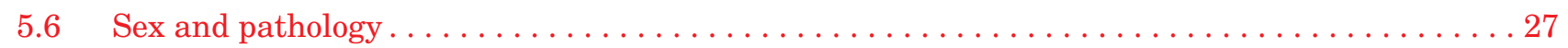

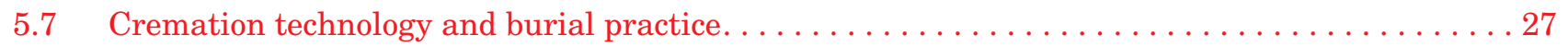

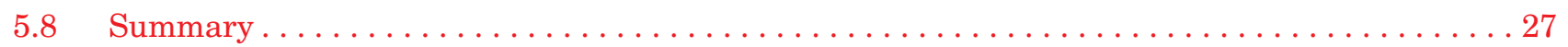

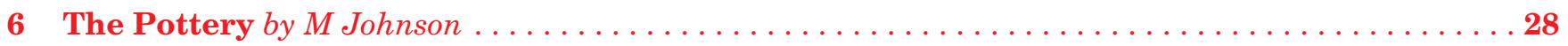

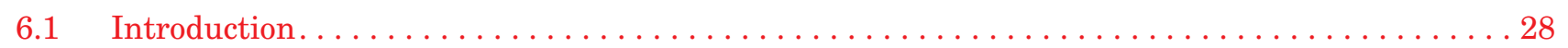

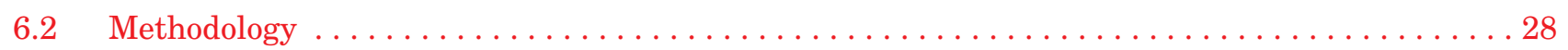

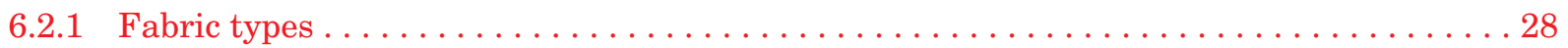

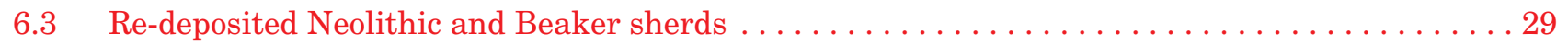

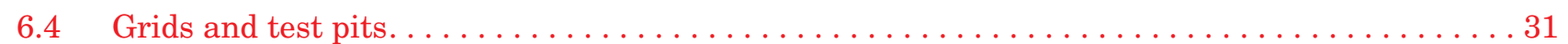

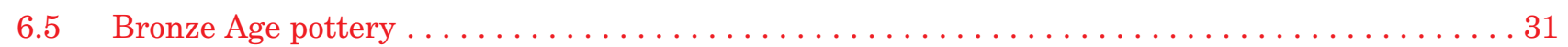

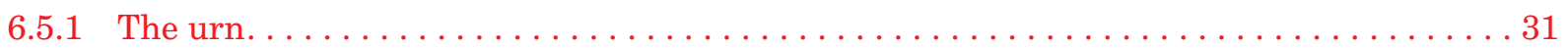

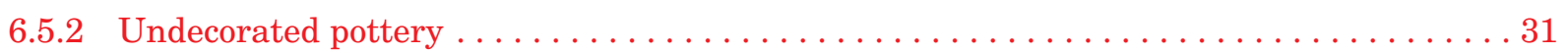

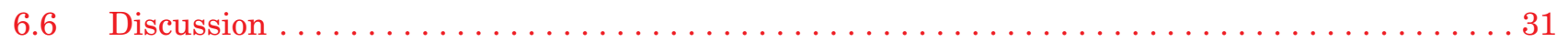

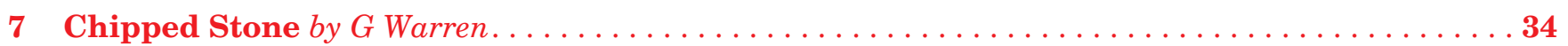

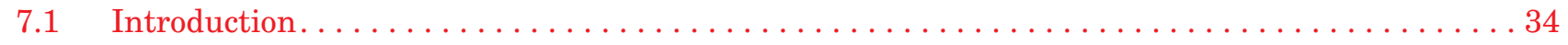

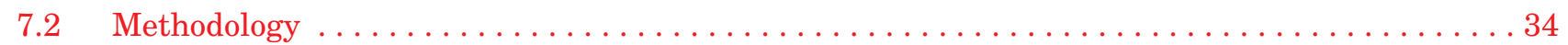

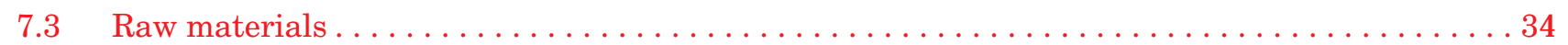

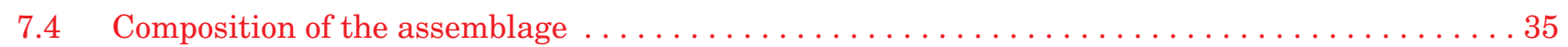

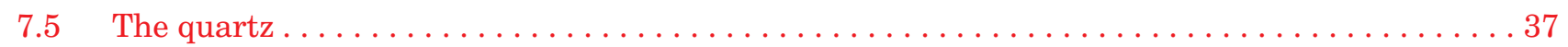

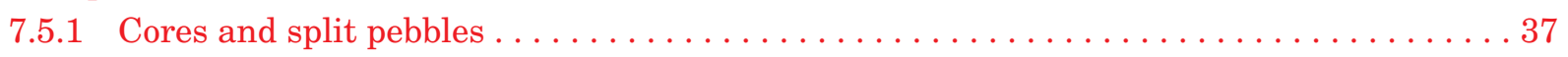

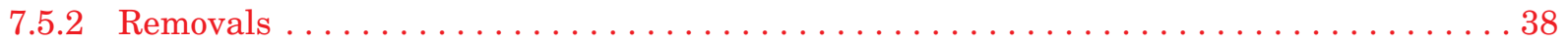

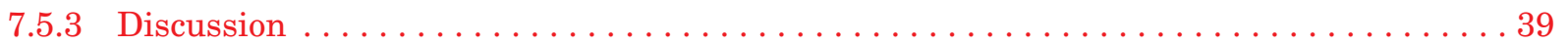

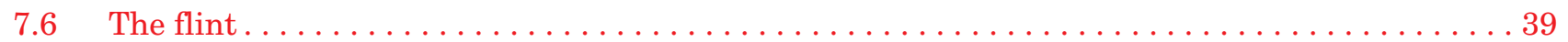

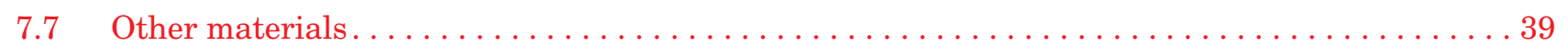

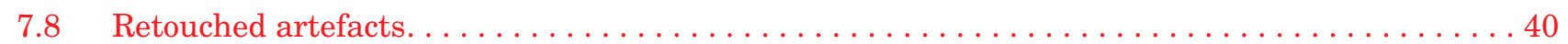

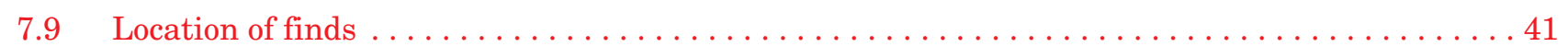

$7.9 .1 \quad$ Smalls. . . . . . . . . . . . .

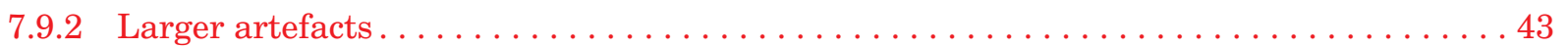

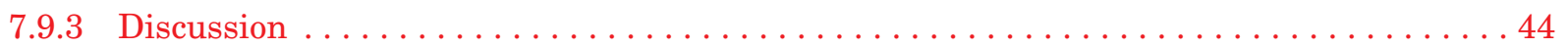

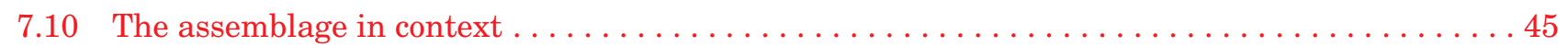

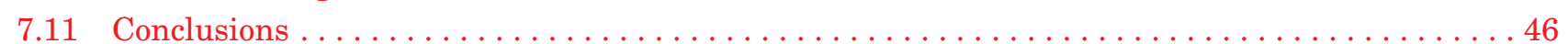

8 Sedimentary Analysis of Soil Samples by $M$ Church $\ldots \ldots \ldots \ldots \ldots \ldots \ldots \ldots \ldots \ldots \ldots$

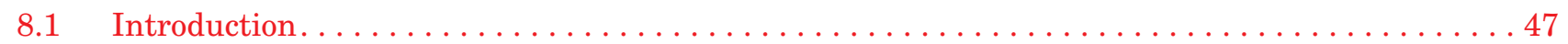

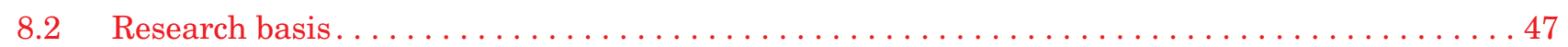

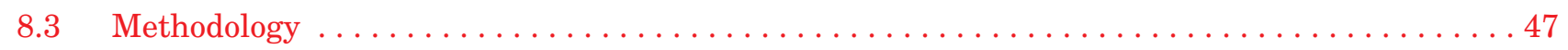

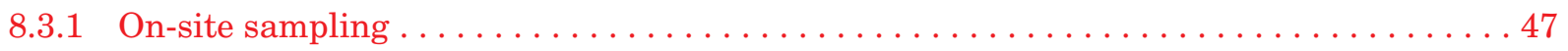

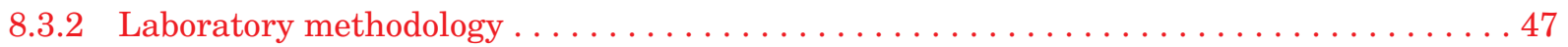

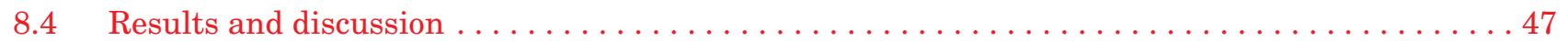

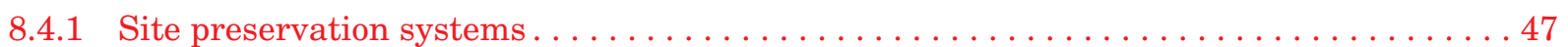

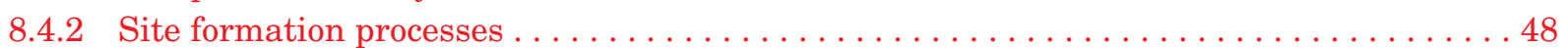

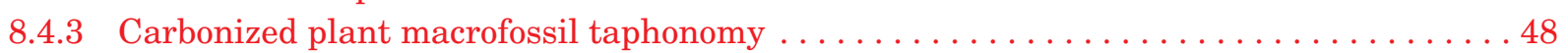

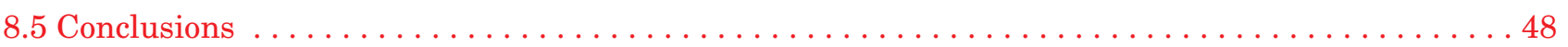

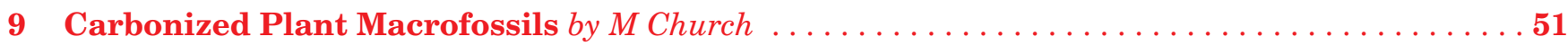

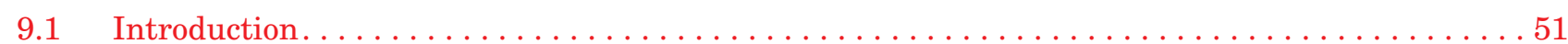




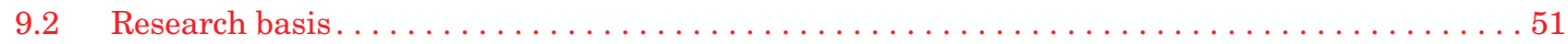

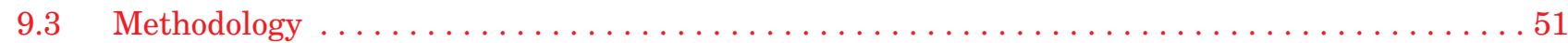

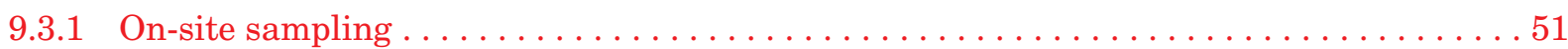

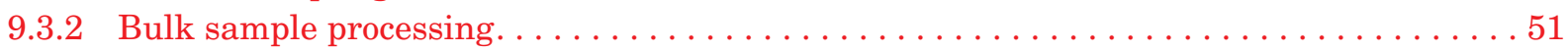

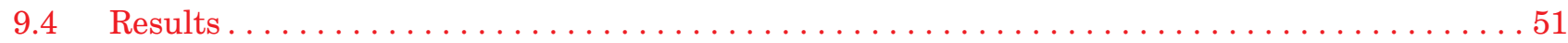

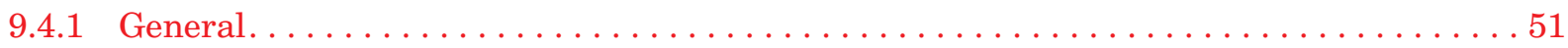

9.4 .2 Macrofossil preservation...................................... 51

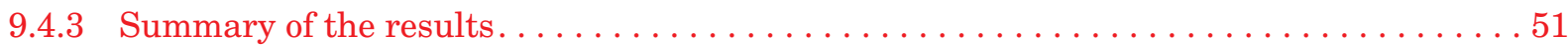

10 Analysis of Thin Sections from Ash Deposits Within the Cairn by $S$ Carter . . . . . . . . . 53

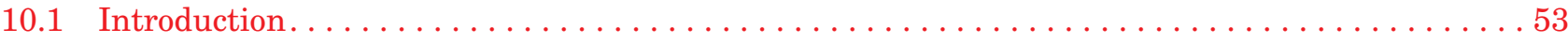

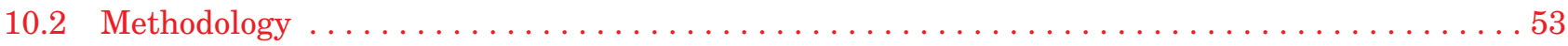

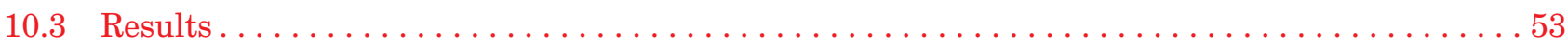

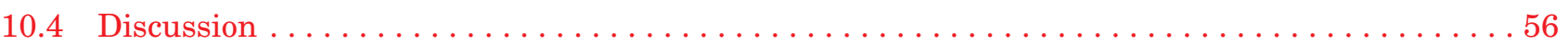

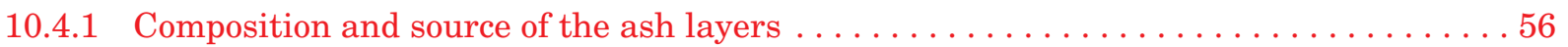

10.4.2 Composition and source of the humified organic bands . . . . . . . . . . . . . . 56

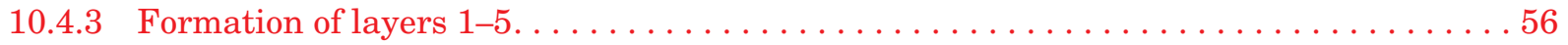

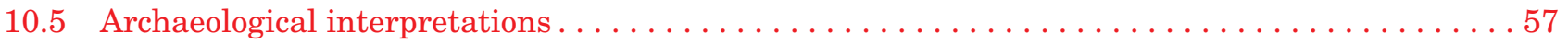

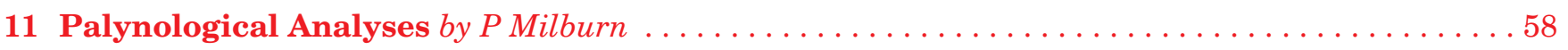

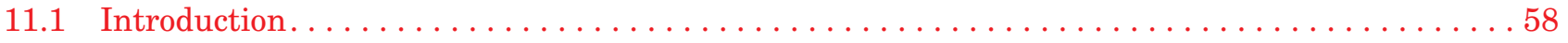

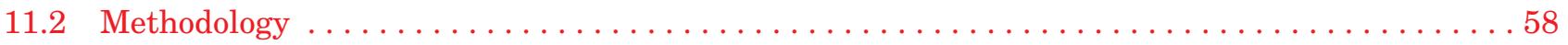

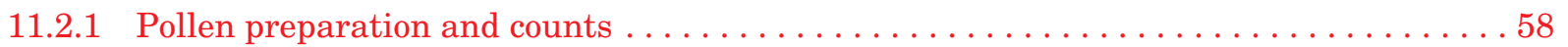

11.3 Results . . . . . . . . . . . . . . . . . . . . . . . . . . . . . . . . . . 58

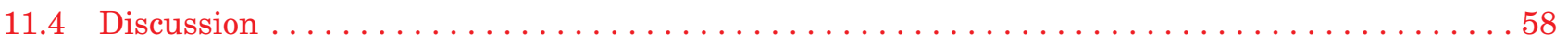

12 General Discussion by $T$ Neighbour ..................................6 60

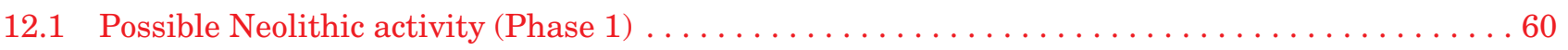

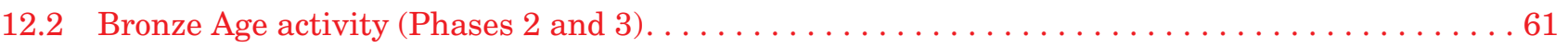

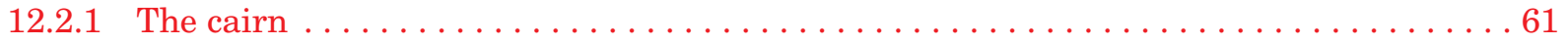

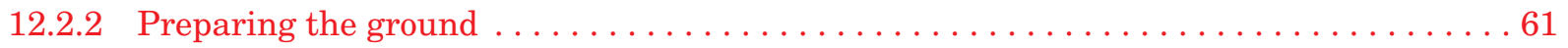

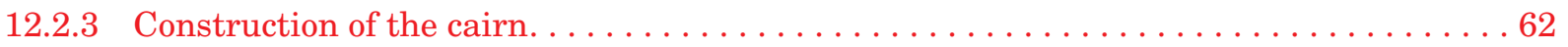

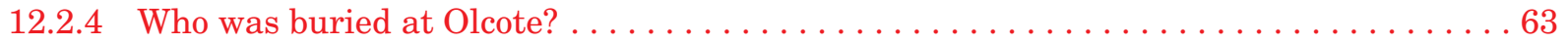

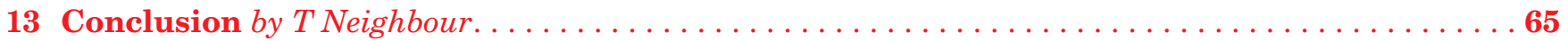

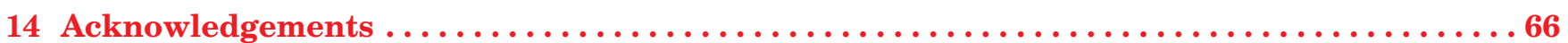

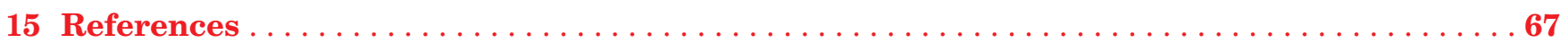

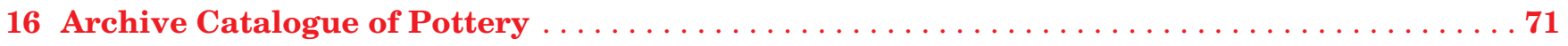

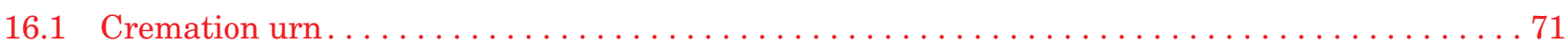

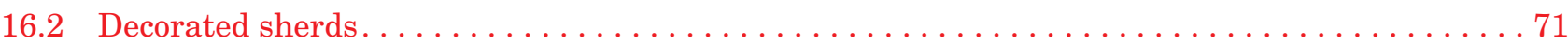

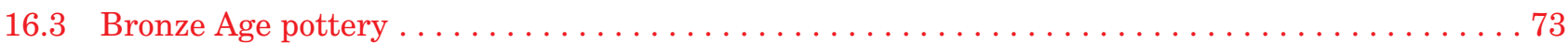

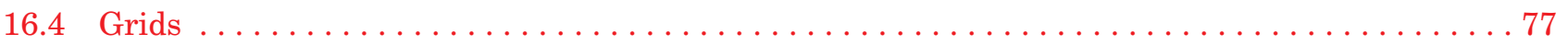

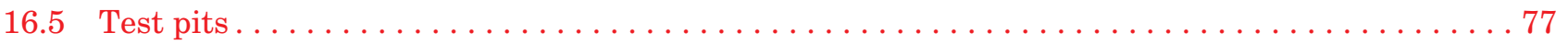




\section{List of illustrations}

Location maps (based on the Ordnance Survey @ Crown copyright)................ 3

The cairn from the south-west (courtesy of Air Sea Rescue) $\ldots \ldots \ldots \ldots \ldots \ldots \ldots \ldots \ldots$

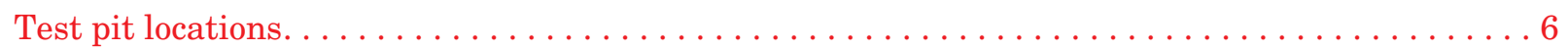

Number of quartz fragments within test pits: (a) absolute values, (b) quartz per

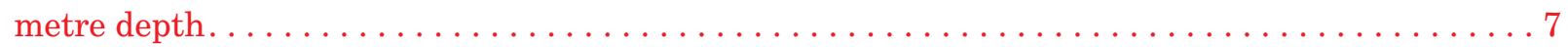

Number of worked and possibly worked quartz fragments within test pits (see Table 11) . . . . 8

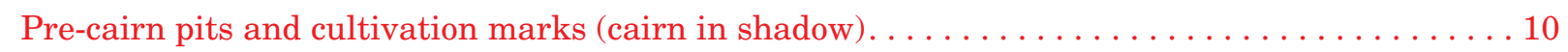

Pre-cairn pits. Dashed lines indicate possible structures (cairn in shadow) $\ldots \ldots \ldots \ldots \ldots 12$

Pre-cairn pits. Dashed lines indicate possible structures (cairn in shadow) $\ldots \ldots \ldots \ldots \ldots \ldots$

Cultivation marks beneath the cairn. Viewed from the south. . . . . . . . . . . . . . . . 14

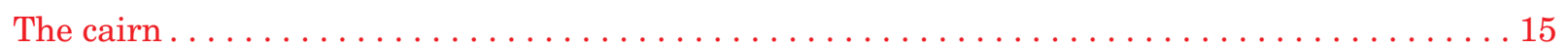

Possible interpretation of the inner kerb: penannular kerb and possible satellite

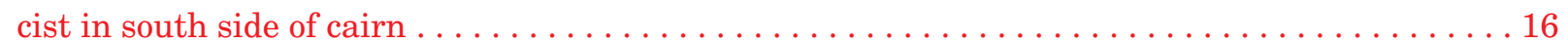

Longitudinal sections through the cairn: (a) east-west, (b) north-south $\ldots \ldots \ldots \ldots \ldots \ldots \ldots$

The central cist defined by three orthostats. The vessel is next to the western orthostat.

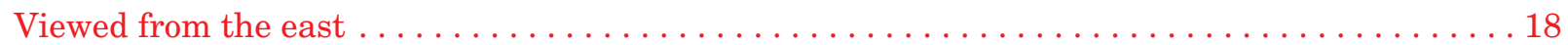

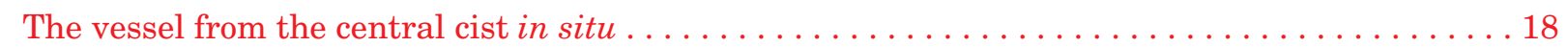

Areas of burnt peat (hatched) and pits within the makeup of the cairn . . . . . . . . . . 19

Pits within the upper surface of the makeup of the cairn, below the upper stones $\ldots \ldots \ldots \ldots 20$

(a) Smashed pot in hollow (167) within the re-deposited burnt peat. (b) Pit 183 in the

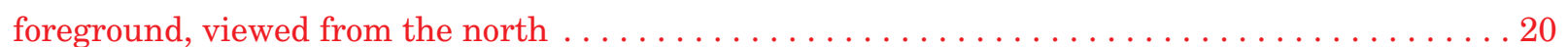

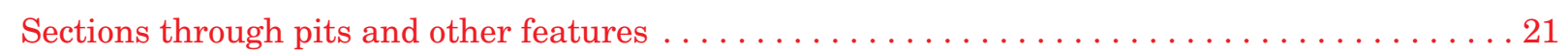

Magnetic susceptibility of burnt material 134 and underlying deposits (top of section

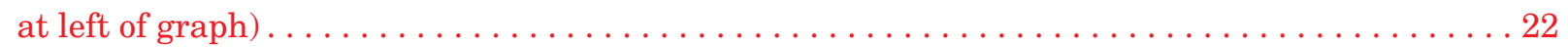

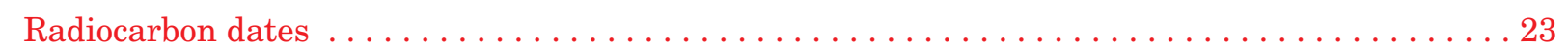

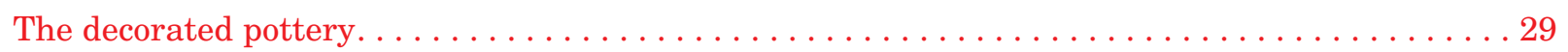

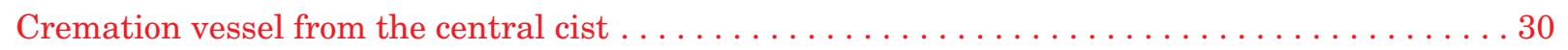

Worked stone. 1-2: cores; 3-7: flakes; 8-10 and 12: bipolar cores; 11: anvil split.

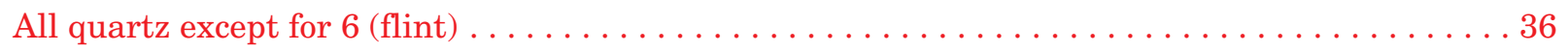

Width of platforms of quartz flakes. . . . . . . . . . . . . . . . . . . . . . 39

Worked stone. 13, 14, 16-21 and 23: short convex scraper; 15: long convex end scraper;

22: heavy convex scraper; 24: side scraper. All quartz except for $13,14,16$ and 19 (flint) $\ldots \ldots 40$

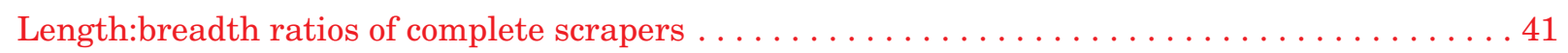

Worked stone from test pits. Top: barbed and tanged arrowhead, banded shale.

Bottom (left to right): scrapers, flint, flint, quartz $\ldots \ldots \ldots \ldots \ldots \ldots \ldots \ldots \ldots \ldots \ldots \ldots \ldots \ldots \ldots \ldots$ 


\section{List of tables}

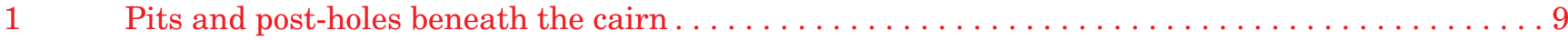

2 Radiocarbon dates from the kerbed cairn . . . . . . . . . . . . . . . . . . . . . 24

3 Radiocarbon dates relating to Bronze Age pottery assemblages in the Hebrides . . . . . . . . 33

4 Total quantities of stone recovered from the main trench . . . . . . . . . . . . . . 34

5 Totals of worked/possibly worked/natural pieces $>10 \mathrm{~mm} \ldots \ldots \ldots$

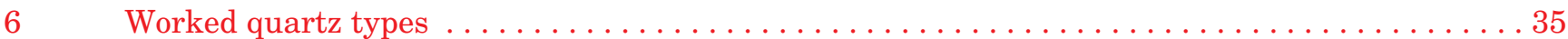

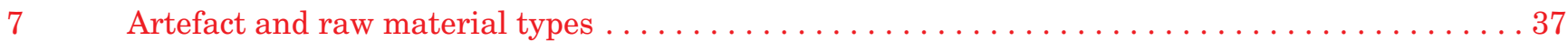

8 Quality of quartz used for anvil splits, split pebbles, bashed lumps, cores and bipolar cores . . . . 37

9 Weight (in g) of anvil splits, split pebbles, bashed lumps, cores and bipolar cores . . . . . . . . 38

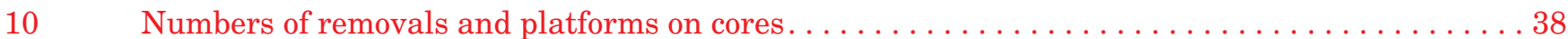

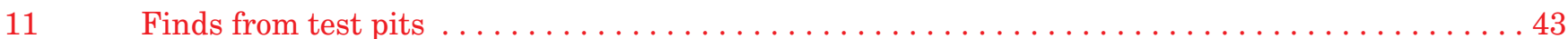

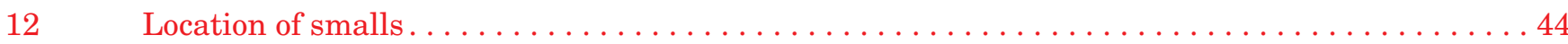

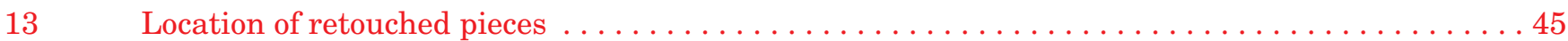

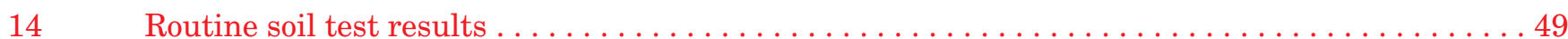

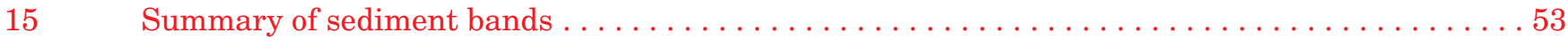

16 Summary descriptions of ash layers . . . . . . . . . . . . . . . . . . . . . . 54

17 Layers sampled for pollen from monolith samples. . . . . . . . . . . . . . . . . . 58

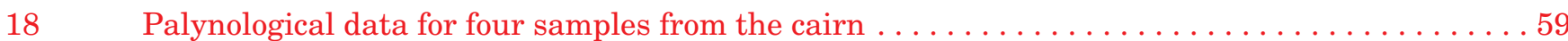




\section{Summary}

An archaeological excavation was carried out by the Centre for Field Archaeology (CFA) from October to December 1995 of a Bronze Age kerbed cairn at Olcote, Breasclete, Isle of Lewis (NGR: NB 2180 3475). The cairn was discovered by CFA during an evaluation of a dense scatter of worked and unworked quartz made by local archaeologists, Margaret and Ron Curtis. The remains lay in the path of the improvement of the single track road through Breasclete. A range of archaeological features and deposits was identified and recorded within the excavation trench. These fell into three groups on stratigraphic grounds: pre-cairn features, including pits, spade or cultivation marks and a buried ground surface; the cairn itself, including inner and outer kerbs, burnt peat deposits, a central cist and other features; and modern deposits which cut the cairn, including post-holes and field drains. Excavation and post-excavation were wholly funded by Historic Scotland. 


\section{Introduction by T Neighbour}

\subsection{General}

This report presents the results of an archaeological excavation carried out by the Centre for Field Archaeology (CFA) from October to December 1995 of a kerbed cairn (NGR: NB 2180 3475; Illus 1). The cairn (Illus 2) was discovered during the removal of topsoil along the line of a road-straightening operation at Breasclete on the Island of Lewis. Fieldwork was conducted in three separate blocks: 13-20 October, 30 October to 15 November and 27 November to 8 December 1995.

Throughout this report the cairn at Olcote is referred to as a 'kerbed cairn'. Other authorities (eg Neighbour 1996b; Campbell \& Coles 1999; Branigan \& Foster 2000; numerous Curtis \& Curtis entries in Discovery and Excavation in Scotland) have referred to similar sites in the Hebrides as 'kerb cairns' (Close-Brooks 1995 is a notable exception to this general rule). However, the term 'kerb cairn' was coined in the early 1970s (Ritchie \& MacLaren 1972) for a particular type of Bronze Age burial monument where very large boulders surround a small area within which a burial is placed (Ritchie memorably compares a kerb cairn to a 'petrified charlotte rousse', Ritchie et al. 1975, 30) and the use of that term to describe the monument at Olcote would be incorrect. Similarly, the site at Olcote cannot be described as a 'small cairn' (Ritchie \& MacLaren 1972) as the kerbs on such monuments tend to be rather more irregular than that at Olcote.

\subsection{Circumstances of discovery}

Following topsoil stripping of an area approximately $17 \mathrm{~m} \times 10 \mathrm{~m}$ in advance of a road-straightening project at Breasclete in mid-September 1995, a scatter of quartz was discovered by Margaret Curtis of Olcote, Calanais. Preliminary analysis suggested that a substantial proportion of the collected assemblage appeared to have been worked: chunks, cores and small flakes were recovered. The artefacts were collected from the surface of natural glacial till exposed within approximately $25 \%$ of the stripped area. The artefact scatter lay within a grassed and formerly cultivated field on a gentle north-facing slope where a soil depth of $0.2-0.4 \mathrm{~m}$ was present. The land dipped northwards to a former stream channel in which lay a deposit of peat over $1 \mathrm{~m}$ deep. To the south, on the summit of the rise and within the wayleave for the road, a scatter of stones was thought to indicate disturbed structural remains, although a purely natural origin was considered equally possible. Any remains associated with the artefact scatter within the road corridor were initially considered likely to have been heavily damaged and probably obliterated by the road construction.

The project was thus initially conceived as an important opportunity to conduct a controlled examination of a worked quartz assemblage recovered in situ. This artefact resource has often been under-researched in excavations in the Western Isles, with even relatively large quartz assemblages, such as those from the Loch Olabhat excavations (Armit forthcoming), being retrieved mostly by sieving. Accordingly, the initial objective of the project was to establish the extent, content, structural associations and date of the artefact scatter and assess the local geomorphological and environmental sequence, as this may have had a bearing upon the taphonomy of the artefacts. The location of the finds on a slope indicated that fieldwork would need to assess whether the artefacts were in their original discard context as opposed to being redeposited there by hillwash.

As it became clear that the artefact scatter was associated with the previously unsuspected buried structure, the objectives of the project altered. The revised objectives were: to record and excavate the structural remains; to determine if possible their nature, function, date and extent; and to place the excavated remains within their immediate environmental, geomorphological and topographic context. 


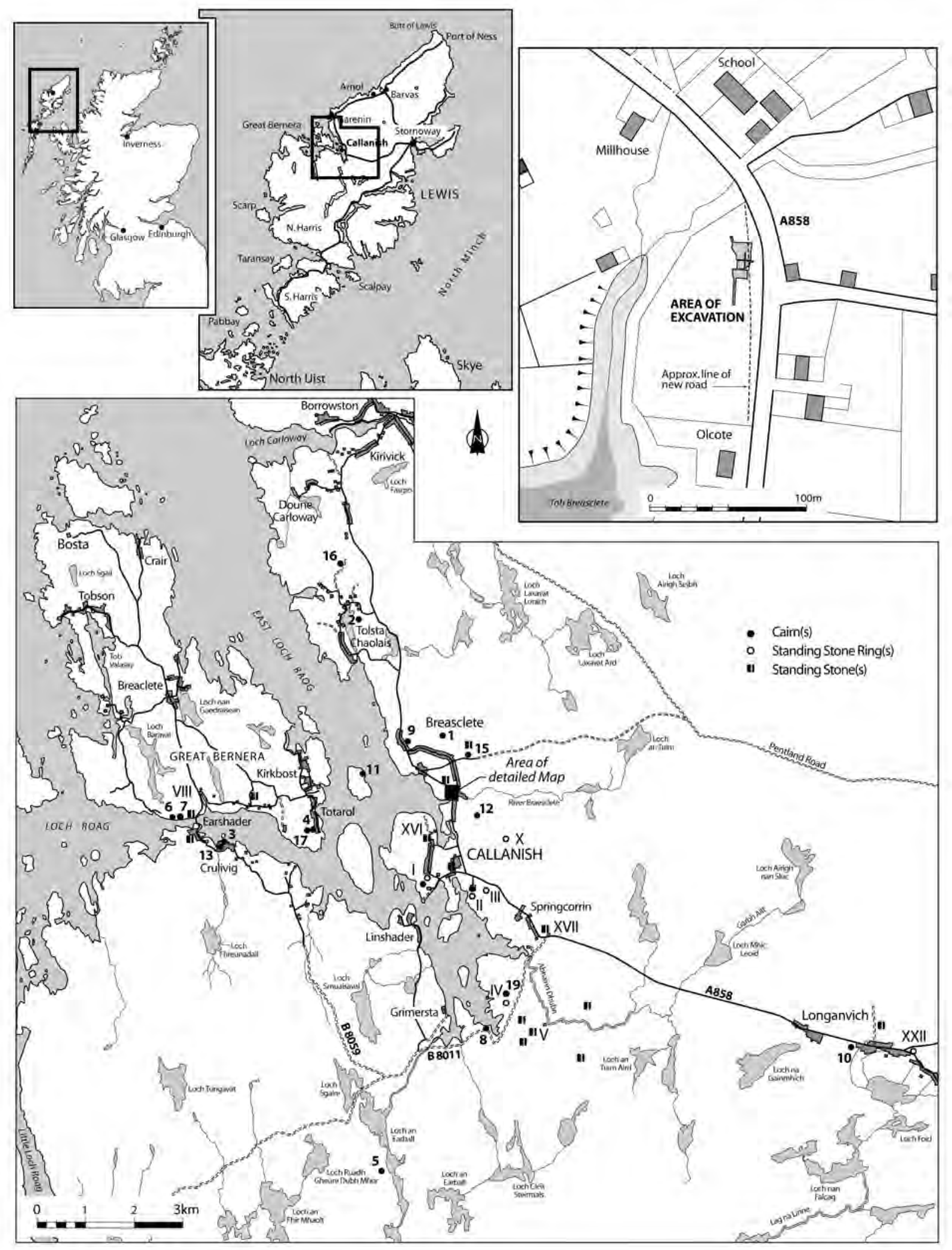

Illus 1 Location maps (based on the Ordnance Survey @ Crown copyright). Key on page 4 


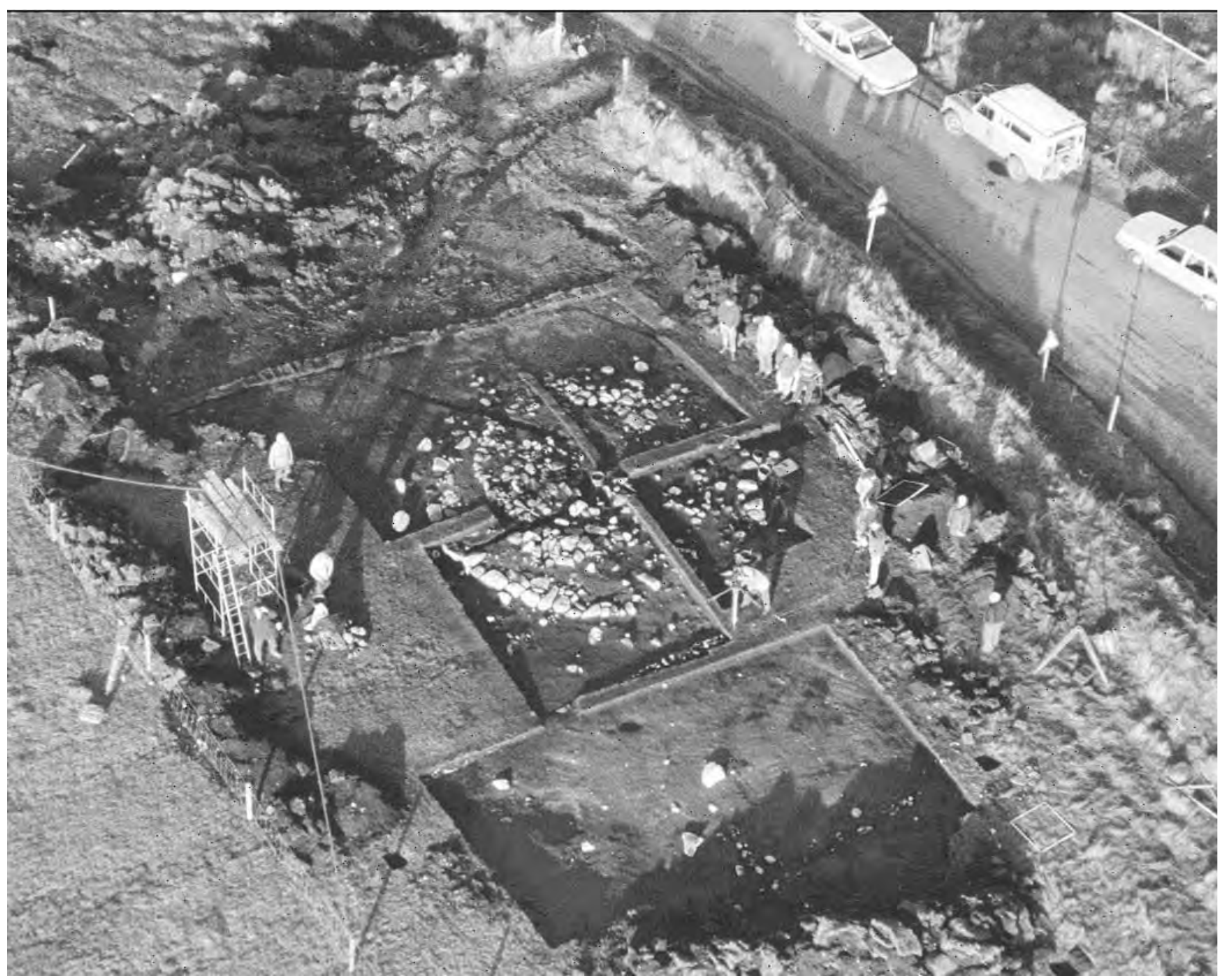

Illus 2 The cairn from the south-west (courtesy of Air Sea Rescue)

Illus 1 (opposite) Location maps (based on the Ordnance Survey Crown copyright). Key: 1: Kerbed cairn (NB23 NW8) - Curtis \& Curtis 1991a; 2: Probable kerbed cairn (NB13 NE12) - Curtis \& Curtis 1991b; 3: Possible burial cairn (NB13 SE15) - Curtis \& Curtis 1991c; 4: Possible burial cairn (NB13 SE16) - Curtis \& Curtis 1991d; 5: Possible kerbed cairn (NB22 NW5) - Curtis \& Curtis 1991e; 6: Possible kerbed cairn (NB13 SE20) - Curtis \& Curtis 1992a; 7: Possible kerbed cairn (NB13 SE21) - Curtis \& Curtis 1992b; 8: Possible kerbed cairn and possible burial cairn (NB22 NW6) - Curtis \& Curtis 1992c; 9: Possible burial cairn (NB23 NW11) - Curtis \& Curtis 1992d; 10: Possible burial cairn (NB32 NW4) - Curtis \& Curtis 1992e; 11: Burial cairn (NB13 NE13) - Curtis \& Curtis 1994; 12: Possible burial cairn (NB23 SW66) - Curtis \& Curtis 1997; 13: Possible kerbed cairn (NB13 SE14) - Curtis \& Curtis 1990a; 14: Chambered cairn (NB23 NW1) Henshall 1972, 460; 15: Two kerbed cairns (NB23 NW3) - Curtis \& Curtis 1995; 16: Possible burial cairn (NB13 NE8) - Curtis \& Curtis 1990b; 17: Kerbed cairn (NB13 SE13) - Curtis \& Curtis 1990c; 18: Kerbed cairn on Cnoc an Tursa - Campbell \& Coles 1999; 19: Burial cairn (NB23 SW4) - Ponting et al. 1976. Roman numerals - Standing stones and circles: numbers follow those on the map of standing stones and circles at Callanish (University of Glasgow, Department of Geography 1978) 


\section{The Excavation by $T$ Neighbour}

\subsection{Methodology}

\subsubsection{Excavation}

Initially, when the site appeared simply to be an artefact scatter, the fieldwork involved collection of artefacts based upon a $1 \mathrm{~m}$ grid within the originally stripped area just to the north of the buried structure. This procedure was abandoned when the emphasis of the project changed to become the more conventional 'set-piece' excavation of a discrete structure.

Excavation of a narrow, linear trench over the top of the rise within the wayleave for the road revealed a structure. The south-west quadrant was excavated through this structure in order to assess its archaeological significance. Subsequently, the entire structure was deturfed and excavated by hand. An 8 m-diameter cairn, defined by an outer kerb of substantial stones laid flat, was revealed. Traces of a probable inner kerb were also present. In the centre of the cairn was a damaged urn and fragments of cremated bone, which lay within the heavily disturbed remains of a possible burial cist. The main body of the cairn was formed from large stones, peaty soil and burnt, peaty turf. Post-holes and spade or cultivation marks were sealed beneath the cairn.

Following the definition of the extent of the cairn (Illus 2), areas to its north and south were machinestripped and rapidly cleaned to allow the identification of archaeological features. Long trenches were machine-excavated on either side of the main trench (Illus 1), to determine the varying depth of peat and to test for further features.

All finds were accurately located in three dimensions by Total Station, logging data on a portable computer running PenMap. It became clear over time that the whole of the cairn was carpeted randomly with quartz, much of it unworked, and thereafter small finds were recorded by context only. Thus, whilst the quartz fragments retrieved from the south half of the cairn were mainly recorded by context only, those recovered from its north side of the cairn were located accurately as small finds.

Modern roots were present within most of the layers that formed the body of the cairn although they do not appear to have led to significant bioturbation. This impression, formed during the excavation, was later confirmed by soil micromorphological analysis of a monolith sample taken through the ash layers that made up much of the body of the cairn (Section 10.4.1). The acidic nature and relatively low organic and moisture content of the site had precluded the preservation of bone, shell, uncarbonized plant macrofossils and insect remains (Section 8). Therefore, the main classes of material recovered were lithics, pottery, carbonized plant macrofossils and burnt bone.

\subsubsection{Research goals}

Of necessity, the principal research questions were formulated during the project, rather than in advance of it, and appropriate techniques and sampling strategies were employed to recover material for specialist analyses to attempt to answer those questions. In summary, the questions asked during the project were:

- Was the site of the cairn used prior to its construction and, if so, what form did that use take?

- How was the ground prepared prior to the construction of the cairn?

- Was the ash, which formed much of the body of the cairn, the result of burning in situ, or had it been imported from elsewhere?

- Did the ash result from the cremation rite?

- When was the cairn constructed?

- Did the cairn continue to form a focus for burial and for how long?

- For how long did the cairn retain its importance? When did the cairn disappear beneath the peat?

- How did the cairn relate to the known archaeological monuments in the wider landscape?

Such reactive research designs are an inevitable consequence of rescue archaeology, particularly on a site like Olcote, which was entirely unknown prior to fieldwork commencing. Despite this, it is felt that the research aims were both appropriate and achievable and, with the benefit of hindsight, that few opportunities to contribute significantly to other research agenda have been missed.

Time and money pressures dictated that only that part of the cairn which could not be saved from the road could be fully excavated. Thus, much of the site was excavated by Margaret and Ron Curtis. Their excavations chiefly focused on the pits beneath the cairn, but also included the putative satellite cist (168). The putative satellite cist is described here and the opportunity has been taken to address the patterning of the pits beneath the cairn and their potential date and significance. However, the struck stones from beneath the cairn and in association with the pits were not available for analysis and will form the subject of a further report. Thus, it should be understood that the interpretation of the pits beneath the cairn must be viewed as provisional. 


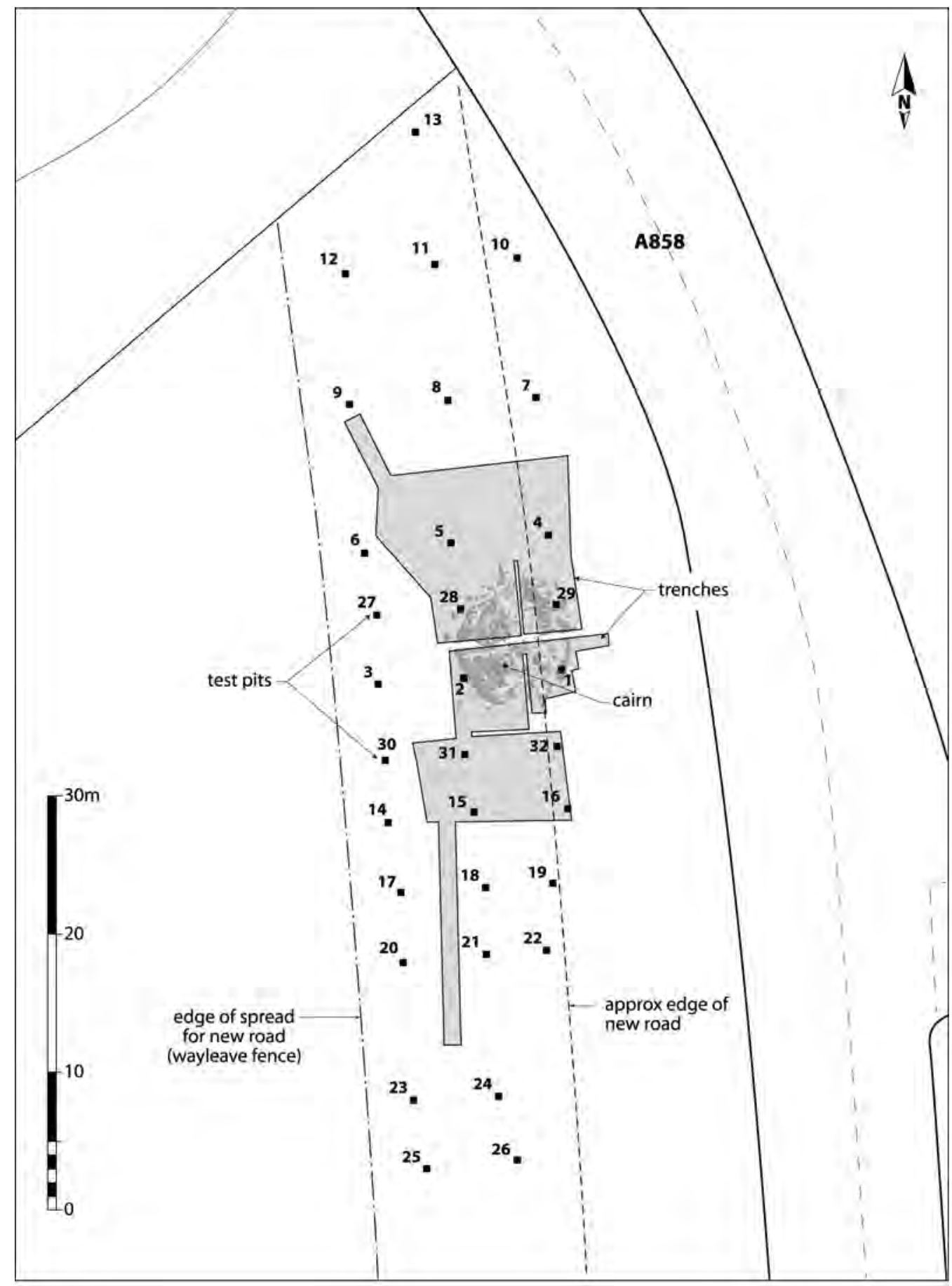

Illus 3 Test pit locations

\subsection{Test pits}

A grid of test pits, each $0.5 \mathrm{~m} \times 0.5 \mathrm{~m}$, was established between the road and the wayleave fence. The pits were positioned at 5-m intervals on three northsouth rows, generally $7.5 \mathrm{~m}$ apart (Illus 3 ), extending from a small burn to the south of the site, over a slight mound to a burn to the north. The test pits were excavated as far as the glacial till and the spoil was wet-sieved.

The quantities of quartz and flint recovered from the test pits were tabulated (Table 11) and plots of the data produced (Illus 4; Illus 5). The first plot (Illus 4a) shows absolute quantities of quartz (worked and unworked) found; the second plot (Illus 4b) shows quartz artefacts per metre depth and was produced to remove the inherent bias resulting from the varying depths of the test pits (from $0.04 \mathrm{~m}$ to $0.60 \mathrm{~m}$ deep). There was no need to calculate the volume of soil removed because the test pits were all the same dimensions in plan. The third plot (Illus 5) shows the quantities of worked and possibly worked 

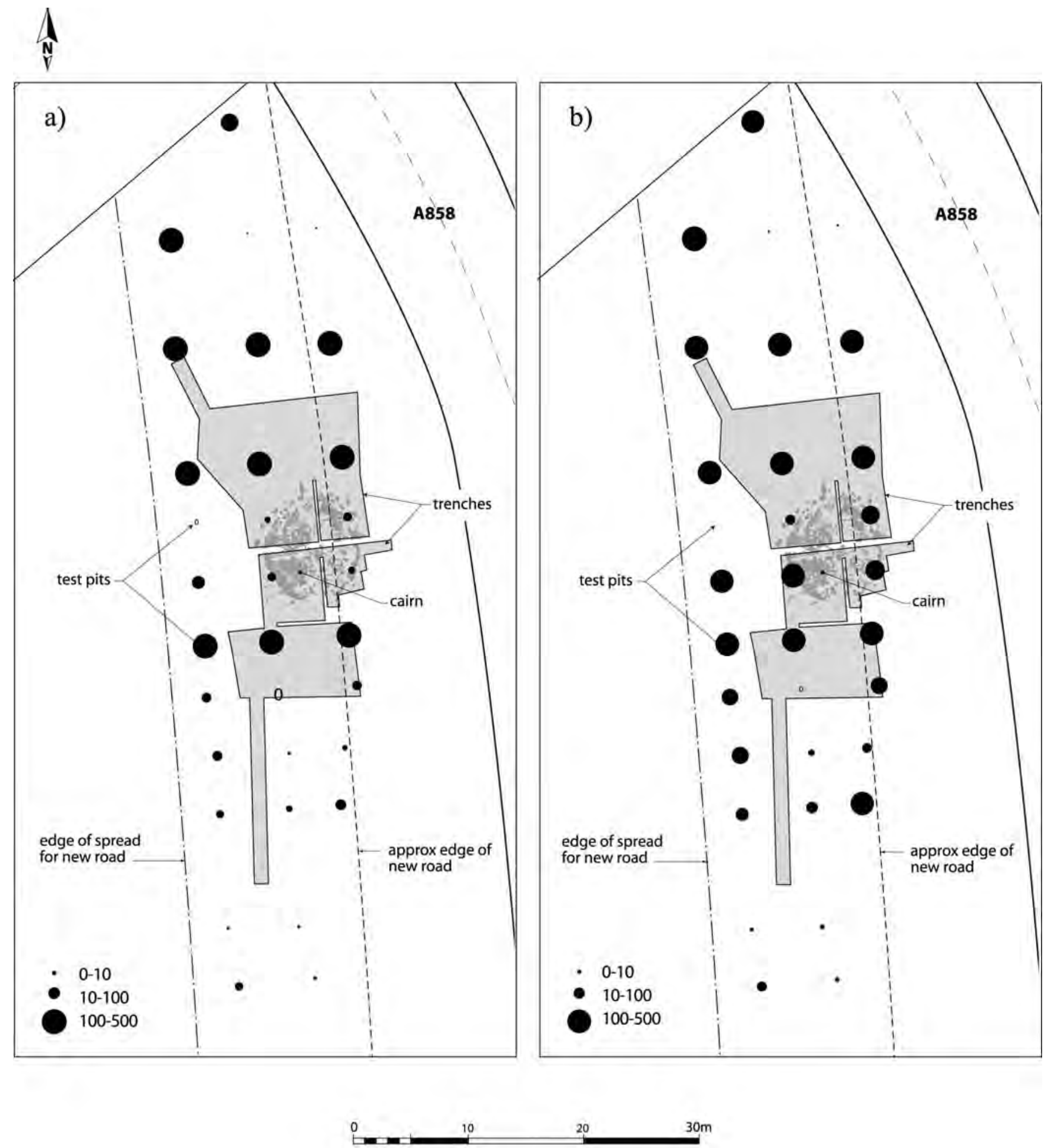

Illus 4 Number of quartz fragments within test pits: (a) absolute values, (b) quartz per metre depth

quartz in each test pit. Only two sherds of prehistoric pottery were recovered from the test pits; a plot of these data would be meaningless. For similar reasons, the low level of flint recovered has not been plotted.

Unsurprisingly, the density of quartz in test pits fell off with increasing distance from the cairn. There was no appreciable difference between the density to the south compared with that to the north of the cairn; the numbers of worked or possibly worked quartz fragments fell with distance from the cairn in a similar manner. The density of quartz was greater at the northern side of the cairn, perhaps indicating that the approach to the cairn in antiquity was from the north or north-east. 


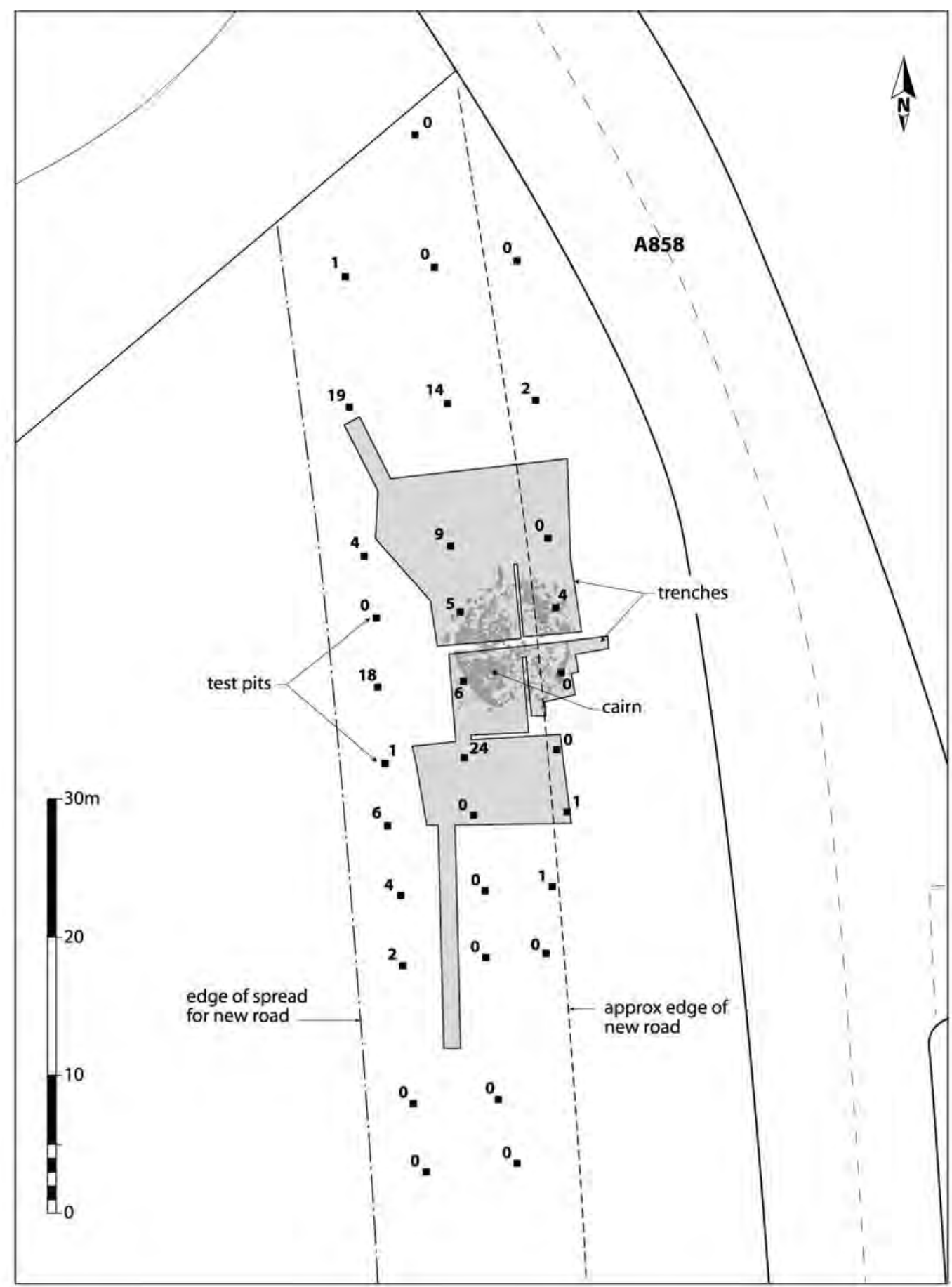

Illus 5 Number of worked and possibly worked quartz fragments within test pits (see Table 11)

\subsection{Excavation summary}

A range of archaeological features and deposits was identified and recorded within the excavation trench. These can be separated into four phases. In the following text, context numbers are used where appropriate to describe individual features and relate them to the plans and sections. The four broad phases that were revealed are summarized below:

- Phase 1: Features beneath the cairn (Illus 6; Illus 7 ; Illus 8)
- Phase 2: Cultivation marks and preparation of the ground (Illus 7; Illus 8; Illus 9)

- Phase 3: The kerbed cairn, including its construction and subsequent adaptation. A number of sub-phases can be identified within the monument (Illus 10-18)

- Phase 4: Post-cairn features, which cut the cairn, including post-holes and field drains (Illus 10)

- Unphased: A variety of negative features of irregular shape, all located outwith the cairn (Illus 7; Illus 8). 
Table 1 Pits and post-holes beneath the cairn

\begin{tabular}{|c|c|c|c|c|c|}
\hline Pit no & North-south or diameter & East-west & Pit no & North-south or diameter & East-west \\
\hline 124 & $0.77 \mathrm{~m}$ & & 244 & $0.25 \mathrm{~m}$ & $0.19 \mathrm{~m}$ \\
\hline 196 & $0.35 \mathrm{~m}$ & $0.18 \mathrm{~m}$ & 245 & $0.08 \mathrm{~m}$ & \\
\hline 197 & $0.22 \mathrm{~m}$ & $0.16 \mathrm{~m}$ & 246 & $0.08 \mathrm{~m}$ & \\
\hline 198 & $0.22 \mathrm{~m}$ & $0.20 \mathrm{~m}$ & 247 & $0.17 \mathrm{~m}$ & $0.07 \mathrm{~m}$ \\
\hline 199 & $0.18 \mathrm{~m}$ & & 248 & $0.08 \mathrm{~m}$ & \\
\hline 200 & $0.54 \mathrm{~m}$ & $0.22 \mathrm{~m}$ & 249 & $0.09 \mathrm{~m}$ & \\
\hline 201 & $0.23 \mathrm{~m}$ & & 250 & $0.07 \mathrm{~m}$ & $0.41 \mathrm{~m}$ \\
\hline 202 & $0.20 \mathrm{~m}$ & & 251 & $0.08 \mathrm{~m}$ & \\
\hline 203 & $0.23 \mathrm{~m}$ & & 252 & $0.09 \mathrm{~m}$ & \\
\hline 204 & $0.08 \mathrm{~m}$ & & 253 & $0.08 \mathrm{~m}$ & \\
\hline 205 & $0.09 \mathrm{~m}$ & & 254 & $0.09 \mathrm{~m}$ & \\
\hline 206 & $0.13 \mathrm{~m}$ & & 255 & $0.07 \mathrm{~m}$ & \\
\hline 207 & $0.08 \mathrm{~m}$ & & 256 & $0.18 \mathrm{~m}$ & \\
\hline 208 & $0.24 \mathrm{~m}$ & $0.20 \mathrm{~m}$ & 257 & $0.19 \mathrm{~m}$ & \\
\hline 209 & $0.07 \mathrm{~m}$ & & 258 & $0.16 \mathrm{~m}$ & \\
\hline 210 & $0.16 \mathrm{~m}$ & & 259 & $0.16 \mathrm{~m}$ & \\
\hline 211 & $0.16 \mathrm{~m}$ & $0.21 \mathrm{~m}$ & 260 & $0.19 \mathrm{~m}$ & \\
\hline 212 & $0.16 \mathrm{~m}$ & $0.08 \mathrm{~m}$ & 261 & $0.08 \mathrm{~m}$ & \\
\hline 213 & $0.12 \mathrm{~m}$ & $0.06 \mathrm{~m}$ & 262 & $0.18 \mathrm{~m}$ & \\
\hline 214 & $0.17 \mathrm{~m}$ & & 263 & $0.21 \mathrm{~m}$ & $0.17 \mathrm{~m}$ \\
\hline 215 & $0.07 \mathrm{~m}$ & & 264 & $0.19 \mathrm{~m}$ & \\
\hline 216 & $0.20 \mathrm{~m}$ & $0.12 \mathrm{~m}$ & 265 & $0.12 \mathrm{~m}$ & \\
\hline 217 & $0.18 \mathrm{~m}$ & & 266 & $0.08 \mathrm{~m}$ & \\
\hline 218 & $0.44 \mathrm{~m}$ & $0.21 \mathrm{~m}$ & 267 & $0.11 \mathrm{~m}$ & \\
\hline 219 & $0.18 \mathrm{~m}$ & & 268 & $0.11 \mathrm{~m}$ & \\
\hline 220 & $0.21 \mathrm{~m}$ & & 269 & $0.08 \mathrm{~m}$ & $0.21 \mathrm{~m}$ \\
\hline 221 & $0.19 \mathrm{~m}$ & & 270 & $0.10 \mathrm{~m}$ & \\
\hline 222 & $0.21 \mathrm{~m}$ & & 271 & $0.09 \mathrm{~m}$ & \\
\hline 223 & $0.10 \mathrm{~m}$ & & 272 & $0.20 \mathrm{~m}$ & $0.18 \mathrm{~m}$ \\
\hline 224 & $0.21 \mathrm{~m}$ & & 273 & $0.09 \mathrm{~m}$ & $0.19 \mathrm{~m}$ \\
\hline 225 & $0.14 \mathrm{~m}$ & & 274 & $0.11 \mathrm{~m}$ & \\
\hline 226 & $0.19 \mathrm{~m}$ & & 275 & $0.15 \mathrm{~m}$ & $0.08 \mathrm{~m}$ \\
\hline 227 & $0.20 \mathrm{~m}$ & $0.10 \mathrm{~m}$ & 276 & $0.07 \mathrm{~m}$ & \\
\hline 228 & $0.13 \mathrm{~m}$ & & 277 & $0.13 \mathrm{~m}$ & \\
\hline 229 & $0.13 \mathrm{~m}$ & & 278 & $0.16 \mathrm{~m}$ & \\
\hline 230 & $0.20 \mathrm{~m}$ & & 279 & $0.14 \mathrm{~m}$ & \\
\hline 231 & $0.18 \mathrm{~m}$ & & 280 & $0.26 \mathrm{~m}$ & $0.19 \mathrm{~m}$ \\
\hline 232 & $0.19 \mathrm{~m}$ & & 281 & $0.12 \mathrm{~m}$ & \\
\hline 233 & $0.21 \mathrm{~m}$ & & 282 & $0.14 \mathrm{~m}$ & \\
\hline 234 & $0.12 \mathrm{~m}$ & & 283 & $0.14 \mathrm{~m}$ & \\
\hline 235 & $0.09 \mathrm{~m}$ & & 284 & $0.13 \mathrm{~m}$ & \\
\hline 236 & $0.21 \mathrm{~m}$ & & 285 & $0.07 \mathrm{~m}$ & \\
\hline 237 & $0.25 \mathrm{~m}$ & & 286 & $0.24 \mathrm{~m}$ & $0.19 \mathrm{~m}$ \\
\hline 238 & $0.07 \mathrm{~m}$ & & 287 & $0.06 \mathrm{~m}$ & \\
\hline 239 & $0.11 \mathrm{~m}$ & $0.18 \mathrm{~m}$ & 288 & $0.06 \mathrm{~m}$ & \\
\hline 240 & $0.14 \mathrm{~m}$ & & 289 & $0.06 \mathrm{~m}$ & \\
\hline 241 & $0.14 \mathrm{~m}$ & & 290 & $0.09 \mathrm{~m}$ & \\
\hline 242 & $0.13 \mathrm{~m}$ & & 291 & $0.08 \mathrm{~m}$ & \\
\hline 243 & $0.09 \mathrm{~m}$ & & 292 & $0.10 \mathrm{~m}$ & \\
\hline
\end{tabular}




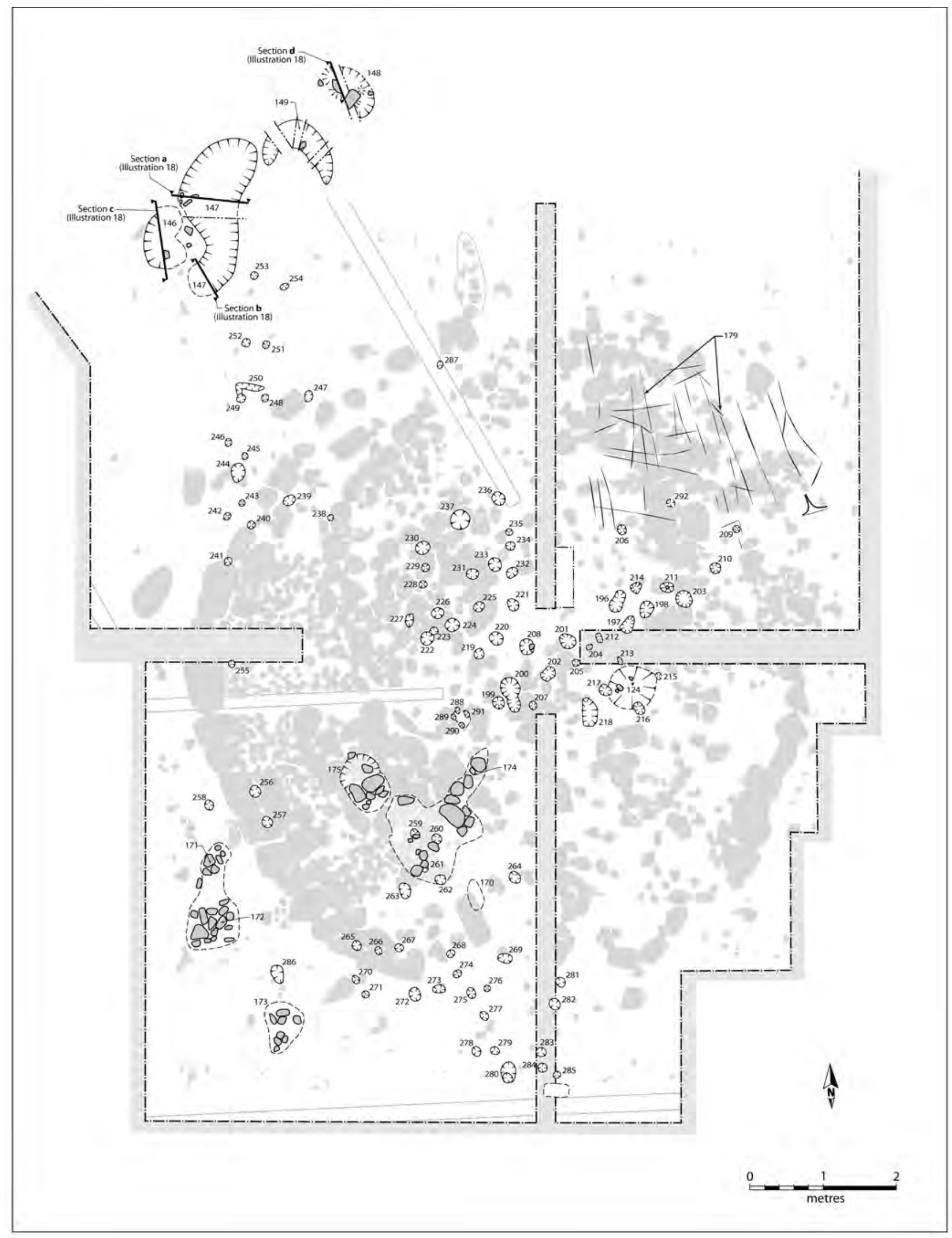

Illus 6 Pre-cairn pits and cultivation marks (cairn in shadow) 


\subsection{Phase 1: Features beneath the cairn}

Table 1 provides summary details of the pits sealed beneath the cairn (Illus 6). The ground upon which the cairn was built was levelled prior to its construction, and thus the pits have been truncated horizontally to an unknown extent. The depths of the features, which were all less than $0.1 \mathrm{~m}$, may bear little relation to their original depths. A large quantity of worked and unworked quartz was recovered from the pits and the area around the pits. This material will form the subject of a future report (see Section 3.1).

Alexander and Armit have had some success in applying spatial and morphological analyses to interpreting myriad pits (Alexander and Armit 1993). They describe an approach to this problem for a Neolithic and Bronze Age site at Wellbrae, near Thankerton, Lanarkshire which involved the use of such considerations as post-hole and pit dimensions, spatial patterning, the limited stratigraphic relationships between inter-cutting features and taking into account artefact content. They were fortunate in having a substantial ceramic assemblage, much of which was recovered from the pits and post-holes, which could be used to construct a relative stratigraphic model of greater elaboration than could have been achieved otherwise (Alexander and Armit 1993). Unfortunately, at Olcote, such diagnostic artefacts were absent from most of the features beneath the cairn. Furthermore, the unknown level of horizontal truncation suggests that the recorded depths and diameters of the pits do not necessarily reflect their original dimensions: the topography of this small area, prior to the construction of the cairn, cannot be convincingly recreated. As a consequence, any analysis of the pits rests upon a consideration of spatial patterning and, to a lesser extent, their dimensions (see Table 1 for these data).

The features fell into three broad sets: a group of pits beneath the main body of the cairn; a second group under the southern side of the cairn; and a further group to the north-west of the cairn. It would not be unreasonable to suggest that at least some of the pits were structural post-holes, despite the lack of packing stones within them.

Two interpretative diagrams of the pits are presented in Illus 7 and Illus 8. In the first (Illus 7), the pits are interpreted as a series of curving post-lines. In the second (Illus 8), a number of roughly rectangular or linear arrangements have been highlighted, although it is difficult to know whether this is purely by chance. Two of these rectangular pit arrays (C \& $\mathrm{M}$ on Illus 8 ) are sufficiently certain to have been included on both illustrations.

\subsection{Phase 2: Cultivation marks and preparation of the ground}

A layer of grey clay-like soil $(157,166)$ lay below the main material of the cairn. Linear marks (179) in this layer survived in the north-east quadrant (Illus 7; Illus 8; Illus 9). The marks ran both north-south and east-west, mostly beneath the cairn. This fact may reflect differing preservation, especially as the general area has been cultivated in the recent past. However, soil micromorphological analysis (Section 10) has demonstrated that, immediately prior to the construction of the cairn, the ground was prepared by removing turf and topsoil to the glacial till surface. This suggests that the fortuitous survival of cultivation marks beneath the cairn is unlikely. Rather, the marks are most likely to have been the result of preparation of the ground prior to the construction of the cairn and, in particular, during deturfing (Barclay 1997, 142). Indeed, it has been suggested that prehistoric cultivation marks, which are generally recorded as ard marks, are more usually the result of spade-work rather than ploughing (Barclay 1997).

A number of irregular depressions (170, 174 and 175) - the latter two filled with small, angular stones - proved to be hollows filled in prior to the construction of the main body of the cairn. There was no clue as to the function (if any) of these voids. Other hollows (unnumbered), clearly formed to accommodate the kerbstones, were generally covered with a crust of iron pan up to $10 \mathrm{~mm}$ thick.

\subsection{Phase 3: The kerbed cairn}

\subsubsection{Structural morphology}

The cairn had two kerbs (Illus 10). The outer kerb (108) was $8 \mathrm{~m}$ in diameter, roughly circular and was constructed of large local stones, laid flat. It appeared that the stone from the cairn had been heavily robbed in places. It survived at its most complete in the south-west quadrant. In the north-east quadrant the kerbs had been heavily disturbed, probably recently. This disturbed region has been numbered separately (109). The inner kerb (111) was formed of smaller stones and survived particularly well on the west side of the monument. Recent disturbance had ensured that the exact path of the inner kerb was difficult to follow.

In a preliminary account of the excavation (Neighbour 1996a) it was suggested that the inner kerb took the form of a flattened circle, with the flattened portion being on the west side. The mathematical construction axis of this inner kerb pointed directly up the avenue of the main site at Calanais some $1.6 \mathrm{~km}$ away. The diameter of such a kerb would have been about $6.5 \mathrm{~m}$ at maximum. However, interpretation of the inner kerb as a penannular feature (Illus 11), with its open side to the south, is now considered more probable. This hypothesis is strengthened by the presence of a roughly rectangular feature, possibly a later satellite cist (168), symmetrically placed between the horns of this feature.

If the inner kerb was a flattened circle, with its 


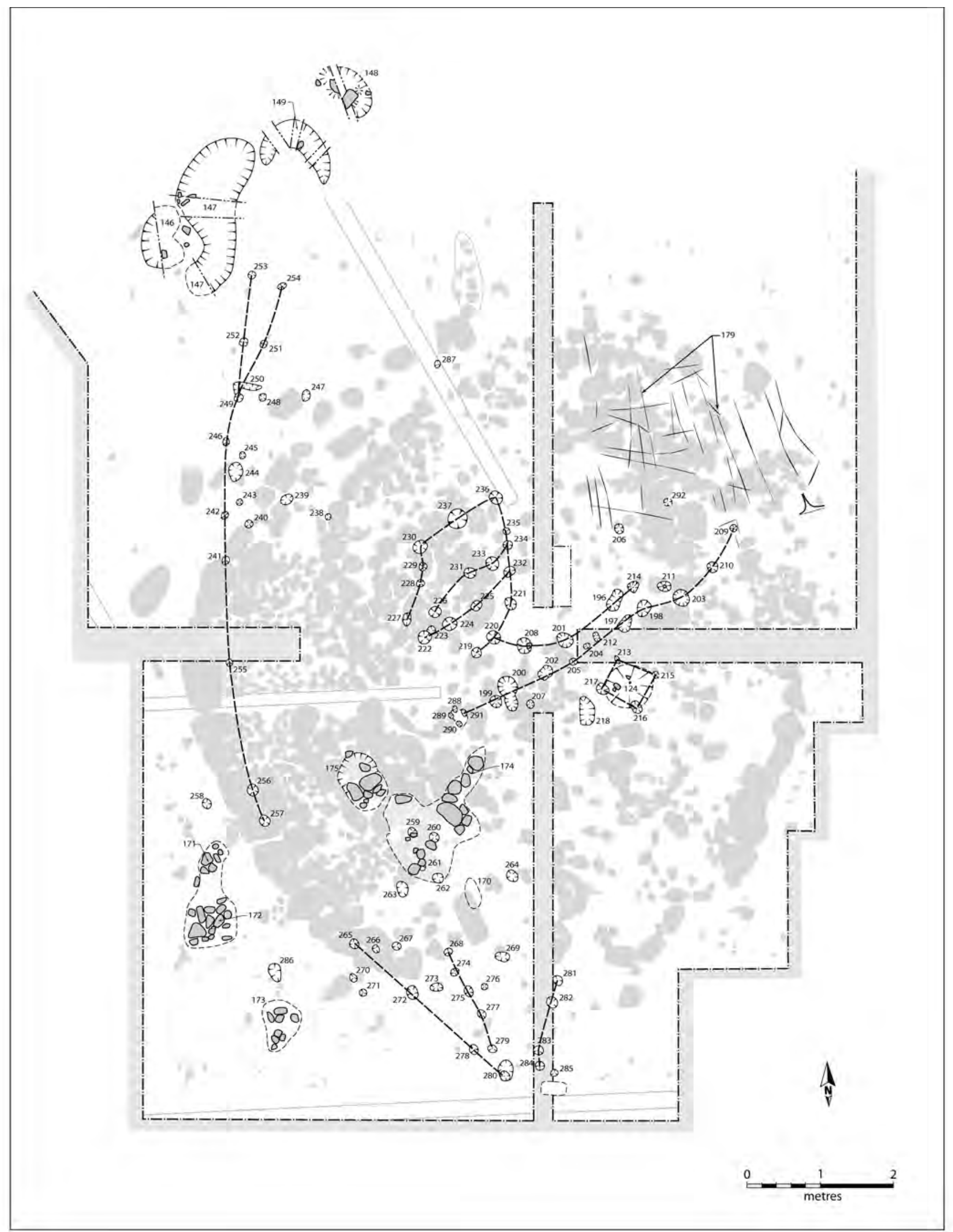

Illus 7 Pre-cairn pits. Dashed lines indicate possible structures (cairn in shadow) 


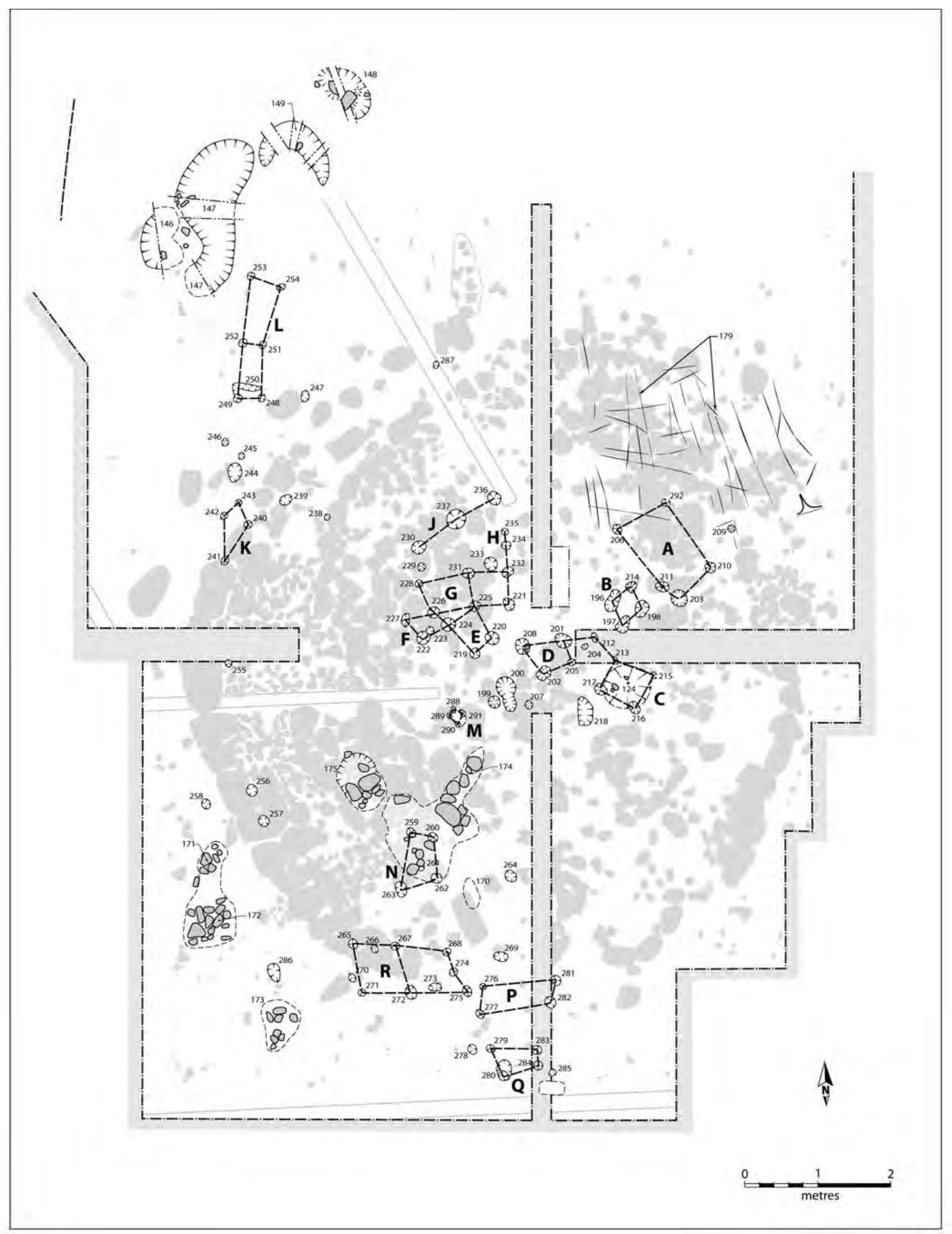

Illus 8 Pre-cairn pits. Dashed lines indicate possible structures (cairn in shadow) 


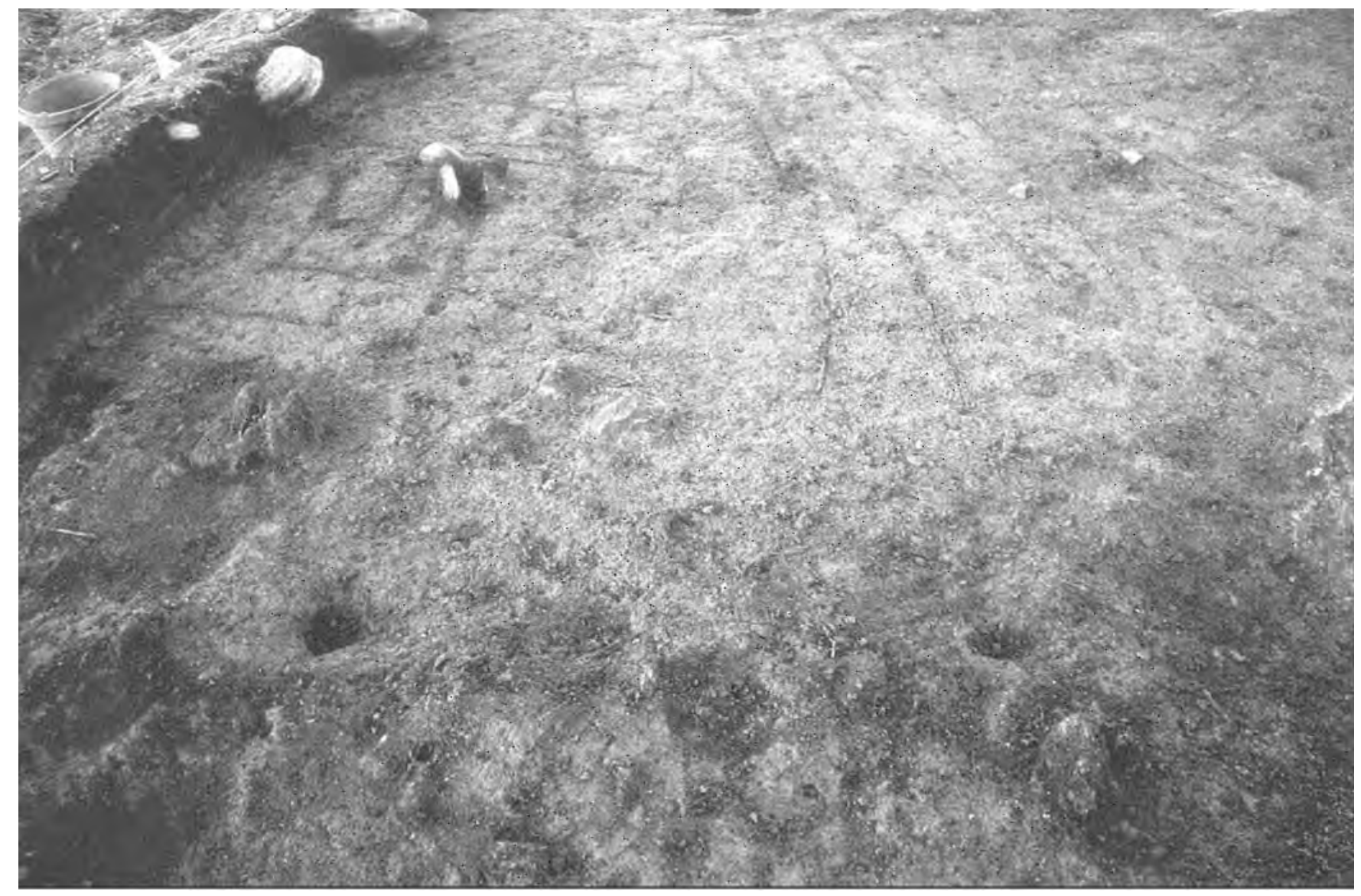

Illus 9 Cultivation marks beneath the cairn. Viewed from the south

construction axis pointing to the main site at Calanais, then an explanation for the presence of two kerbs is readily available. At Olcote, the outer kerb was roughly circular, in common with other examples of this tradition recorded throughout Scotland, whereas the inner kerb may have been designed intentionally to copy the flattened circle of stones at the main site. The flattened circle interpretation of the inner kerb was presented initially in a preliminary account of the excavation (Neighbour 1996a), although reflection has led to it being considered the less likely of the alternative morphologies. It is included here for completeness.

The different structural components of the cairn were difficult to phase. In particular, the two kerbs were at the same stratigraphic level (Illus 12a; Illus $12 \mathrm{~b}$ ) and it is impossible to say which came first by any other criterion, such as spatial arrangement. However, both kerbs clearly focused on the central cist (142, Illus 10; Illus 12a), and it seems most likely that both cairns were built at the same time. Cairns with double kerbs have been discovered elsewhere in the Hebrides.

The central cist (142) was formed by three orthostats (Illus 10; Illus 13), two of which had collapsed. A stone-hole (143; Illus 15) was located immediately to the east of the southern orthostat. A slightly broken, plain cremation urn (Illus 13; Illus 14; Section 6) nestled next to the western orthostat and a quantity of cremated bone was found to its south within a peaty fill (129, Illus 15). Several sherds of the urn were missing. It is possible that the urn was originally inverted over the cremated bone. It is suggested that the central cist had been heavily disturbed by stone robbing and that the three stones (142, Illus 15) were probably all that remained of a more elaborate cist that had been substantially robbed. It seems likely that the urn was disturbed at the same time.

A cut (122, Illus 15) through the body of the cairn may relate to either the construction of the cist or the probable later disturbance. The low relief of the cairn and the homogenous nature of the upper layers (Illus 12) preclude a definitive interpretation: the cut could have been made at any time from the laying of the soil that formed the body of the cairn onwards. If the cut (122) was related to the formation of the cist, this suggests that most of the cairn was constructed prior to the burial being performed. If the cut (122) related to the presumed stone robbing, the order in which the cist and cairn were constructed is unknowable. However, the 


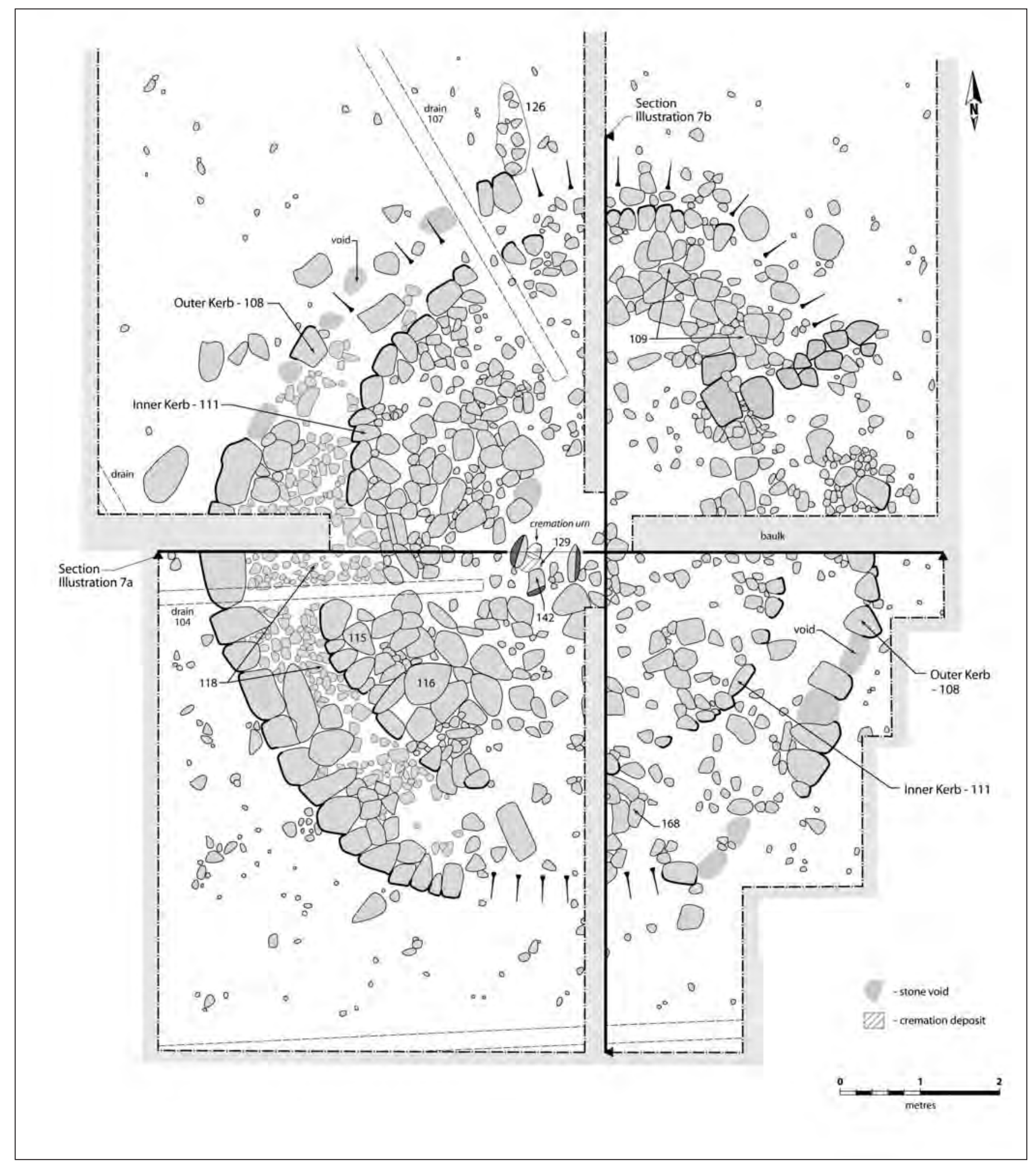

Illus 10 The cairn

western orthostat appears to have remained in situ close to the edge of cut 122 and the urn has been disturbed, rather than completely removed, which suggests that the cut is more readily interpreted as the construction cut for the cist.

\subsubsection{The body of the cairn}

The south-west portion of the cairn was made more imposing by the presence of two large boulders (Illus 10, 115 and 116), the remainder of the cairn's composition being of re-deposited peaty soil and smaller stones. 


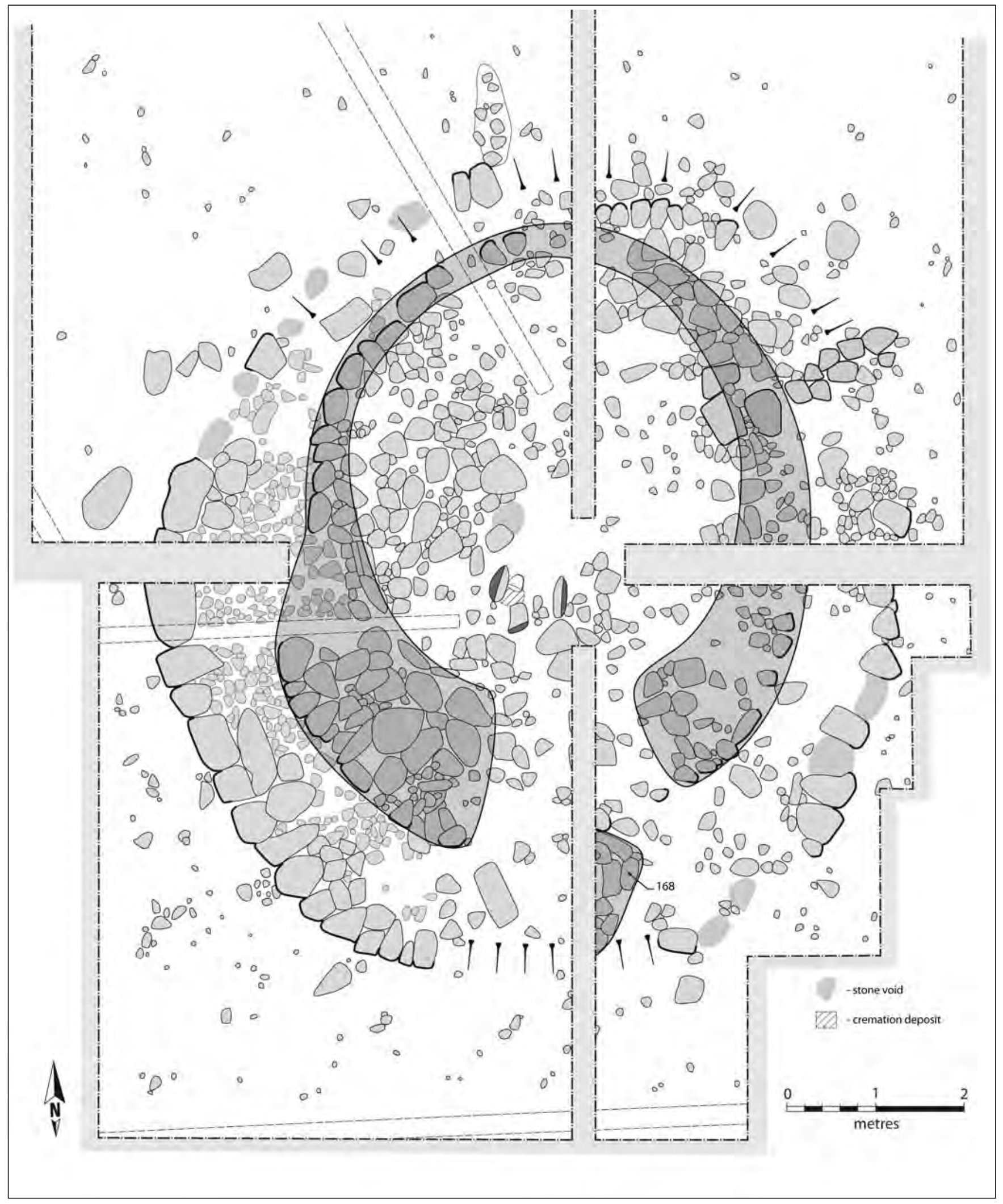

Illus 11 Possible interpretation of the inner kerb: penannular kerb and possible satellite cist in south side of cairn 


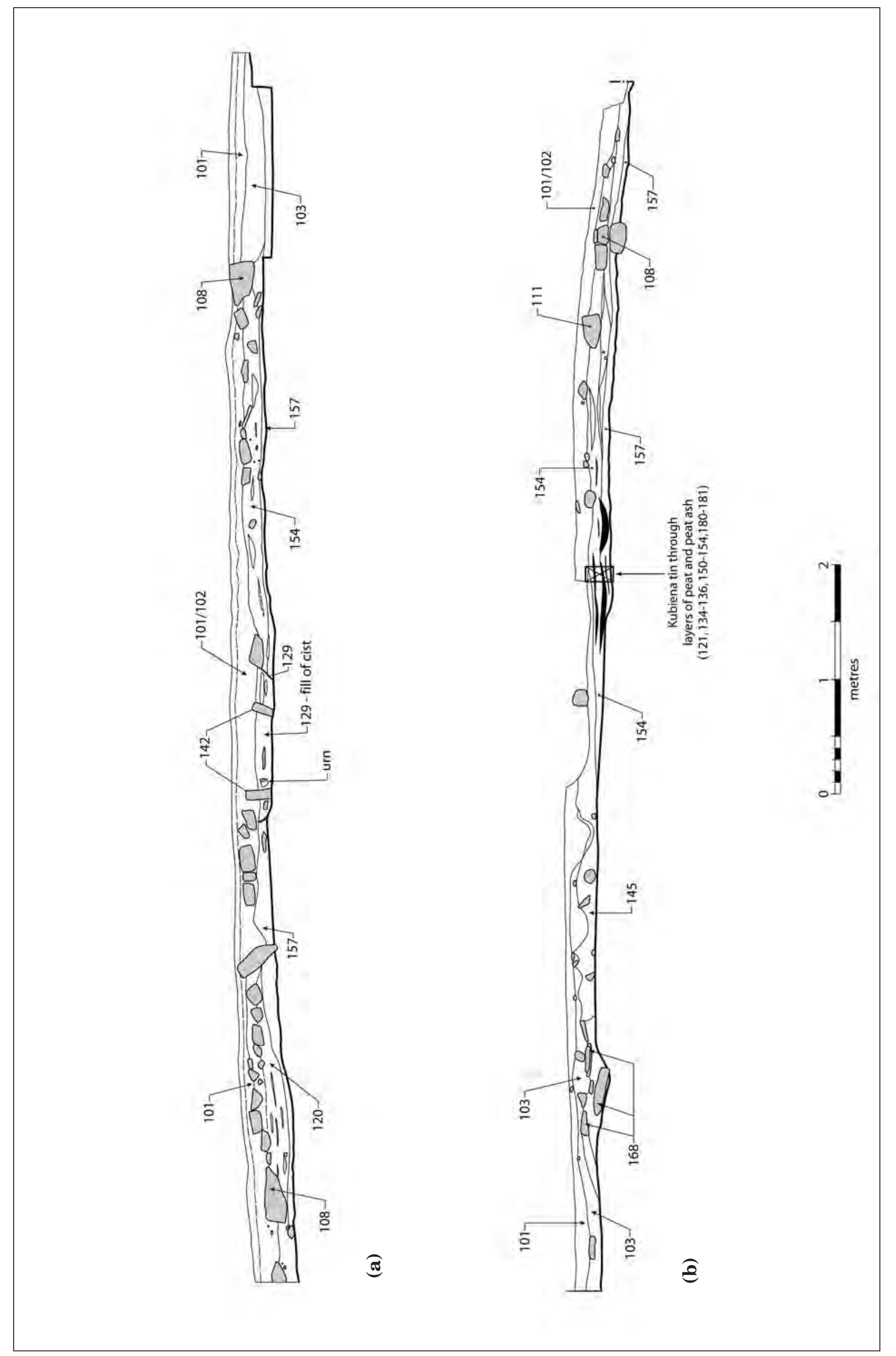

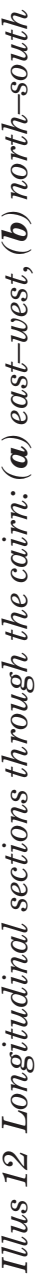




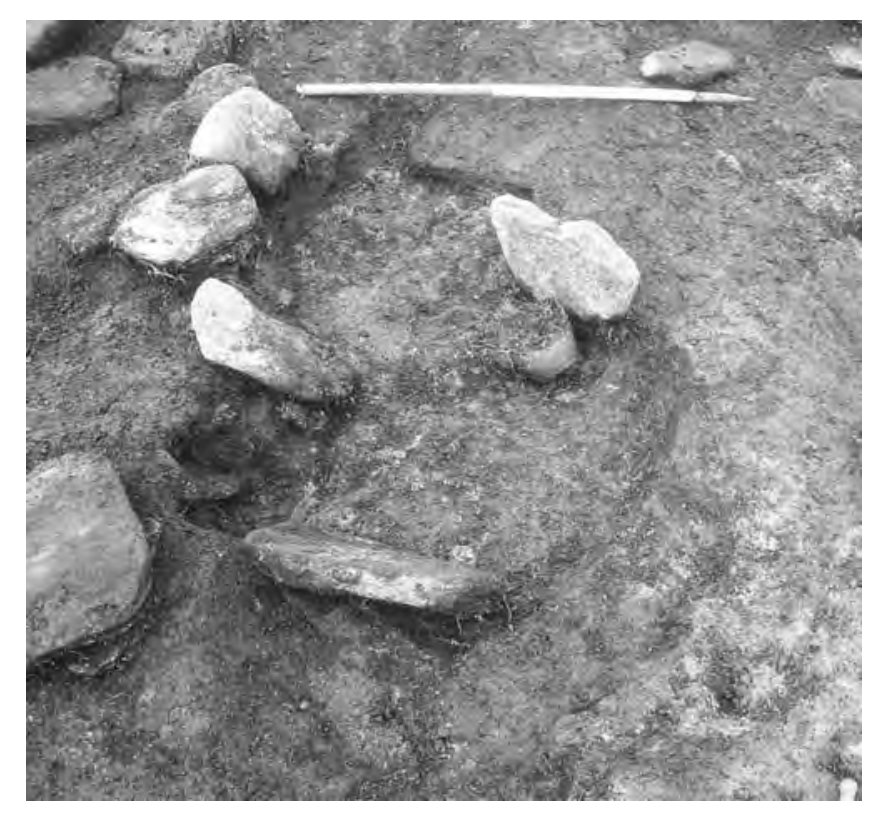

Illus 13 The central cist defined by three orthostats. The vessel is next to the western orthostat. Viewed from the east

Layers and lenses of orange and black ash (Illus 12, $121,134-136,150-154,180-181$ ) were predominant in the cairn's construction in the north-west quadrant (Section 10). It appeared that the central cist (142) had been cut (122) through the ash lenses.

Soil micromorphology thin-sections were prepared from the burnt peat in the north-west quadrant of the cairn. Five layers were distinguished, three being fuel ash derived from the burning of peaty turves, the other two layers of highly decomposed herbaceous plants. Small fragments of bone and pottery were present in some layers. The sediments had been deposited within a relatively short period of time on a soil surface (154) which had been truncated immediately beforehand, by removing the topsoil. The plant material comprised predominantly heather and moorland species (Section 11). Full results of the thin-section analysis are presented below (Section 16).

\subsubsection{Pits cut into the body of the cairn (Illus 16)}

A number of slight hollows and pits were uncovered, principally in the north-west quadrant. Most of the pits had been cut into the laminar layers of redeposited burnt peat which dominated this quadrant of the cairn.

Two features (167 and 169) were sealed by a layer of burnt peat (134). The remainder cut through the burnt material, or lay to the north of it and were sealed by the stones of the cairn or the upper levels of the cairn.

Feature 167 was not a pit, but a cluster of broken sherds from a single pot tightly grouped within the burnt peat. This cluster measured about $0.15 \mathrm{~m}$ east-west by $0.20 \mathrm{~m}$ north-south and was $0.06 \mathrm{~m}$ deep (Illus 17). It is thought likely that the pot was deposited as a single act during the deposition of the burnt materials that made up the cairn.

Pit 169 measured $0.30 \mathrm{~m}$ east-west by $0.22 \mathrm{~m}$ wide and was $0.07 \mathrm{~m}$ deep. It was filled with a dark brown,

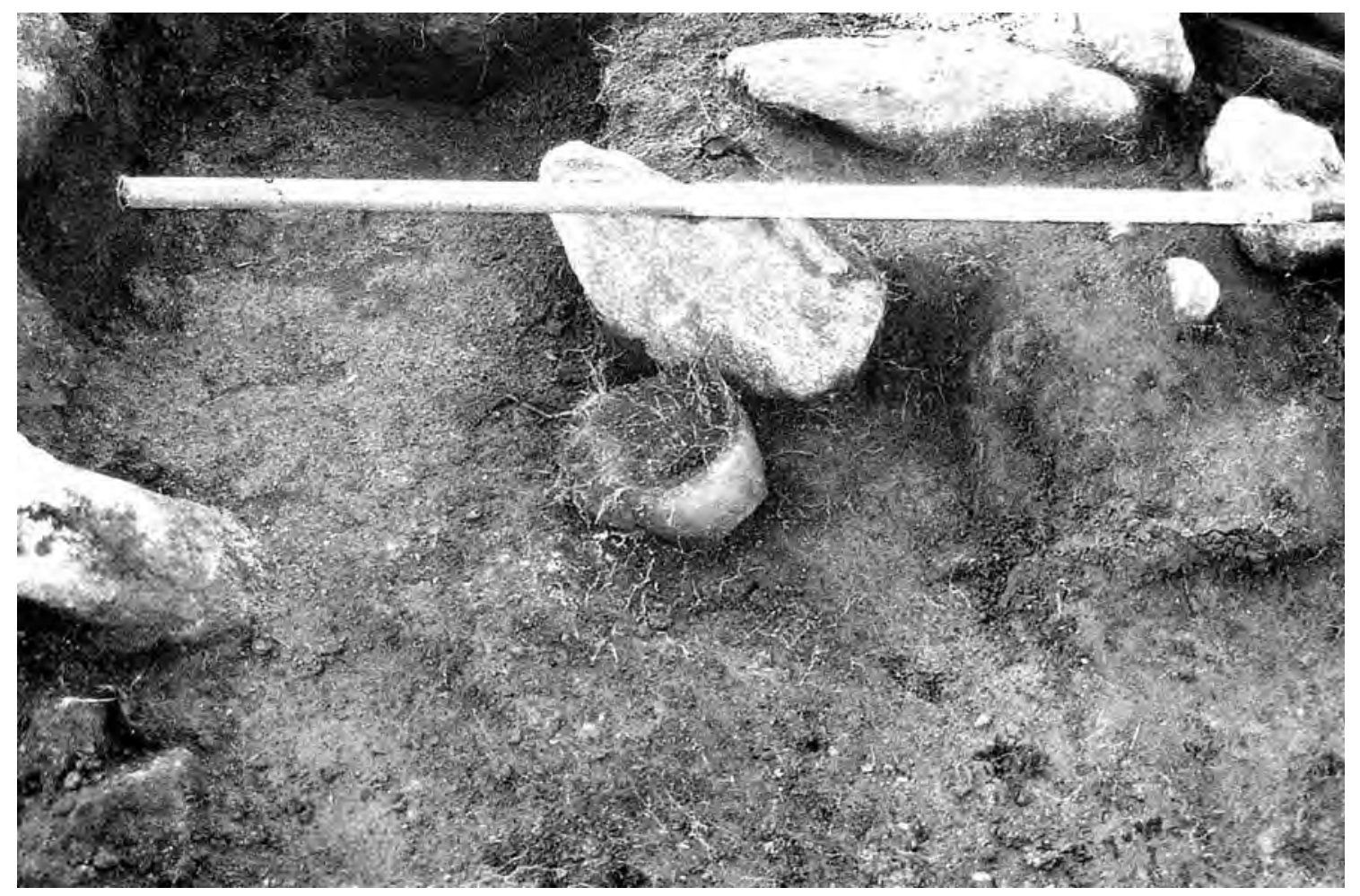

Illus 14 The vessel from the central cist in situ 


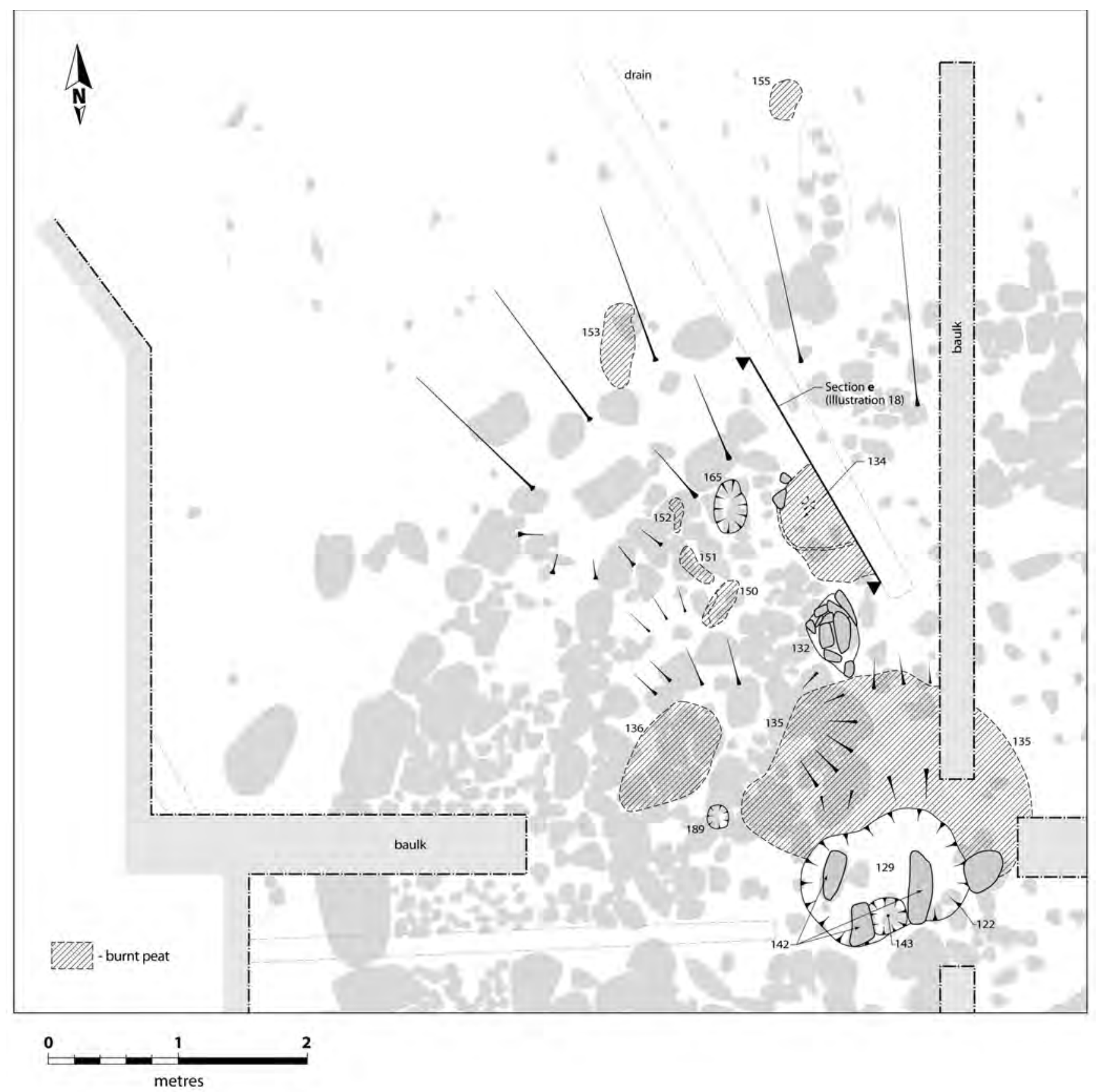

Illus 15 Areas of burnt peat (hatched) and pits within the makeup of the cairn

peaty soil. Pit 183 measured $0.14 \mathrm{~m}$ east-west by $0.18 \mathrm{~m}$ north-south and $0.04 \mathrm{~m}$ deep and was filled with a brown, peaty soil. Pit 184 measured $0.22 \mathrm{~m}$ north-south by $0.28 \mathrm{~m}$ east-west and was $0.12 \mathrm{~m}$ deep and was filled with a brown, peaty soil which contained a single, small rectangular stone, set on end. Pit 186 measured 0.20 m east-west by $0.32 \mathrm{~m}$ north-south and $0.10 \mathrm{~m}$ deep. A small, rectangular, flat laid slab formed the uppermost fill of this feature. A slightly smaller stone lay beneath it, within in a dark brown, peaty soil matrix. Pit 132 measured $0.56 \mathrm{~m}$ east-west by $0.34 \mathrm{~m}$ northsouth and was $0.09 \mathrm{~m}$ deep. A large number of irregularly placed stones set in a brown, peaty matrix formed the fill of this feature. There was no evidence of a post-pipe within this feature. Pit 165 measured $0.26 \mathrm{~m}$ east-west by $0.40 \mathrm{~m}$ north-south and was $0.08 \mathrm{~m}$ deep. This pit was also filled with brown, peaty soil. Pit 188 measured $0.80 \mathrm{~m}$ north-east to south-west by $0.55 \mathrm{~m}$ transversely and was $0.10 \mathrm{~m}$ deep. This pit was cut by a field drain.

One patch of red burnt peat (134) was particularly noteworthy (Illus 18e). This thin layer was $0.03 \mathrm{~m}$ in depth and measured at least $0.40 \mathrm{~m}$ east-west by $0.60 \mathrm{~m}$ north-south. It was truncated on its eastern side by a later field drain (107). Unlike all of the other layers and lenses of burnt peat, this appeared to have 


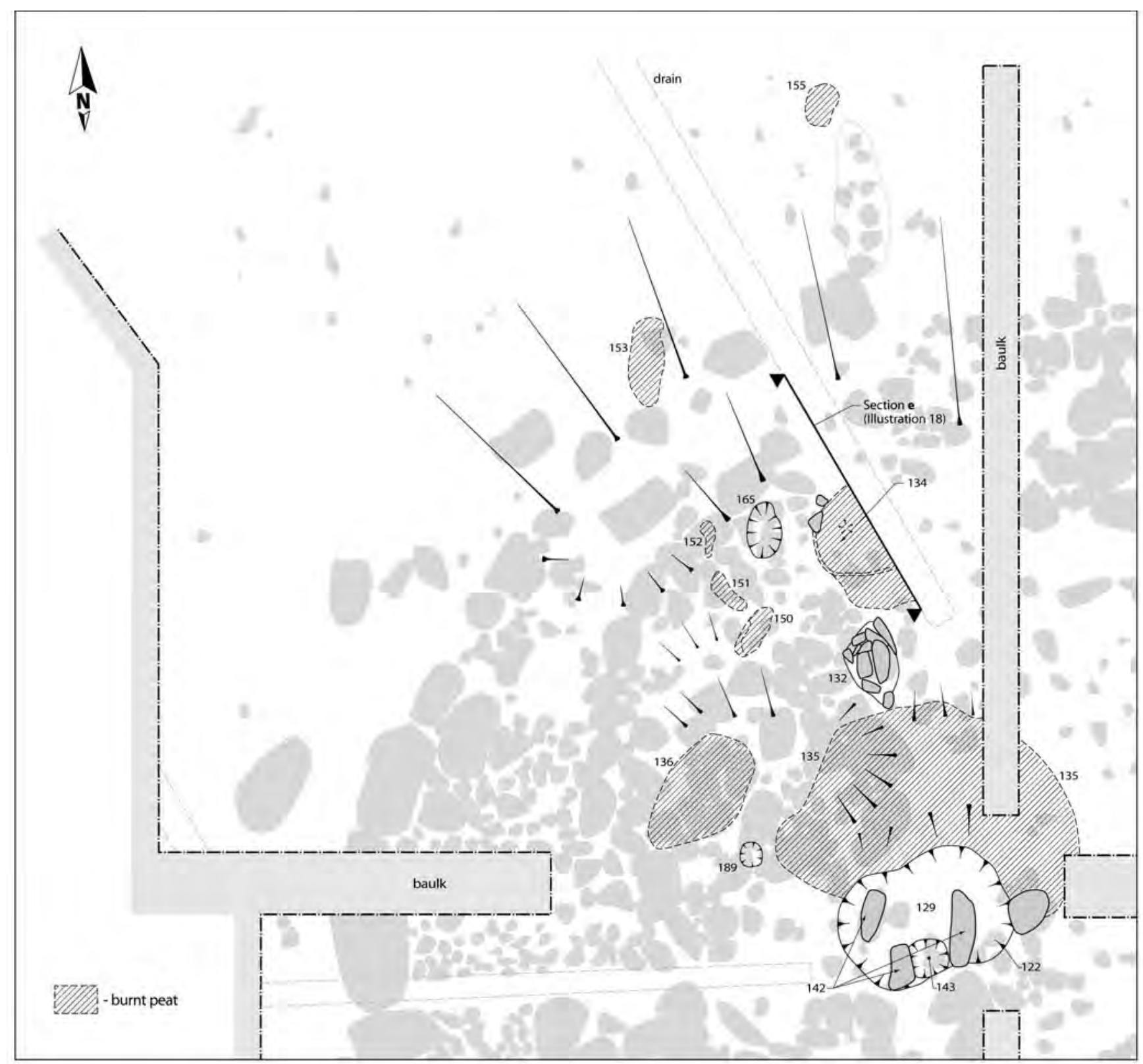

0

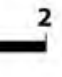

metres

Illus 16 (above) Pits within the upper surface of the makeup of the cairn, below the upper stones

Illus 17 (right) (a) Smashed pot in hollow (167) within the re-deposited burnt peat. (b) Pit 183 in the foreground, viewed from the north

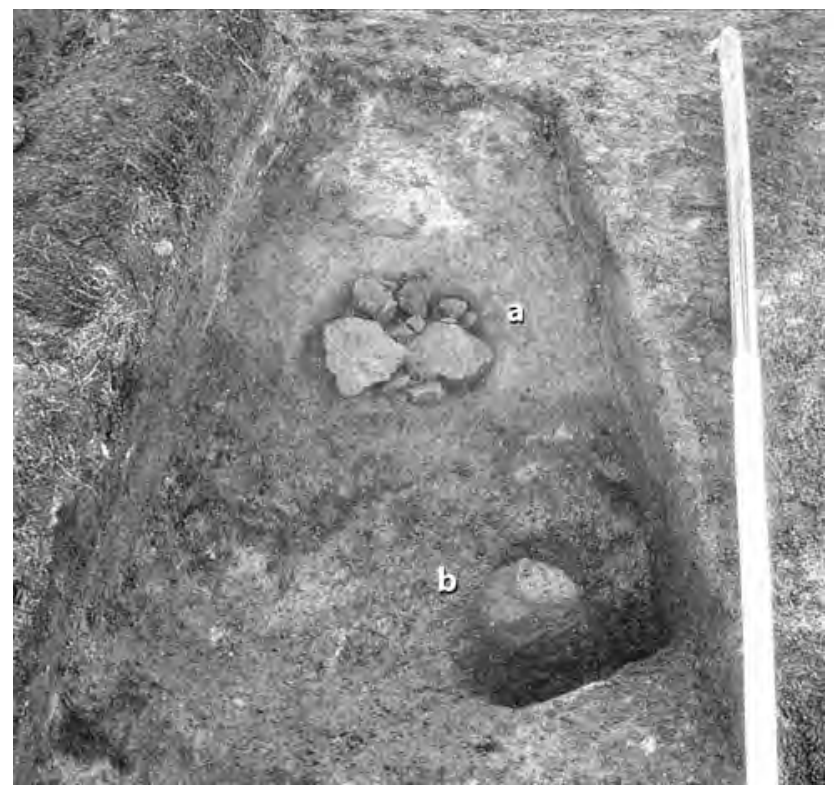


a

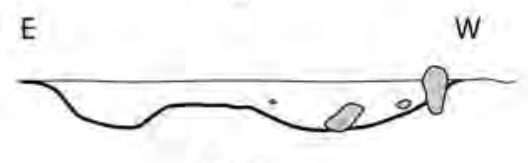

147

c

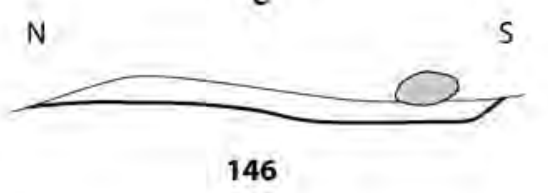

b

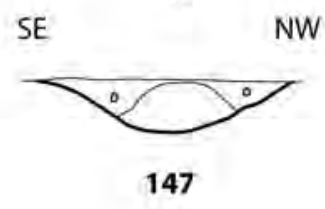

d

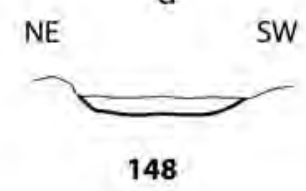

e
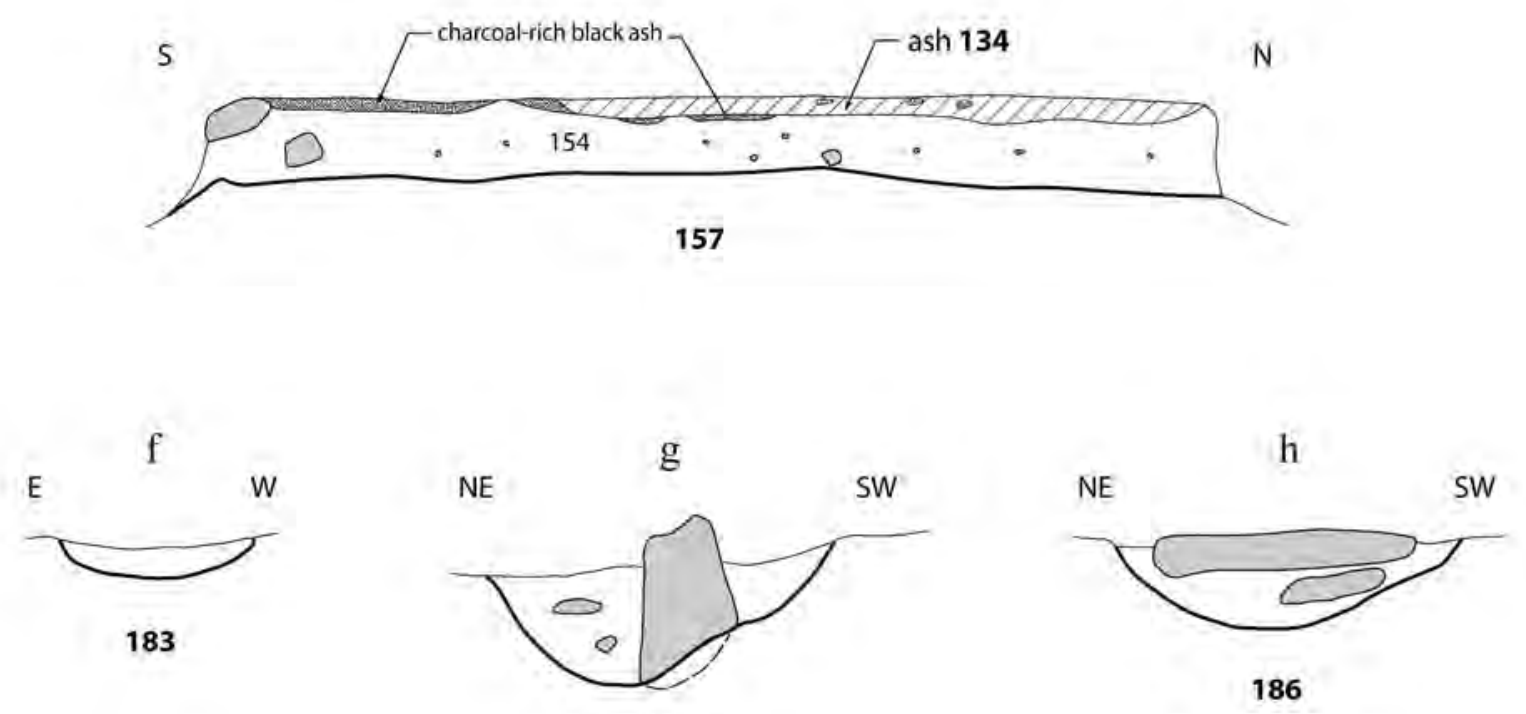

184

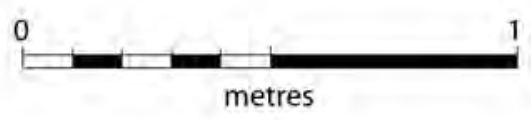

Illus 18 Sections through pits and other features

been burnt in situ and comprised a core of red ash surrounded by a halo of blacker material. A series of magnetic susceptibility samples was taken from a section through this material and the layers that underlay it. Analysis of these samples demonstrated that this burnt material, contrary to expectations, had not been burnt in situ. The dramatic fall in the magnitude of the readings (Illus 19) indicated that the soil beneath the burnt peat had not been heated.
Thus, this layer simply forms another component of the burnt material which made up the body of the cairn.

\subsubsection{Possible satellite burial}

On the south edge of the cairn a series of stones (168) appeared to form part of a disturbed rectangular 


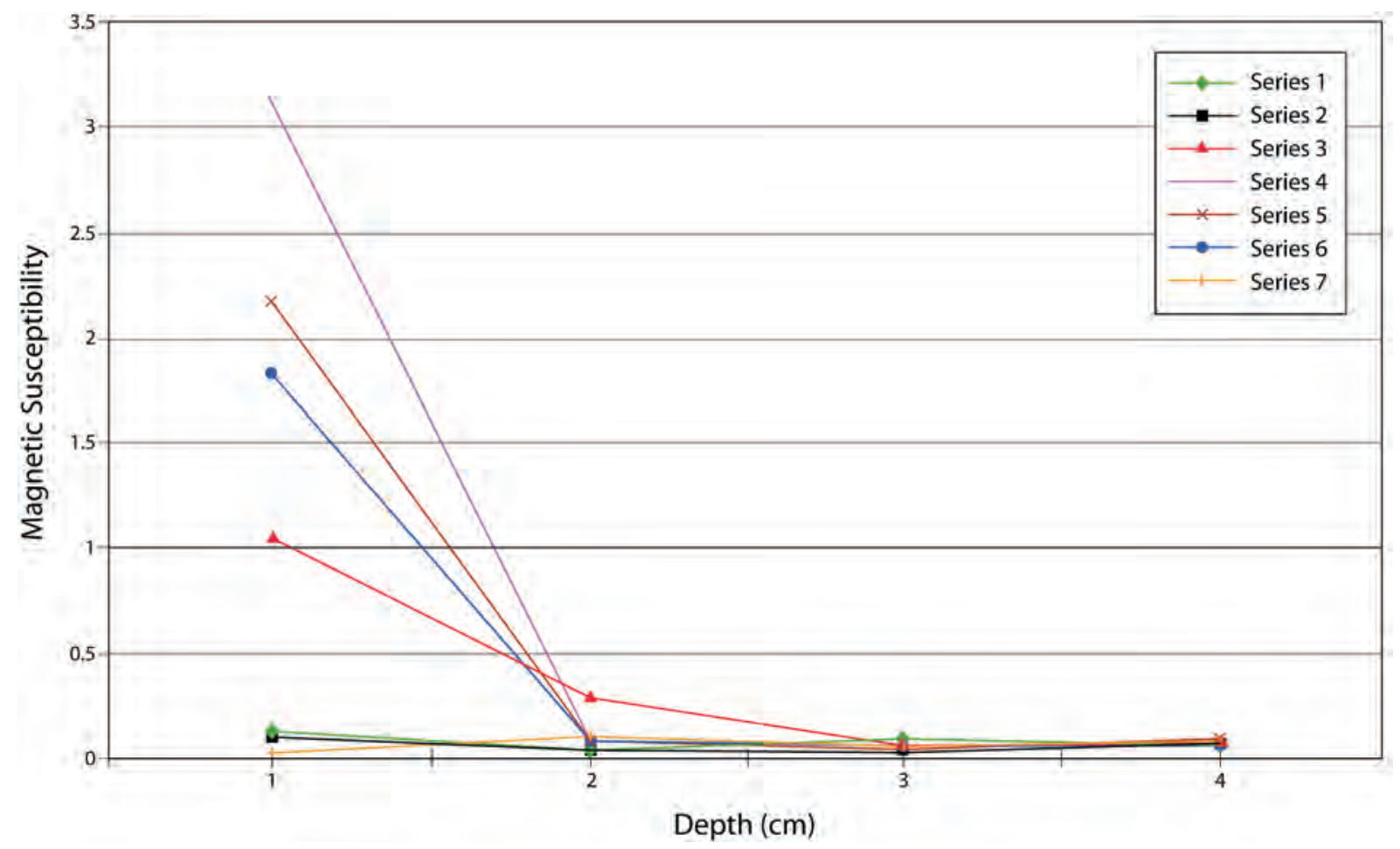

Illus 19 Magnetic susceptibility of burnt material 134 and underlying deposits (top of section at left of graph)

setting, measuring about $1.5 \mathrm{~m}$ north-south by $0.75 \mathrm{~m}$ east-west (Illus 10; Illus 11; Illus 12b). This feature, which sat in the aperture of the penannular inner kerb, might have been the disturbed remains of an inhumation burial inserted into the pre-existing cairn. Unfortunately, the soil was too acid to preserve uncarbonized bone (Section 8.4.1). The absence of human remains from this heavily disturbed, putative cist has meant that we cannot be certain of its interpretation.

\subsection{Phase 4: Post-cairn features (Illus 10)}

The cairn was cut by two late field drains. Rubble drain 104 ran east-west while 107, which was filled with peaty soil, ran north-west to south-east. This difference between the two features suggests that two attempts had been made to drain the area.

Three post-holes with packing formed a line running north to south across the eastern side of the cairn (not illustrated). Their morphology was quite distinct from the Phase 1 pits found beneath the cairn although they did cut into the till. It is suspected that these post-holes were part of a fence line that post-dated the cairn by a considerable length of time.

\subsection{Unphased: Irregular depressions (Illus 7)}

Several irregular hollows (146-149) were found to the north-west of the cairn. No finds were recovered from these features and their fills comprised a uniform dark brown, peaty soil. Two further hollows to the south-east of the cairn were filled with small stones in a dark brown, peaty soil matrix. The function of these features is unclear: they could relate to the construction of the cairn, pre-date it or post-date it. 


\section{Radiocarbon Dates by $T$ Neighbour}

Radiocarbon dates were obtained from four contexts. Two dates were obtained from each context (Table 2). Plant macrofossils for the single entity dating were identified by Mike Church (Section 7.2, below). The dating was carried out by the Radiocarbon Accelerator Unit at Oxford University.

The dates are presented in context order in Illus 20. With the exception of OxA-9931, a date from the basal fill of the central cist (which is presumed to be re-deposited), the dates cluster around the period 1900 to 1500 BC. This supports an early/middle Bronze Age date for the cairn. No attempt has been made to tighten the individual dates using Bayesian statistics and a priori stratigraphic information. It is suspected that much of the cairn was built as a single event and that much of the soil which formed the cairn was imported (Section 7.3, below); thus the possibilities for stratigraphic inversion during this process are high. Rather, an average of the dates has been provided (excluding the outlier, OxA-9931), as the main body of the cairn and the cist appear to have been constructed as one episode. This produces a date range of 1750 to $1520 \mathrm{BC}$ at the $95 \%$ confidence interval, with the bulk of the probability distribution lying between 1700 and $1600 \mathrm{BC}$ (Illus 20). This combined date should be treated with caution.

Unfortunately, no suitable carbonized remains were available to date the decline and abandonment of the cairn, as material recovered from the surface of the cairn was judged to be too insecure taphonomically to be submitted for radiocarbon dating.

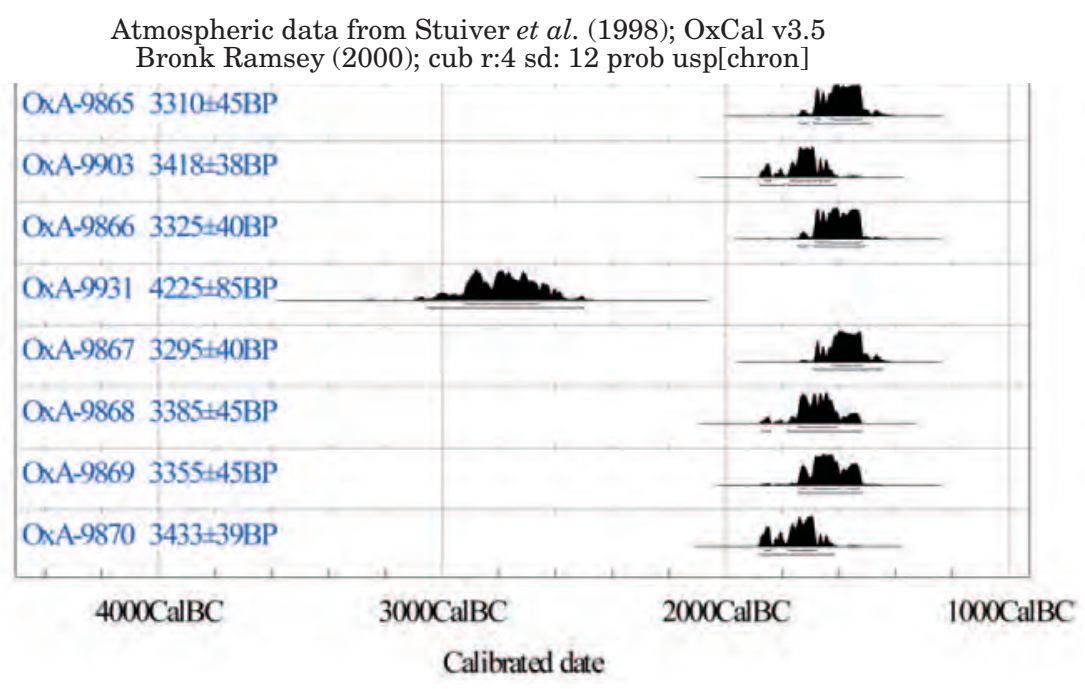

Atmospheric data from Stuiver et al. (1998); OxCal v3.5 Bronk Ramsey (2000); cub r:4 sd: 12 prob usp[chron]

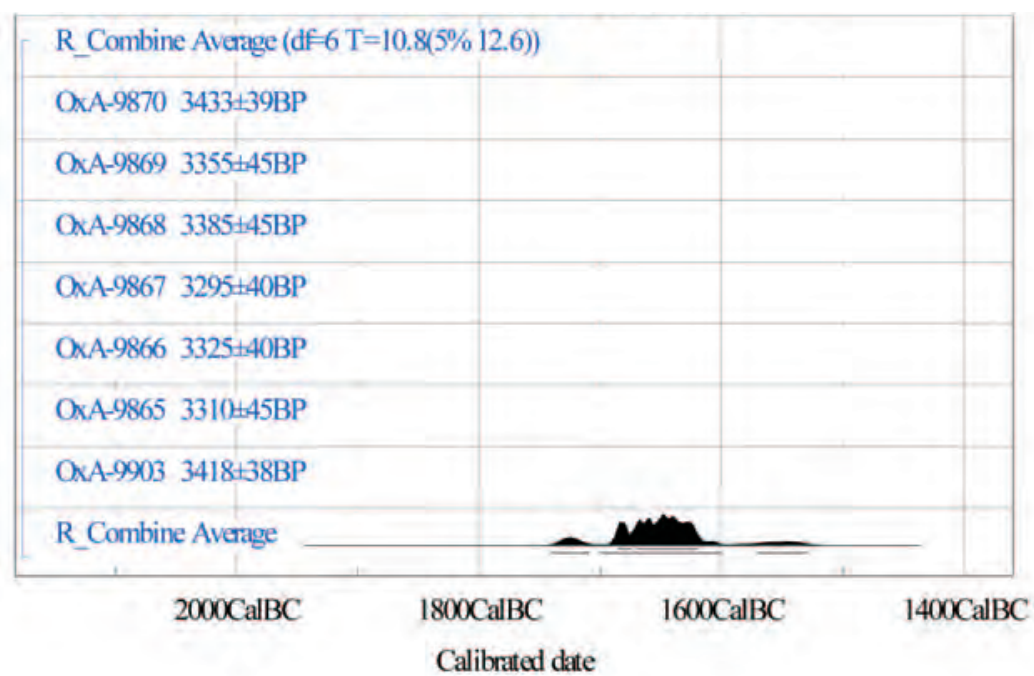


Table 2 Radiocarbon dates from the kerbed cairn

\begin{tabular}{|c|c|c|c|c|}
\hline OxA no & Context & Material & $\begin{array}{c}\text { Measured/assumed } \\
\delta 13 \mathrm{C}(\%)\end{array}$ & $\begin{array}{l}\text { Radiocarbon } \\
\text { age (BP) }\end{array}$ \\
\hline OxA-9865 & 121 & Charred seed, Hordeum sp. & -22.5 & $3310 \pm 45$ \\
\hline OxA-9903 & 121 & Charred seed, Hordeum sp. & -24.1 & $3418 \pm 38$ \\
\hline OxA-9866 & 129 & Charred seed, Hordeum sp. & -23.3 & $3325 \pm 40$ \\
\hline OxA-9867 & 135 & Charred seed, Hordeum sp. & -23.4 & $3295 \pm 40$ \\
\hline OxA-9868 & 135 & Charred seed, Hordeum sp. & -24.5 & $3385 \pm 45$ \\
\hline OxA-9869 & 181 & Charred seed, Hordeum sp. & -21.5 & $3355 \pm 45$ \\
\hline OxA-9870 & 181 & Charred seed, Hordeum sp. & -22.2 & $3433 \pm 39$ \\
\hline OxA-9931 & 129 & Charred seed, Hordeum sp. & -22.6 & $4225 \pm 85$ \\
\hline
\end{tabular}




\section{Cremation Report by $K M c$ Sweeney}

\subsection{Introduction and methodology}

The cremated remains were divided between those still in situ in the broken cremation urn and the remainder, thought originally to be spill from the urn within a matrix of soil and plant fibre. These remains had been collected as a bulk sample, together with the surrounding soil matrix and air-dried at room temperature. No bone was retrieved from the urn.

It was very difficult to separate all of the bone from the soil matrix. The bone fragments were in exceptionally poor condition, many were extremely tiny and some crumbled away when touched. The contents of the box were sieved in a $4.5 \mathrm{~mm}$ sieve but the remaining soil matrix still contained numerous tiny flakes of bone. This residue was further examined for identifiable fragments but, because it was clear that the remaining material would provide no meaningful contribution to this report, further, time-consuming extraction of these fragments was not undertaken.

The extracted bone fragments were very dirty and their poor condition meant that they could not be washed or brushed. Occasionally, where absolutely essential, the surfaces of fragments were very carefully cleared of soil.

Each extracted fragment was examined and sorted into anatomical area although in some instances only a general area of origin could be established. For example, some fragments, which, on the evidence of their size, shape and fracture pattern, were clearly from one of the six major longbones of the body but were too incomplete to be more positively identified, have been classified simply as 'longbone'. Because of size or distortion, even a general anatomical provenance could not be established for some fragments which have been classified as 'unidentified'.

The bone remains were weighed using scales accurate to $1 \mathrm{~g}$. General methods of ageing and sexing have been outlined previously (Breathnach 1965; Brothwell 1981; Bass 1987). The identification and assessment of age of the dental remains is based on Dental Morphology: An Illustrated Guide (van Beek 1983).

\subsection{Description of the remains}

\subsubsection{Skull}

Fragment of external auditory meatus of temporal bone.

Two fragments of cranial wall with both tables intact and with sutural edges. The sutures have not yet closed, possibly indicating a younger rather than older individual. (Generally speaking, cranial sutures gradually close and become obliterated with age although this varies considerably among individuals and some old individuals can retain open sutures.) Two fragments of cranial wall with only the outer table remaining and open sutural edges.

Seven fragments of cranial wall with both tables intact. Cranial wall thickness approximately $3 \mathrm{~mm}$. Six fragments of cranium with only a single table remaining.

\subsubsection{Mandible}

Fragment of the external surface of mandible. Traces of a tooth socket are visible, probably for permanent M1 or M2.

\subsubsection{Dentition}

Roots, part of crown and pulp chamber (no enamel) of probably a lower third molar. The roots are fused together and the apex of the roots are fully closed. As fusion of the roots of third molars is normally complete by 18-25 years, this tooth is probably from an individual aged over 18 . There is also a possibility that this is a lower second molar. Although the roots of this tooth are not normally found fully fused together, in some individuals the roots can be partly fused.

Part of the crown of a tooth, enamel missing, showing part of the pulp chamber. Morphology suggests that this is part of a molar, probably lower. The inferior edge of the fragment is not broken but tapered, suggesting that it is a developing permanent tooth with the roots just starting to form. Age would depend on which tooth this is but it would be in the region of $3-5,8-10$, or $14-16$ years depending on whether this was a first, second or third molar.

Fragment of tooth root?

\subsubsection{Ribs}

Seven fragments of body of ribs.

\subsubsection{Innominate}

Fragment of ilium?

\subsubsection{Humerus}

Three fragments of shaft of humerus. 


\subsubsection{Radius/ulna}

Three fragments of shafts of radius or ulna.

\subsubsection{Femur}

Fragment of condyle, too small to indicate whether epiphyseal fusion had taken place.

Two fragments of shaft of femur.

\subsubsection{Tibia}

Fragment of condyle? Too small to indicate whether epiphyseal fusion had taken place.

Two adjoining fragments of shaft of tibia.

Fragment of shaft of tibia.

\subsubsection{General longbone}

Twenty-seven fragments of shafts of various longbones.

\subsubsection{Hands}

Fragment of carpal bone - lunate?

Fragment of carpal bone - hamate?

Detached head of metacarpal. Epiphyseal fusion had taken place.

Middle phalanx, almost complete apart from slight damage to the proximal end. However, enough remained of the proximal end to establish that epiphyseal fusion had taken place, indicating an age at death of over 15 years.

Head and part shaft of proximal or middle phalanx of hand.

\subsubsection{Hands/Feet}

Head and part shaft of proximal or middle phalanx of hand or foot.

Ten fragments of shafts of metacarpals or metatarsals.

Eight fragments of shafts of phalanges of hands or feet.

\subsection{Condition of the remains}

The condition of the remains was extremely poor; fragments were very fragile and prone to further disintegration, even with careful handling.

With the exception of one almost complete hand phalanx, there were no complete bones. Fragment size was generally small. A few longbone fragments were about 55-60 $\mathrm{mm}$ in length but, in general, fragments were only about $20 \mathrm{~mm}$ or less. The largest pieces of cranium were about $20 \mathrm{~mm}$. These measurements are much smaller than those found by McKinley in her analysis of modern cremations where skull fragments of up to $95 \mathrm{~mm}$ and longbone fragments up to $195 \mathrm{~mm}$ were found (McKinley 1993, 284).

The Olcote cremated material displayed considerable splintering, distortion and splitting of layers of bone as a result of burning, and it is likely that the material had been subjected to post-depositional deterioration. Past experience has shown that cremated bone within an urn survives much better than cremation deposits from the same site that do not have the protection of a pottery container.

The poor condition of the remains meant that the identification rate was low, only $43 \%$ of the total weight ( $68 \mathrm{~g}$ from a total of $158 \mathrm{~g}$ ).

\subsection{Completeness of the remains}

The total weight of the extracted remains was $158 \mathrm{~g}$. In a study of 15 modern cremations, McKinley found that total weight ranged from $1227.4 \mathrm{~g}$ for an 83-year-old female, to $3001.3 \mathrm{~g}$ for a 90 -year-old male (McKinley 1993, 284). She estimated that, in an archaeological setting, a realistic range would be 1001.5-2422 g. The Olcote remains clearly fell far short of this.

In general, compact bone, mostly fragments of longbone shaft, survived. Even this material was in poor condition and the total volume was much less than would normally be anticipated. Areas of soft, cancellous bone, such as that found in the pelvis, vertebrae and the ends of longbones, were virtually absent. The identified fragments were from the cranium, mandible, dentition, ribs, all six major longbones, hands and, possibly, feet.

The small quantity of cremated bone might have been intended as only a token gesture, or the total deposit may have been originally fuller and diminished as a result of post-depositional erosion. Alternatively, both factors could have been involved.

\subsection{Number of individuals and age at death}

With the exception of some possibly conflicting evidence from the dental remains, there was no clear evidence for the presence of more than one individual within this deposit. There were no duplicated bones and the robustness of the remains was consistent with derivation from the same person.

On the basis of full fusion of the roots and general morphology, the roots and part of the crown of a tooth appeared to be a lower third molar. Full development of the roots of a third molar would give an age at death of over 18. Also present was part of a crown of a developing molar from an individual aged either 3-5, 8-10 or 14-16 years, depending on whether the tooth was a first, second or third molar. However, clearly none of these ranges is compatible with an age of over 18. It is not entirely clear whether this evidence 
indicates the presence of one or more individuals. The absence of enamel precludes categorical identification of the fully developed tooth and it could conceivably be a second molar. This develops before the third molar, suggesting that age at death could be as low as 14-15 years, which is compatible with the latest age range for the developing tooth (14-16 years).

The presence of a hand phalanx and a metatarsal with fused epiphyses provides an age at death of over 15. Thin cranial walls and unfused cranial sutures, while not in themselves accurate indicators of age, are suggestive of an individual who had not reached advanced adulthood. Although an age range of 14-16 would not be entirely consistent with this non-dental evidence of ageing, human variation should allow for such a combination.

Taking all of this evidence into account, it would appear that there are two possible options:

1 Both teeth (together with the rest of the remains) are from the same individual, who was aged about $14-16$, the fully developed tooth being a second molar and the developing tooth was a third molar. This could just about fit with an age of $15+$ from the fully developed hand bones although some evidence that the epiphyses had only recently fused might be expected, and there was none.

2 The teeth are from two different individuals, one probably aged over 18 years (this would sit comfortably with an age of $15+$ from the other remains) and another, immature individual, perhaps only represented by a single tooth, who could have been aged $3-5,8-10$ or $14-16$.

Either option is feasible. Unfortunately, because of the nature of the material, it is impossible to be specific.

\subsection{Sex and pathology}

As the most reliable indicators of sex, such as the pelvis and the femoral and humeral heads, were either missing or too small to be useful, an assessment of sex was not possible. No pathological lesions were noted.

\subsection{Cremation technology and burial practice}

The bones had been subjected to a fairly marked degree of cracking, twisting and curved lateral splintering. In addition, many cranial fragments had warped, causing the inner and outer tables to separate. These occurrences indicate that a high temperature was achieved during firing. Ubelaker suggests that curved lateral splintering and marked warping can be indicative of bone being burnt while still 'fresh', ie soon after death (Ubelaker 1978, 35).
This suggestion, however, is difficult to support in an archaeological context.

It is known that the colour of bone changes with increasing temperature (Ubelaker 1978, 34). In general, the higher the temperature, the lighter the colour. Black colouration occurs below $800^{\circ} \mathrm{C}$, while temperatures above $800^{\circ} \mathrm{C}$ produce calcined bone, ranging in colour from bluish-gray to white. Furnaces in modern crematoria operate at between $820^{\circ} \mathrm{C}$ and $980^{\circ} \mathrm{C}$ (Wells 1960,35 ).

In their uncleaned state, the Olcote bone fragments appeared brown, whereas the predominant colour of the cleaned bone was pale beige-white throughout. Despite the poor condition of these remains, the presence of warped and splintered bones and the light, even colouration suggests that the entire skeleton had been fired to a high temperature and that cremation technology was well understood. Sufficiently high temperatures can be achieved by using peat (Section 10.4.1).

It is unclear how carefully the remains were collected following firing. The presence of some small hand bones and teeth suggests that they had been carefully collected. It is possible that subsequent erosion has reduced what were originally much fuller remains.

It is uncertain whether the small fragment size is to some degree due to the remains being deliberately broken after cremation. Many of the fragments had clearly broken along fracture lines during the burning process although some deliberate crushing cannot be ruled out.

\subsection{Summary}

The cremated remains from the Olcote cairn were found beside a broken cremation urn. The volume of the cremated remains was very small and the individual fragments were in very poor condition. Consequently, only a small percentage of the total could be identified and very few of the fragments provided any meaningful information.

Unfortunately, because of the poor condition of the remains, it cannot be stated with certainty how many individuals were represented in this cremation. The most convincing evidence points to most of the remains belonging to a young adult. However, the presence of a single, developing, permanent molar indicates that either this was a stray tooth, which somehow became incorporated with the remains of another individual, or that the entire remains were those of an adolescent, aged about 16 years.

The sex of this individual (or individuals) is unknown. There was no evidence of disease and the cause of death could not be ascertained.

Cremation technology appears to have been well understood and high, even temperatures were achieved during firing. 


\section{The Pottery by $M$ Johnson}

\subsection{Introduction}

The pottery assemblage from Olcote cairn comprises 42 sherds from a near-complete cremation urn with a total weight of $1094 \mathrm{~g}$, plus a further 397 sherds and fragments weighing $2248 \mathrm{~g}$. The minimum number of vessels represented is 20 . The majority of the pottery consists of plain body sherds and, apart from the urn, there are only 17 diagnostic sherds: five plain rim sherds, three decorated rim sherds and nine decorated body sherds. The sherds are mostly very small, with an average weight of only $6 \mathrm{~g}$ (excluding the urn); many of them are also abraded. Pottery was recovered from contexts throughout the cairn and from pre-cairn and post-cairn horizons.

\subsection{Methodology}

The pottery was dry-cleaned with a soft brush, marked, examined with a hand lens and sorted into fabric types based upon differences in the inclusions and the appearance and texture of the clay matrix. Eight fabric groups were identified although many of the sherds and fragments recovered from the wetsieved samples at 5-11 mm were too small to categorize by fabric. Colours are based upon the Munsell Soil Color chart. The minimum number of vessels was estimated from the number of rim forms and fabric groupings.

\subsubsection{Fabric types}

1 Soft. Sandy to granular texture, cracks in surfaces. Average thickness $12 \mathrm{~mm}$. Oxidized exterior, unoxidized core. Internal face very dark grey (10YR 3/1), external face light red (2.5YR 6/ 6 ) to red (2.5YR 5/8), core reddish yellow (5YR 6/ 8). Inclusions: $3-10 \%$ quartz $<3 \mathrm{~mm}, 2-5 \%$ small stones $2-8 \mathrm{~mm}, 1 \%$ mica $<1 \mathrm{~mm}$, organic fibre impressions only present on the exterior.

2 Soft. Sandy to granular texture, very crumbly with cracks in surfaces. Average thickness $16 \mathrm{~mm}$. Oxidized exterior, unoxidized core. Internal face very dark grey (10YR 3/1), external face reddish yellow (7.5YR 6/8) to strong brown (7.5YR 5/8), core dark greyish brown (10YR 4/2). Inclusions: $5-10 \%$ gneiss $2-8 \mathrm{~mm}, 3-5 \%$ quartz $<$ $2 \mathrm{~mm}, 1 \%$ small stones $4-12 \mathrm{~mm}, 1 \%$ mica $<$ $1 \mathrm{~mm}$.

3 Hard. Soapy to sandy texture. Average thickness $12 \mathrm{~mm}$. Irregularly fired. Internal face very dark grey (10YR 3/1) to brown (10YR 5/3), external face brownish yellow (10YR 6/8) to yellowish brown (10YR 5/6), core greyish brown (10YR 5/2) to yellowish brown (10YR 5/6). Inclusions: 7-10\% small stones 1-14 mm, 3-10\% mica $<1 \mathrm{~mm}, 1-$ $2 \%$ quartz $<1-5 \mathrm{~mm}$, rare $1 \%$ organic fibres.

4 Hard. Sandy to granular texture. Average thickness $12 \mathrm{~mm}$. Unoxidized. Internal face pale brown (10YR 6/3), external face dark grey (10YR 4/1) to greyish brown (10YR 5/2), core pale brown (10YR 6/3) to greyish brown (10YR 5/2). Inclusions: $10-15 \%$ mica $<2 \mathrm{~mm}, 1 \%$ quartz $<2 \mathrm{~mm}, 1-3 \%$ small stones $3-20 \mathrm{~mm}, 1 \%$ organic fibres.

5 Hard. Soapy texture, lots of cracks in surfaces. Average thickness $10 \mathrm{~mm}$. Oxidized exterior, unoxidized core. Internal face very pale brown (10YR 7/4) to light yellowish brown (10YR 6/4), external face yellowish brown (10YR 5/6) to very dark grey (10YR 3/1), core grey (10YR 6/1). Inclusions: $7-15 \%$ small stones $2-10 \mathrm{~mm}, 1 \%$ organic fibres.

6 Hard. Sandy texture, some cracks in outer surface. Average thickness $14 \mathrm{~mm}$. Irregularly fired, internal face pale brown (10YR 6/3) to greyish brown (10YR 5/2), external face brown (10YR 5/3) to dark greyish brown (10YR 4/2), core dark grey (10YR 4/1) to light yellowish brown (10YR 6/4). Inclusions: $20-30 \%$ mica < $1 \mathrm{~mm}, 20 \%$ quartz $<2 \mathrm{~mm}, 1 \%$ small stones 2 $10 \mathrm{~mm}, 1 \%$ shell $<2 \mathrm{~mm}$, organic fibre impressions only present on exterior.

7 Hard. Very sandy texture. Average thickness $11 \mathrm{~mm}$. Unoxidized. Internal face dark grey (10YR 4/1), external face greyish brown (10YR 5/ $2)$, core dark grey (10YR 4/1). Inclusions $25-30 \%$ shell $<1 \mathrm{~mm}, 3-5 \%$ gneiss $2-6 \mathrm{~mm}, 1 \%$ mica $<$ $1 \mathrm{~mm}$.

8 Hard. Sandy texture, cracks in surfaces. Average thickness $13 \mathrm{~mm}$. Unoxidized. Internal face dark grey (10YR 4/1), external face dark greyish brown (10YR 4/2), core dark grey (10YR 4/1) to dark greyish brown (10YR 4/2). Inclusions: $1 \%$ mica $<1 \mathrm{~mm}, 1 \%$ quartz $3-7 \mathrm{~mm}, 1 \%$ small stones 1-6 mm, 1\% organic fibres.

The pottery is handmade and generally thick and coarse in appearance, with inclusions consisting mainly of quartz, mica and small stones, which would either be locally available or already present within the clay. There is some organic temper in the form of grass and seed impressions. The fabrics are similar, the small differences relating to the quantity and size of a limited range of inclusions, the rock and mineral elements of which derive from the local geology. The presence of small quantities of organic matter may be deliberate or accidental 


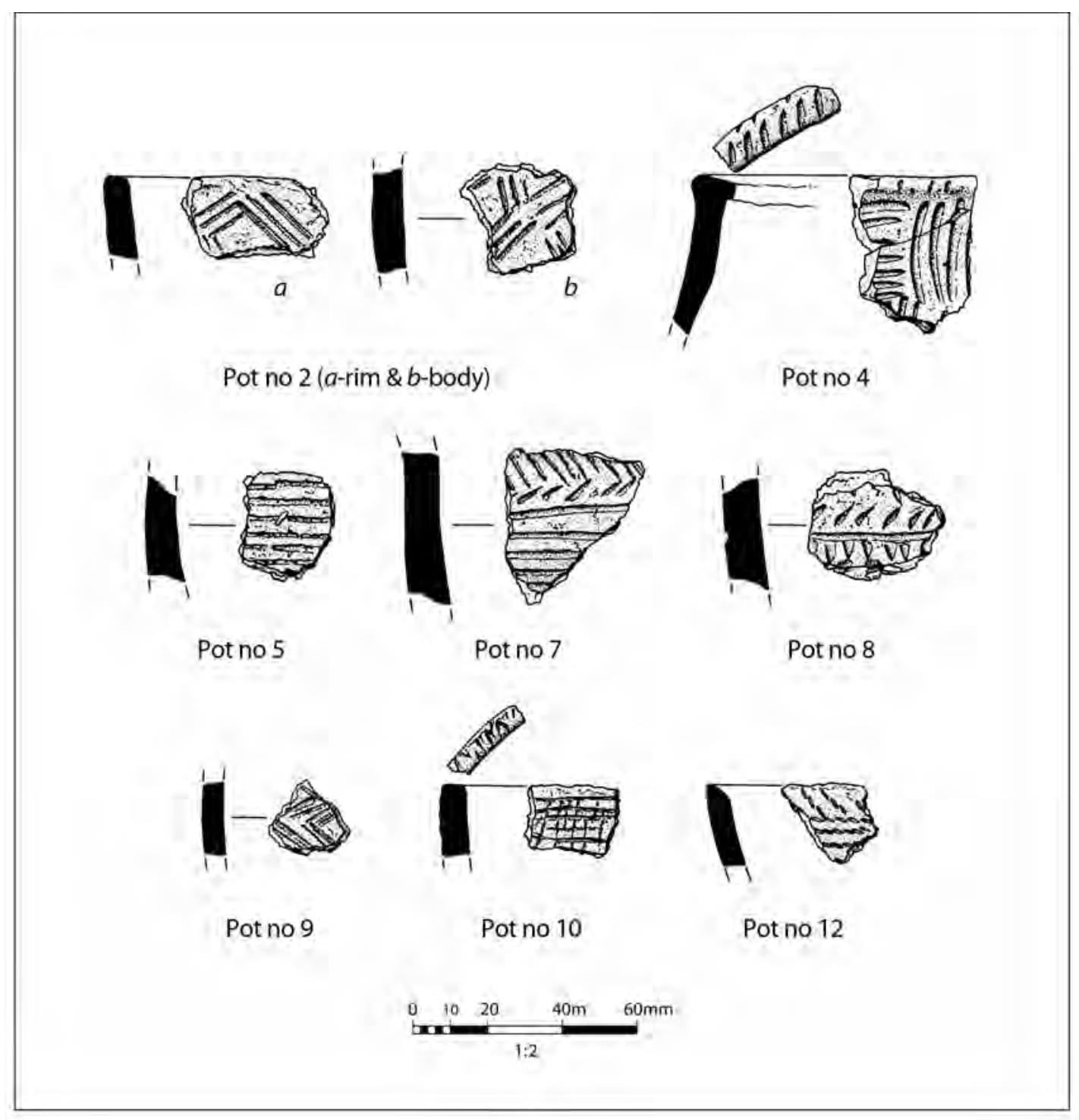

Illus 21 The decorated pottery

although the quantities are never high enough to suggest that organic materials had been added deliberately. The colour range of browns and greys with dark cores suggests relatively short firing times at fairly low temperatures in a reducing atmosphere, probably in simple pit kilns. However, the red colour of fabric 1 suggests an oxidizing atmosphere in an open fire, probably a bonfire. The majority of the sherds are manifested in fabric 3 , while a small percentage cannot be attributed to any of the fabric types, usually because they are too small and abraded, although this category does include a number of re-deposited sherds discussed further below.

Just over a third of the sherds have burnt organic material adhering to one or both of their surfaces, indicating that many of the vessels were used prior to deposition. A number of them also have iron oxide deposits on the surfaces, as a result of postdepositional processes.

\subsection{Re-deposited Neolithic and Beaker sherds}

There are 12 decorated sherds within the assemblage representing 11 different vessels (pot nos 2-12: see Illus 21 for pot nos $2,4,5,7-10,12$ ), which could not be assigned to one of the eight main fabric types. The decoration and form of these sherds indicates that they are all residual Neolithic and Beaker pottery. These sherds are generally more finely made than the plain coarse wares present, with thinner walls, smaller inclusions and better-finished surfaces. They are small in size and abraded, making it difficult to reconstruct the vessel's form or overall pattern of decoration or to determine a sherd's position on the vessel. Three of the sherds are from rims (pot nos $4,10,12$ ), while the remaining nine are small body sherds.

The decoration consists primarily of incised and grooved geometric motifs, with only one example of 
impressed decoration (rim no 12), which has rows of narrow, twisted cord impressions below the rim, a typical Beaker technique. Beaker pottery in the Hebrides is very richly decorated with zones of herringbone, short diagonal lines, horizontal and vertical lines, executed through incision or impressed comb, cord or shell, and can be seen at sites such as Northton, Harris (Simpson 1976; Gibson forthcoming), Calanais Stone Circle, Lewis (Henshall \& Johnson in prep), Sorisdale, Coll (Ritchie \& Crawford 1978) and Rosinish, Benbecula (Shepherd 1976), as well as in the later horizons of some chambered tombs, for example Clettraval and Unival (Scott 1935; Scott 1948). The majority of the sherds from the Olcote excavation are most likely to be Beaker pottery. Characteristically Neolithic decorative motifs can have similarities with those on Beaker pottery and it should not be ruled out that some of the incised sherds are Neolithic rather than Beaker, particularly pot nos 5 and 6 . However, impressed decoration is rare in Hebridean Neolithic assemblages.

Two of the rim sherds (nos 4 and 10) are Neolithic. Pot no 4 consists of a slightly flattened rim with panels of grooved, horizontal and vertical lines on its exterior and short transverse lines along the rim top, while pot no 10 has a flat-topped rim decorated with incised lines and an incised motif on the neck. These are very characteristic of Neolithic pottery and find ready parallels in the large Neolithic assemblages at Eilean Domhnuill, North Uist (Brown forthcoming), Allt Chrisal, Barra (Gibson 1995), Northton, Harris (Johnson forthcoming b) and Eilean an Tighe, North Uist (Scott 1951).

These sherds occur in levels throughout the cairn and were also recovered from pre-cairn features, indicating disturbance and/or incorporation of earlier deposits during the construction of the cairn. Pot no 4 comprises two conjoining sherds, one of which was found at the base of the cairn $(157,166)$ and the other beyond it (103), indicating disturbance and movement of at least some of the pottery. Two other vessels (nos $2 \& 3$ ), represented by single sherds, were found after the topsoil had been removed, while pot nos 5, 7, 8, 9, 10 and 11 were all retrieved from the layer $(157,166)$ between the body of the cairn and features pre-dating its construction. One of the sherds (no 6) was recovered from the same context (129) within the cist which contained the cremation vessel and another was unstratified (no 12). It is possible that these sherds were contained within the prehistoric soil and incorporated into the cairn during its construction.

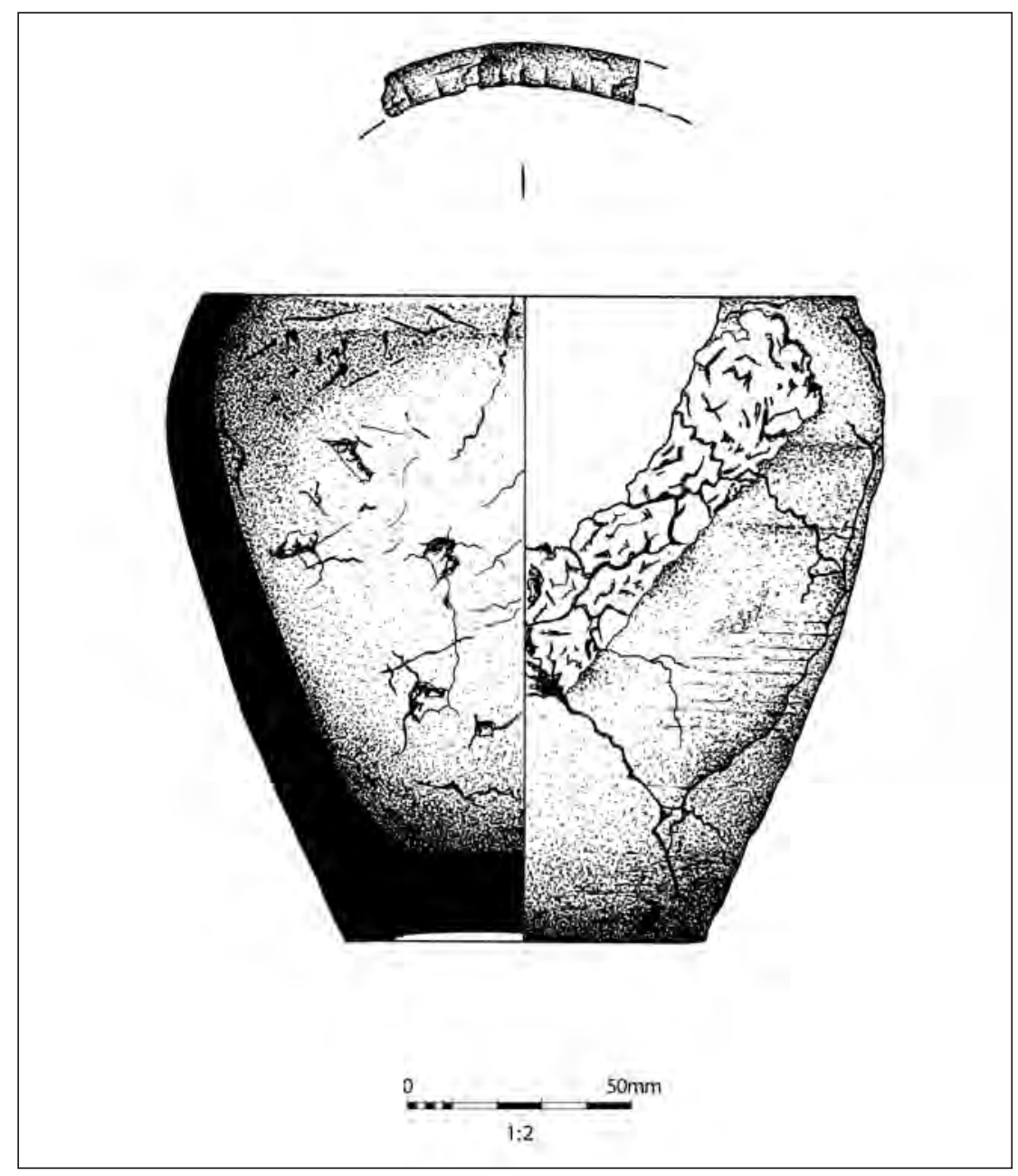

Illus 22 Cremation vessel from the central cist 


\subsection{Grids and test pits}

Several small featureless sherds of what is thought to be prehistoric pottery (nos 90-94) were recovered from two of the grids and two of the test pits, outwith the area of the cairn. The locations of these sherds, together with their size and condition, makes it impossible to say anything meaningful about their fabrics.

\subsection{Bronze Age pottery}

\subsubsection{The urn}

Within the central cist were the remains of an urn (pot no 1 , Illus 22), which was approximately $75 \%$ complete, comprising three large sherds and a number of smaller ones. The urn lay against the western orthostat of the small cist at the centre of the cairn. It measures $155 \mathrm{~mm}$ in height and has a rim diameter of $160 \mathrm{~mm}$ and a base diameter of $75 \mathrm{~mm}$. It ranges in thickness from $15 \mathrm{~mm}$ at its base to $8 \mathrm{~mm}$ at the rim. The urn is bucket-shaped and tapers towards the base. Its rim curves inwards and is flattened.

The urn is plain except for a series of short transverse incised lines along the top of the inside edge of the rim. This pattern is discontinuous, occurring at two separate points along the rim. There is a slight depression in the profile of the vessel about a third of the way down from the rim, perhaps at the junction of clay slabs or coils or because the vessel was made in two parts. The outside surface of the urn had been deliberately smoothed, unlike its interior. Finger marks can be seen and felt around the rim and the underside of the base has an impression, perhaps from being formed upon a plinth or from its position during firing. On the outside of the vessel is considerable orange staining, probably iron oxide and, below the rim, there is some mineralized organic deposit of insufficient quantity to allow analysis.

The urn was incomplete, which implies that recent damage to the cairn had removed part of the vessel.

\subsubsection{Undecorated pottery}

Excluding the urn (pot no 1), the majority of the plain body sherds found within the cairn are likely to be of Bronze Age date, and it is these sherds that are considered in this section. The vast majority of this pottery consists of featureless body sherds, which do not allow the profiles of vessels to be reconstructed. The fragmentary and often abraded condition of the sherds and the very incomplete nature of the vessels suggest that the sherds had been abraded prior to deposition.

Almost half of this Bronze Age pottery was recovered from the uppermost layer of the cairn (102) and the peat surrounding the outer kerb (103); 139 sherds weighing $1200 \mathrm{~g}$ from pot nos 13-45, one of which (no 39) is a small rim sherd. There are a further three small sherds from later cut features: field drain 104 (pot no 46) and post-hole 194 (nos 85 and 86), one of the latter being a rim sherd. These rims are very small, pot no 86 being a flat-topped rim with a slight external lip, while no 39 is a slightly everted rim. Both are plain with very little of their profile present and it is very difficult to ascribe a specific period to them. These sherds could represent disturbed material from some of the other vessels represented, or be post-Bronze Age intrusions onto the site.

A small amount of pottery was also found in earlier levels beneath the cairn; 32 sherds were recovered from these layers and from several shallow features. The fabric and nature of these sherds suggest that they are of Bronze Age type.

The body of the cairn itself, comprising layers of burnt peat, had only 12 sherds of pottery within it, some of which could have been brought onto the site with ash deposits (Section 10.4.1). A considerable deposit of featureless pottery (106 sherds weighing 514 g: nos 76-77) was contained in a small hollow (167) within this burnt peat. A quantity of pottery (nos 47-53), found in a pottery-rich region in the north-east quadrant (121) comprised 75 sherds weighing $144 \mathrm{~g}$ and included two base sherds. The fabric of these pottery groups is consistent with Bronze Age pottery types and similar to that of the cremation urn.

The presence of these large concentrations of pottery could indicate that, as well as the urn, other complete or partial vessels had been placed within the cairn. Such vessels could perhaps have also contained cremations although there is no evidence for this. Alternatively, they might have contained food or drink to accompany the main burial or perhaps be associated with funerary rites carried out during the construction of the cairn or deposition of the cremation.

\subsection{Discussion}

The radiocarbon dating of the site places it in the early to mid 2nd millennium BC. The search for parallels within the Western Isles for the Olcote urn has turned up a number of difficulties. Archaeologically, the Bronze Age is a remarkably blank period in the Hebrides, with a surprising lack of excavated pottery assemblages compared to the profusion retrieved from earlier and later prehistoric sites. Burials, and other types of site, securely dated to the Bronze Age, are scarce in the Western Isles. However, a few sites do have pottery associated with them and a number of recent and ongoing excavations are beginning to fill this gap, with the result that it may now be possible to start disentangling post-Beaker Bronze Age ceramic traditions.

A series of isolated finds of urns accompanying inhumations and cremations are known which may have broad similarities with the Olcote vessel, 
namely Rosinish, Benbecula (Crawford 1978) and Cnip, Lewis (Dunwell et al. 1995) and those found within the cist at Northton, Harris (Johnson forthcoming a).

At Rosinish a number of urns were found within a funerary monument (Crawford 1978), which consisted of a beehive corbelled cist, covered by a low mound and surrounded by a ring of stones. Within the cist were three inhumations accompanied by two urns, with an additional two smaller cists outside the ring of stones, one of which also contained an urn although no skeletal remains were found. A fourth urn was found within the stonework of the monument. Although there were no radiocarbon dates, this complex was dated by the excavator to the latter part of the early Bronze Age, the 2nd millennium BC. The cist had been cut into Beaker midden layers but, without radiocarbon dates, it is difficult to pinpoint the date any closer. Structurally, this monument may have links with one at Cnip (Close-Brooks 1995). Crawford commented that the vessel types at Rosinish were unusual and he suggested that they were immediately post-Beaker and represented a local development of Beaker wares (Crawford 1978). The Rosinish vessels are fairly small barrel-shaped pots and were found relatively intact. One pot (fig 6 in Crawford 1978, 165) had simple incised decoration and a cordon below a simple rounded incurving rim. Two others had rims with external bevels forming a roughly triangular section almost like a collar.

A Bronze Age cist inhumation excavated at Cnip (Dunwell et al. 1995) appeared to have a kerb of stones surrounding it although no mound survived. Accompanying this burial was a coarse, squat vessel of a simple tub shape with bipartite profile attributable to a slight shoulder and an upright, slightly flattened rim. This burial was radiocarbon-dated to the first half of the 2nd millennium BC.

At Northton, there was a cist inhumation accompanied by a vessel (Simpson 1976; Johnson forthcoming b). This vessel, which lacked its rim, was a small barrel-shaped coarse plain pot. Another vessel, also a small barrel-shaped pot and very thick and heavy, was associated with another grave. Further vessels from middens at Northton were remarkably similar and consisted of two types: plain pots in simple barrel-shapes with rounded or more flattened rims, slightly inturning or upright with splayed bases or with a slight foot; or simple tub or bucket-shaped pots with straight walls. Only one of them is decorated, with a plain cordon around its upper body. No dates are available for those features.

Other vessels which could provide parallels for Olcote are those recovered from cist burials at Port na Long and Trecklett, North Uist (Megaw and Simpson 1961). Again, they consist of simple urns with limited decoration and are likely to be of Bronze Age date.

The Olcote vessels also have close similarities with a series of domestic plain coarse wares from Cladh Hallan, South Uist (Marshall et al. 1999; Parker Pearson et al. 2000). This late Bronze Age round- house settlement has a pottery sequence comprising plain, coarse, barrel-shaped vessels with rounded or flattened rims, some of which appear to be very similar to the cremation urn from the Olcote cairn, with examples showing rim top decoration consisting of incised, short diagonal lines.

Several other excavations in the Western Isles which yielded plain pottery assemblages in a domestic Bronze Age context are Dalmore and Barvas (Dunwell et al. 1995, 286). There is a further burial complex at the Udal, North Uist, where one of the inhumations was dated to the first half of the 2nd millennium BC, although details of this monument are sparse (Crawford \& Switsur 1977; Crawford 1996).

Other funerary monuments of this period, however, have produced pottery of a very different character. At Cnip, Lewis a second burial complex was found adjacent to the cist inhumation, which included a corbelled chamber with inurned cremation (Close-Brooks 1995). Despite the similarity of burial tradition and its proximity to the corbelled cist at Rosinish, the Cnip cremation urn was a large, flat-based, plain shouldered jar (Illus 9, no 5, within Close-Brooks 1995) with an out-turning rim. It has been suggested that it is a plain version of an Enlarged Food Vessel, indicating a local development of that tradition (Close-Brooks 1995, 268). Burnt deposits on the interior of the urn were radiocarbon-dated to the first half of the 2nd millennium BC. This cist formed one part of a multi-phased monument at Cnip, where there was also an earlier cist inhumation and later kerb cairn with central cremation.

Slightly further afield, three cists were exposed by erosion at Traigh Bhan, Islay (Ritchie \& Stevenson 1982). One of the cists contained two inhumations dated to the 2nd millennium BC. A complete vessel found beside the skulls consisted of a large, flatbased, sharply carinated jar with an everted rim and wide internal bevel. The exterior of the body was plain although the rim was decorated with a single line of cord impression on its outer lip, while the bevel was decorated with a series of interlocking, infilled triangles in whipped cord. It is suggested that the vessel has more affinities with the Food Vessel tradition than any other but is unusual in being plain and fairly squat.

This tradition may be seen in a domestic context at Kilellan Farm, Islay (Burgess 1976) where Food Vessels and both plain and decorated shouldered jars were recovered. The shouldered jars from Kilellan Farm and also seen at Traigh Bhan compare favourably with the vessel found in the Cnip corbelled cist (Close-Brooks 1995). Although Kilellan Farm has no radiocarbon dates, Burgess dates the occupation of the site to the late 3rd or first half of the 2nd millennium BC (Burgess 1976, 206). He also suggests that the decorated shouldered jars form a new Kilellan Style (Burgess 1976, 200) of Bronze Age pottery, which may be a local version of the Food Vessel tradition.

There is a tradition throughout Scotland of 
Table 3 Radiocarbon dates relating to Bronze Age pottery assemblages in the Hebrides

\begin{tabular}{llllll}
\hline Site & Reference & Context & Code & Date (BP) & Date (BC) \\
\hline Udal & Crawford \& Switsur 1977 & Cist inhumation, human bone & Q-1458 & $3430 \pm 85$ & $1960-1520$ \\
Cnip & Close-Brooks 1995 & Inurned cremation & GU-1174 & $3410 \pm 55$ & $1890-1530$ \\
Cnip & Dunwell et al. 1995 & Cist, human bone & GU-3488 & $3360 \pm 50$ & $1870-1520$ \\
Traigh Bhan & Ritchie \& Stevenson 1982 & Inhumation & GU-1378 & $3330 \pm 95$ & $1880-1430$ \\
Traigh Bhan & Ritchie \& Stevenson 1982 & Inhumation & GU-1379 & $3005 \pm 105$ & $1550-900$ \\
\hline
\end{tabular}

inurned cremations and inhumations with accompanying vessels, often in cists under a cairn, which developed from the late Neolithic period onwards. We may just be beginning to find out what the local manifestation of this tradition is, as well as the nature of its associated ceramic tradition. There appears to have been some variation within Bronze Age funerary rites. There certainly appears to be two different types of pottery associated with these monuments: the plain barrel-shaped pots and the plain and decorated shouldered jars. However, radiocarbon dating suggests no chronological distinction between the two, with the two monuments at Cnip having different pottery types yet dates of the same period, which also corresponds to the dating of Ardnave and Traigh Bhan (Table 3). Although there is not necessarily any concordance between domestic wares and contemporary funerary vessels (their striking functional difference could result in very different pottery types), it seems clear from the domestic assemblages excavated so far in the Hebrides that these two pottery types are also represented on settlement sites. However, without detailed chronological and regional analysis, it is difficult to assess the significance of this and the possibility of regional diversity within the Hebrides cannot yet be ruled out. Clearly, more excavation and more comprehensive dating of the associated assemblages is necessary to clarify this situation. Although the typology of Bronze Age pottery is not yet well understood, results from recent excavations and those from other, more targeted excavations in the future should provide information to start filling in this blank period and establish a secure ceramic sequence, in both funerary and domestic contexts. 


\section{Chipped Stone by G Warren}

\subsection{Introduction}

A vast assemblage of worked and natural quartz, flint and other kinds of stone was recovered from on, within, under and near the cairn at Olcote. This material presents a series of analytical challenges and opportunities. For understandable reasons archaeologists have been cautious about categorizing quartz industries, not least because of the inherent vagaries of the material (see below). It is also significant that, until recently, the focus of lithic analysis has been formal artefacts rather than craft traditions, of which formal pieces formed a part. Given the comparative rarity of formal artefacts in quartz, the dominance of typological criteria has contributed to the marginalization of quartz-working in accounts of prehistoric stone craft. There are exceptions, for example Mercer's work on the quartzrich late Mesolithic assemblages from Lussa River, Jura (Mercer 1971) but, in a general sense, our understanding of quartz-working is underdeveloped, often simply framed within categories of 'expediency'. ${ }^{1}$ This is compounded by the fact that quartz has often formed a small part of assemblages, rather than the bulk of them, and consequently it is harder to assess the character of the industry as a whole. Furthermore, difficulties of recognition of worked quartz in the field lead to unrepresentative assemblages. Whereas policies of retention of all flint are common, facilitated by the fact that in a Scottish context flint is often a non-local material, it is unusual to extend this approach to all quartz, which can be superabundant.

The difficulties of analysing quartz industries are fairly well recognized. Because of its crystalline structure, quartz fractures in a less predictable fashion than more homogenous silica minerals such as flint or chert (Whittaker 1994; Andrefsky 1998). Consequently, signatures of stone crafting (such as bulbs of percussion, ripple scars and coherent morphology) are underdeveloped and it is not always possible to be completely confident of the human origin of quartz 'artefacts'. These analytical problems can be particularly acute in an area where natural quartz may be present, although Bradley offers one approach to this problem (Bradley 1995). Olcote is in such an area, and many pieces in the assemblage are clearly natural. In other instances it is difficult to assess whether an artefact is clearly struck. This is especially significant given that

1 Since the completion of this report in 2000, work on Scottish quartz has continued apace, with Torben Ballin involved in the analysis of numerous assemblages (for discussion see Saville and Ballin 2001). This has included discussion of quartz quarries in the vicinity of the Olcote site (Ballin 2004). quartz pebbles appear to have been smashed on site, producing many very simple chips and fragments that are especially difficult to interpret confidently as intentional products of human activity. In order to reflect these difficulties, a category of 'possibly worked' has been retained in this analysis.

\subsection{Methodology}

An assemblage of 15,456 worked and natural stones was recovered during excavations at the cairn itself (Table 4) and a further 77 worked items from test pits (see below). This assemblage was macroscopically analysed and divided into a number of basic categories. Artefacts less than $10 \mathrm{~mm}$ in maximum dimension are described as 'smalls'. These are further divided into 'worked' and 'possible/natural' groups (see below for discussion of the problems of this methodology). Smalls from test pits were not subdivided into types but identified by material. Artefacts more than $10 \mathrm{~mm}$ in maximum dimension were classified as 'worked', 'possibly worked' or 'natural'. Natural or possible artefacts were bagged in bulk, whilst worked artefacts were described according to standard analytical procedures and received individual catalogue references. The following totals were recorded.

Table 4 Total quantities of stone recovered from the main trench

\begin{tabular}{lrrr}
\hline & Smalls & $\mathbf{1 0 ~} \mathbf{~ m m}$ & Total \\
\hline Quartz & 12,369 & 2729 & 15,098 \\
Flint & 94 & 73 & 167 \\
Sedimentary & 174 & 10 & 184 \\
Other & 1 & 6 & 7 \\
Total & 12,638 & 2818 & 15,456 \\
\hline
\end{tabular}

The bulk of the assemblage is comprised of quartz and a high proportion of this material was natural. For example, only $6 \%$ (754 of 12,369$)$ of the quartz smalls from the main site were worked; $47.6 \%$ of the larger quartz artefacts were also natural and a further 368 (13.5\%) only possibly worked (Table 5).

When only clearly worked artefacts $>10 \mathrm{~mm}$ in maximum dimension are considered, the number of artefacts drops dramatically to 1219 .

\subsection{Raw materials}

A range of raw materials was found in the assemblage. Quartz was by far the most common (92\% of 
Table 5 Totals of worked/possibly worked/natural pieces $>10 \mathrm{~mm}$

\begin{tabular}{llc}
\hline Raw material & & Main site \\
\hline Quartz & Natural & 1298 \\
Quartz & Possible & 368 \\
Quartz & Worked & 1063 \\
Flint & Worked & 73 \\
Sedimentary & Possible & 8 \\
Sedimentary & Worked & 2 \\
Other & Worked & 6 \\
\hline
\end{tabular}

Table 6 Worked quartz types

\begin{tabular}{lrr}
\hline Quartz type & $\boldsymbol{n}$ & \% age \\
\hline QTZ1 & 941 & 84.0 \\
QTZ2 & 1 & 0.1 \\
QTZ3 & 166 & 14.8 \\
QTZ4 & 12 & 1.1 \\
Total & 1120 & \\
\hline
\end{tabular}

total $>10 \mathrm{~mm}$ ) and varied widely in quality. In order to categorize this diversity, a crude system of differentiating between quartz types was used (Table 6). Two groups are the most important: QTZ1 describes the predominant material, grey, white or slightly yellowish in colour and varying in homogeneity. Because of the continuous variation of quartz this category includes 'powdery' crystalline quartz and more homogenous material. It has been argued (Lacaille 1937, 282) that granular quartz is the highest quality material on Traigh na Beirgh, on the Bhaltos peninsula of north-west Lewis, but this does not appear to be true of the Olcote assemblage. Although experimental knapping was not undertaken, much of the granular 'powdery' quartz is friable and seems unlikely to be the most desirable raw material.

QTZ3 is the highest quality raw material although this category again describes a spectrum of quartzes. Examples of this type are either clear with occasional banding or milky-white in colour - they are always homogenous. Artefacts of this fine material tend to be more regular in character than those of other types of quartz and are more likely to be retouched. They are often slightly smaller than those of QTZ1. QTZ2, a shiny laminated material, is very rare although more frequently observed amongst natural pieces, while QTZ4 is grey, notably veined low-quality quartz. It must be stressed that these types are not discontinuous and that QTZ3 represents the upper end of a spectrum of variation. Further divisions of raw material type are made in the analysis of cores (see below). A variety of sources of quartz was being utilized, including outcropping veins of quartz, locally on the beach, and rolled pebbles. Unfortunately, it is impossible to differentiate between these sources unless cortex is present and it was therefore not possible to make an accurate assessment of the proportions of material utilized from them.

A total of $87 \mathrm{flint}$ artefacts $>10 \mathrm{~mm}$ in size were retrieved from the excavations and test pits. This material was of quite low quality and much of it was affected by heat $(n=21,24.1 \%)$ or patination $(n=21$, $24.1 \%$ ). Fresh flint tended to be grey in colour although it did vary slightly and a few $(n=5)$ honey flints were observed. Most of the flint was very small and much of it, including ten primary flakes $(n=43$, $49.4 \%$ ), was cortical. A derived pebble source, probably from local beaches, is likely for this material.

A number of flakes of unusual raw materials were identified in the assemblage. Of most interest is the presence of metamorphosed sedimentary rocks, identified as baked or banded shales. This material is presumably comparable to the mylonite identified by Ballin at the main Calanais ritual complex (Ballin forthcoming), being characterized by weathering and thin horizons of grey or blue material. These are poorly understood materials; mylonite for example was identified by Simpson at Northton (Simpson 1976) but later described as banded mudstone from Skye (Wickham-Jones 1986, 7). Standardization in terminology is to be desired. In this report the materials are described as sedimentary. They are friable, heavily weathered materials, found frequently as small fragments in the gridded collections. Some of the larger pieces have been flaked and it is clear that this material does form a small part of the assemblage on site, even if it is very difficult to characterize this dependency. The most notable artefact among this material is a fine barbed and tanged arrowhead. Outcrops of shales to the north of the site are known although further work is required on this raw material in order to clarify patterns of exploitation. Other materials include two certain and one possible flake of granodolerite, a coarse-grained Hebridean rock, and a possible flake and small chunk of epidosite, also known locally.

\subsection{Composition of the assemblage}

Archaeological research into prehistoric stone craft is dominated by analytical techniques derived from the study of high quality silicates such as flint (for discussions see Holm \& Knutsson 1998). The fracture properties of quartz are different from flint and it is therefore arguable that different classifications are required. Knuttson, for example, has developed very detailed models of fracture properties for a range of Swedish materials and proposes alternative classifications for quartz (Knuttson 1998, 76). Despite concern about the validity of flint-derived classifications, it is not clear that the use of Scandinavian models would necessarily be appropriate in this context. Local experimental studies are required in order to understand the varied fracture properties of Scottish quartz (these are currently being organized by the author). In the absence of such analyses, it was decided to utilize a standard classification technique, which also has the advantage of facilitating comparisons between different materials on site. The only unusual description is that of 'anvil split'. This is a subdivision of split pebbles, referring 

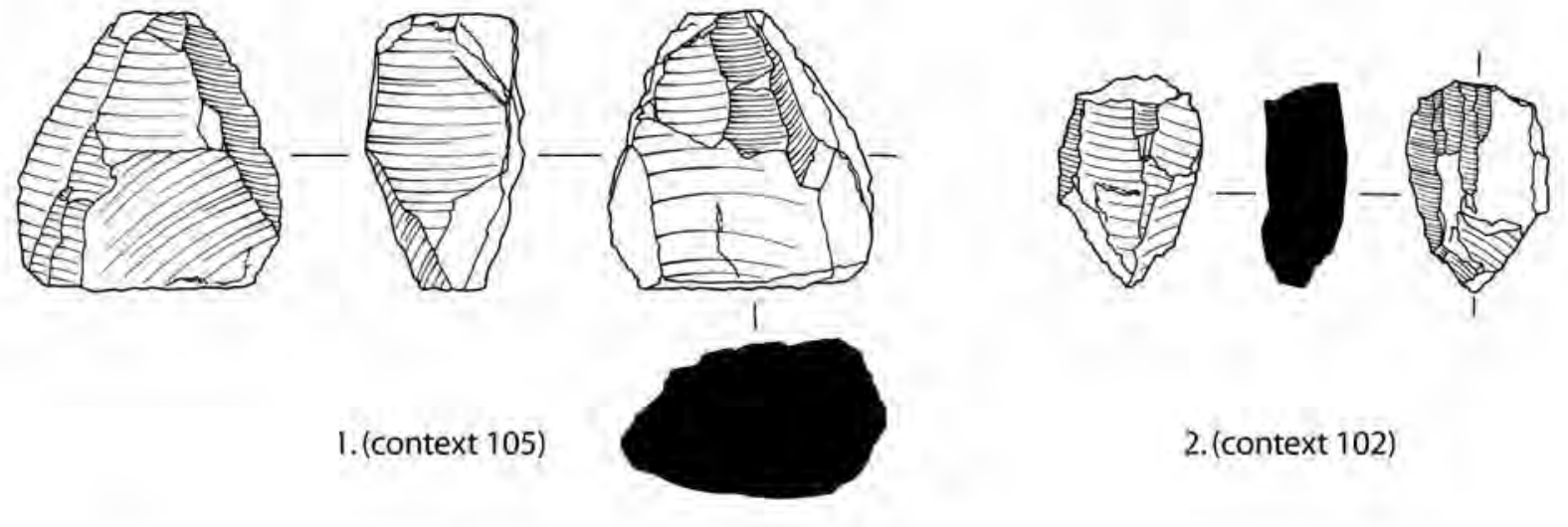

2. (context 102)
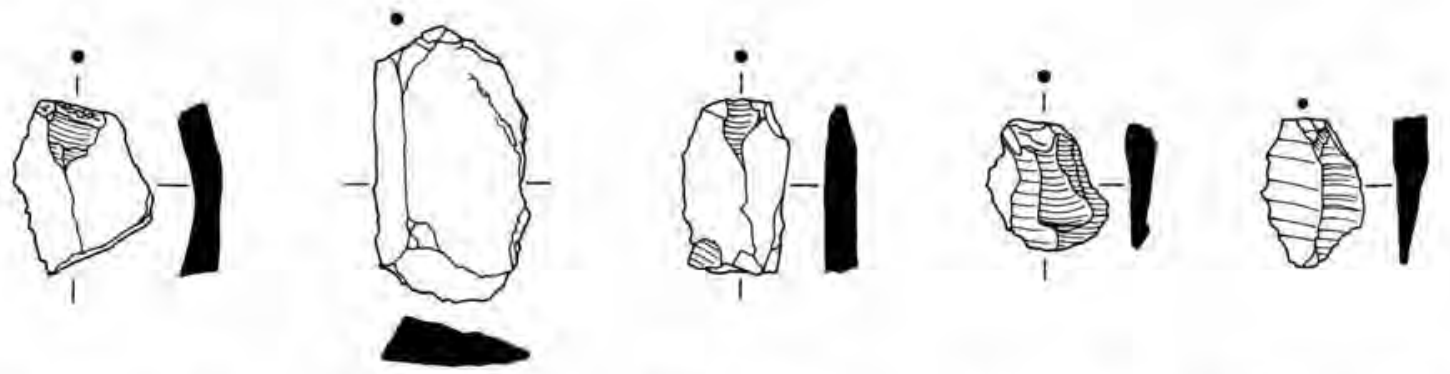

3. (context 102)

4. (context 102)

5. (context 102)

6. (context 102)

7. (context 102)

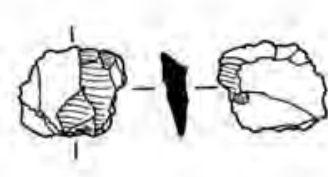

8. (context 101)

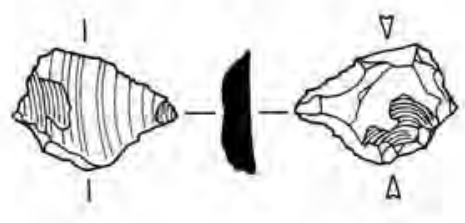

9. (context 102)

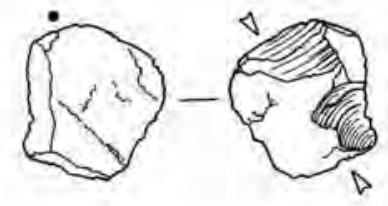

10. (context 102)

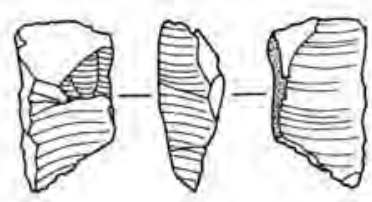

11.(context 102)

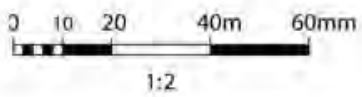

Illus 23 Worked stone. 1-2: cores; 3-7: flakes; 8-10 and 12: bipolar cores; 11: anvil split. All quartz except for 6 (flint) 
Table 7 Artefact and raw material types

\begin{tabular}{|c|c|c|c|c|c|c|c|c|}
\hline & Quartz & $\begin{array}{l}\% \text { of raw } \\
\text { material }\end{array}$ & Flint & $\begin{array}{l}\% \text { of raw } \\
\text { material }\end{array}$ & Sedimentary & $\begin{array}{l}\% \text { of raw } \\
\text { material }\end{array}$ & Other & $\begin{array}{l}\% \text { of raw } \\
\text { material }\end{array}$ \\
\hline Anvil split & 37 & 3.3 & & & & & & \\
\hline Bashed lump & 33 & 2.9 & & & & & & \\
\hline Bipolar core & 65 & 5.8 & 1 & 1.1 & & & & \\
\hline Blade & 9 & 0.8 & 2 & 2.3 & & & & \\
\hline Chunk & 282 & 25.1 & 26 & 31 & & & & \\
\hline Core & 30 & 2.7 & & & & & & \\
\hline Flake (irregular) & 354 & 31.5 & 27 & 43.7 & 2 & 66.7 & 2 & 33.3 \\
\hline Flake (regular) & 268 & 23.9 & 16 & 20.7 & 1 & 33.3 & 4 & 66.7 \\
\hline Split pebble & 43 & 3.8 & 1 & 1.1 & & & & \\
\hline Pebble & 2 & 0.2 & & & & & & \\
\hline Total & 1123 & & 73 & & 3 & & 6 & \\
\hline
\end{tabular}

Table 8 Quality of quartz used for anvil splits, split pebbles, bashed lumps, cores and bipolar cores

\begin{tabular}{|c|c|c|c|c|c|}
\hline & Very low & Low & Medium & High & Very high \\
\hline Anvil splits & & & 24 & 13 & \\
\hline Split pebble & 1 & 1 & 32 & 7 & 1 \\
\hline Bashed lumps & & 1 & 16 & 16 & \\
\hline Cores & & 1 & 4 & 20 & \\
\hline Bipolar cores & & 2 & 9 & 28 & 18 \\
\hline
\end{tabular}

to pebbles that have clearly been split on an anvil but are not bipolar flake cores (see below and Illus 23). The assemblage is discussed as a whole, including the finds from the test pits.

\subsection{The quartz}

Although regular flakes are significant, irregular flakes and chunks dominate the quartz assemblage (Illus 23, 3-7), presumably in part reflecting the irregular fracture of this material. Blades are rare. Formal platform cores are rare, whereas bipolar cores are common (Illus 23, 1, 2, 8-12). There is also a range of split pebbles, some - anvil splits (Illus 23, 11) - with clear evidence of bipolar traditions. The presence of micro-débitage ('smalls') confirms that this assemblage includes material originating from stonecrafting activities although it is not possible to identify whether this is primary or secondary manufacture.

Given very varied raw material, unless very heavy weathering or battering is present there are difficulties in clearly ascertaining whether a piece of quartz has originated from the outside of a pebble or an outcrop. Because of this factor, the proportions of primary or secondary material identified may be too low and, because primary material comprises only $4.1 \%$ of the assemblage and secondary material $28.1 \%$, this does appear to have been a problem in analysis. Despite the low proportion of exterior flakes, it seems that most stages of the reduction process are present in the assemblage, including primary testing and structured reduction strategies.

\subsubsection{Cores and split pebbles}

All cores and split pebbles from the main site were analysed in order to characterize the technological characteristics of this industry (material from test pits was not incorporated into these analyses). The number of removals, blows or platforms present and the weight were catalogued for each piece. A further subjective interpretation of the raw material quality was made, irrespective of the raw material type already identified, loosely describing material as very low, low, medium, high or very high in quality (Table 8).

Split pebbles and anvil splits are split quartz pebbles or chunks. Sometimes they have been clearly split on an anvil by a bipolar blow (anvil splits), in other cases not so clearly (split pebble). It is, therefore, necessary to note that the division of anvil splits, bipolar cores and split pebbles describes only the final form of the artefact, not the processes involved in its manufacture. It is possible, for example, that bipolar blows did not result in clear bipolar evidence. Notwithstanding these difficulties, there are differences between these types. For example, there are 37 anvil splits, all manufactured of QTZ1, and 42 split pebbles, 40 of QTZ1 and one each of QTZ3 and QTZ4. Most of the material is of medium quality but it is notable that anvil splits are frequently of slightly higher quality than split pebbles. Anvil splits also 
Table 9 Weight (in g) of anvil splits, split pebbles, bashed lumps, cores and bipolar cores

\begin{tabular}{llclc}
\hline & Range & Mean & Interquartile range & n \\
\hline Anvil splits & $2-322$ & 29.7 & $9-33$ & 37 \\
Split pebbles & $1-64$ & 20.1 & $8-26$ & 42 \\
Bashed lumps & $8-577$ & 107.5 & $33-117$ & 33 \\
Cores & $5-125$ & 37.7 & $11.75-48.5$ & 25 \\
Bipolar cores & $1-77$ & 8.9 & $3-8$ & 57 \\
\hline
\end{tabular}

tend to be a little heavier than split pebbles and have a wider range of weight (Table 9). This differentiation suggests that the categories may capture something of technological decisions made in prehistory. It is possible that anvil splits, with the hints of bipolar working, reflect a more structured approach to working than split pebbles. Indeed the latter are little more than fractured pebbles and it is possible that some have resulted from activities as simple as throwing a quartz pebble onto the cairn.

There are 33 bashed lumps of quartz in the assemblage. These are large pebbles or chunks with few removals and no signs of formal platforms. Sixteen are of high quality quartz, 16 of medium quality and one of low quality quartz, 30 are of QTZ1 and one of QTZ4. Bashed lumps range in weight from 8 to $577 \mathrm{~g}$, averaging $107.5 \mathrm{~g}$ with an interquartile range of $33-$ $117 \mathrm{~g}$. Most bashed lumps have one $(n=7)$ or two ( $n=$ 22) removals, two have three removals and one has four.

Twenty-five platform cores are present, all manufactured on QTZ1. Most of this material is of high quality ( $n=20)$, the rest is medium or low quality; cores are therefore slightly higher quality material than bashed lumps. Cores are much larger than bipolar cores but tend to be a smaller than bashed lumps, averaging $37.7 \mathrm{~g}$ with an interquartile range of 11.75-48.5 g. Most cores only have one platform ( $n$ =17), six have two platforms and two have three platforms (Table 10). The minimum number of removals from the cores is generally low, which probably reflects the large size of most of the flakes in a quartz industry (see below). Platforms are either natural or very simple artificial types.

The 57 quartz bipolar cores range greatly in size and many very small cores are of high quality material (Illus 23, 8-12). Only one bipolar core is of flint and this is excluded from the analyses that follow. Many bipolar cores are very small, averaging only $8.9 \mathrm{~g}$ with an interquartile range of $3-8 \mathrm{~g}$. This pattern is especially true for the higher quality cores and those manufactured on QTZ3, which often weigh

Table 10 Numbers of removals and platforms on cores

\begin{tabular}{lllllll}
\hline $\begin{array}{l}\text { No of } \\
\text { platforms }\end{array}$ & \multicolumn{6}{c}{ No of removals } \\
\cline { 2 - 7 } & $\mathbf{1}$ & $\mathbf{2}$ & $\mathbf{3}$ & $\mathbf{4}$ & $\mathbf{5}$ & $\mathbf{6}$ \\
\hline 1 & 1 & 9 & 6 & 1 & 0 & 0 \\
2 & 0 & 1 & 2 & 1 & 2 & 0 \\
3 & 0 & 0 & 0 & 0 & 1 & 1 \\
\hline
\end{tabular}

less than $5 \mathrm{~g}$. Whilst this pattern may partly reflect the importance of these high quality raw materials, it is possible, given the very small size of the resulting flakes, that some of these smallest bipolar cores result from little more than deliberate smashing of quartz items. It is interesting to note that bipolar cores are manufactured on QTZ3 $(n=14$, $24.5 \%$ ), whereas no platform cores utilize this material. This may reflect the size of this material, which is often small, or the value attributed to it.

These simple analyses of core types show a number of interesting patterns. Notwithstanding the simple split pebbles, which may reflect either testing of material or merely the deliberate fracturing of quartz pebbles, there are some distinctions between the other categories identified. Bashed lumps tend to be large and consist of a variety of raw materials, whereas platform cores are smaller and of slightly higher quality. These are not absolute distinctions but rather they reflect a continuum of testing of material and removal of flakes as part of skilled routines of stone crafting. Bipolar cores are much smaller than other cores and are often manufactured from high quality raw material. Sometimes the size of these cores is such that a practical use for their products is unlikely.

\subsubsection{Removals}

A total of 259 regular quartz flakes are present in the assemblage. These are quite large and tend to be thick and slightly longer than they are wide (interquartile ranges of 20-33.5 $\mathrm{mm}$ for length, 15-26 $\mathrm{mm}$ for breadth and 5-10 $\mathrm{mm}$ for thickness for complete flakes). The importance of structured routines of flake removal is clear from the proportion of regular flakes with platforms. The presence and character of platform preparation was noted for 127 quartz flakes. Most of these had very simple artificial $(n=100)$ or natural $(n=20)$ platforms. Seven showed evidence of more complex preparation, sometimes isolation or scrubbing and, in one case, a bird's wing platform. Platform sizes varied from 1 to $19 \mathrm{~mm}$ (Illus 24) but were generally quite large (interquartile range 3$8 \mathrm{~mm}$ ). It is difficult to identify the hammer types used on quartz industries because of the irregular fracture properties of the material. However, large platform sizes, together with the number of crushed platforms, suggest that direct percussion with a fairly hard hammer was frequent. 


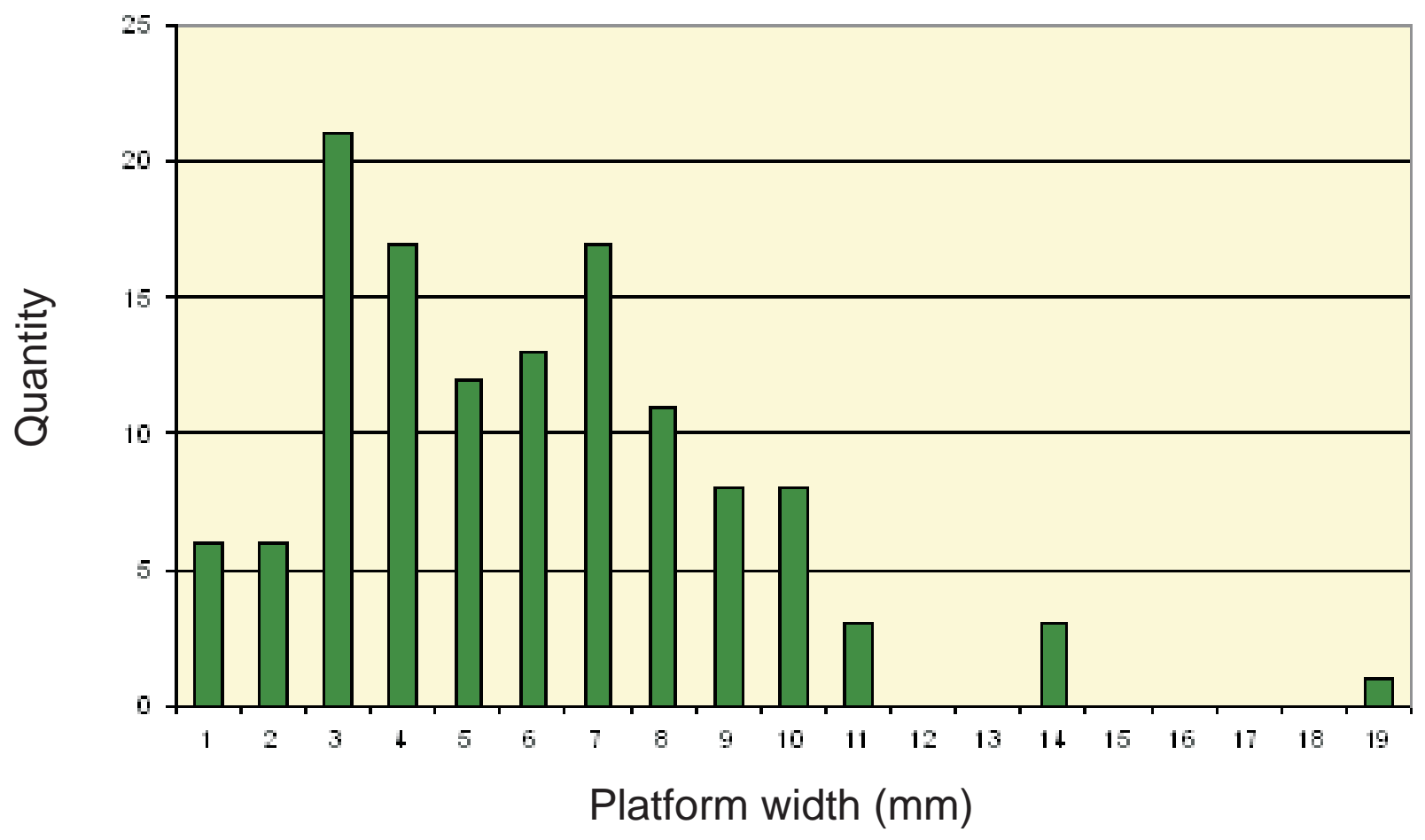

Illus 24 Width of platforms of quartz flakes

\subsubsection{Discussion}

The analysis of this large quartz assemblage has highlighted a number of distinctive features of its primary technology. A variety of craft processes can be identified amongst the Olcote assemblage, from testing of material through to the structured production of flakes from platform cores. Interestingly, there are no cores of the highest quality quartz (QTZ3) except for small bipolar examples and these are unlikely to have provided the source for the flakes within this assemblage. This implies some complexity in the treatment of this attractive material. It is also notable that, although the knapping activity is clearly responsible for much of the assemblage, the high numbers of crude, broken materials such as split pebbles can be interpreted simply as the result of deliberately smashing pebbles. This interpretation is also possible for some of the small bipolar cores of QTZ3 and may help explain the large numbers of chunks and 'possibly worked' artefacts.

\subsection{The flint}

The flint assemblage is dominated by chunks and irregular flakes (Table 7). There are no formal cores, only one small bipolar core and a split pebble of exceptionally poor quality flint. It is therefore difficult to say much about the technological characteristics of the flint industry, other than to highlight that the presence of micro-débitage indicates that the assemblage derives in part from stone tool production activities as well as use. The absence of cores might be understood in terms of the importance or scarcity of this material. These may have been valuable, curated items. This in turn implies that stone-crafting routines extended across the wider landscape with cores being carried to and from varied locations. The presence or absence of platform preparation was noted on seven flint flakes, which tended to be simple platform isolation or edge scrubbing $(n=4)$. Two flakes had unprepared artificial platforms and one had a bird's wing platform. Platform widths were small, one of $1 \mathrm{~mm}$, five of $2 \mathrm{~mm}$ and one of $4 \mathrm{~mm}$. It appears that flint was treated differently from quartz, which implies the use of slightly differing skills.

\subsection{Other materials}

The few flakes of banded shales and granodolerite do not allow any characterization of the exploitation of this material. The presence of seemingly unworked sedimentary material away from the cairn (see below) 
is difficult to interpret although it may reflect the degradation of artefacts or débitage.

\subsection{Retouched artefacts}

A total of 33 clearly retouched and seven possibly modified artefacts were recovered from Olcote. The seven possibly retouched artefacts are fragmentary or abraded pieces. In addition, there is one irregular flint flake with extensive damage or possible irregular retouch. Of the 33 definitely retouched artefacts, 26 are quartz, seven are flint and one is of banded shale. Flint is greatly over-represented amongst retouched artefacts as compared to the assemblage as a whole. Nine of the retouched quartz artefacts are of QTZ3, the high quality banded or milky quartz. This is also an over-representation.

The dominant tool type are scrapers $(n=29)$ (Illus 25). These are mainly of three types: heavy convex scrapers manufactured on chunks of quartz $(n=4)$ (Illus 25, 22); convex end scrapers $(n=2)$ (Illus 25, 15); and short convex (or 'thumbnail') scrapers ( $n=$ 18) (Illus 25, 13, 14, 16-21, 23). There are a further five varied scrapers (Illus 25, 17-21), all mainly convex but including short tangs or multiple scraper edges as well as a neat side scraper (Illus 25, $24)$. One is a fine artefact (Illus 25, 18) with neat retouch extending all around the edges of an oval flake. This piece is clearly distinct from the rest of the scraper assemblage. The short convex (thumbnail) scrapers are the most notable formal types and are all very small, less than $20 \mathrm{~mm}$ in maximum size, and many are abraded or edgedamaged. The amount of retouch present on these pieces varies, some being approximately $90 \%$ retouched, others almost the entire piece. The angle of the scraper edge also varies, from steep to shallow. Despite this variation, they clearly form a group. Illus 26 shows the size of the complete

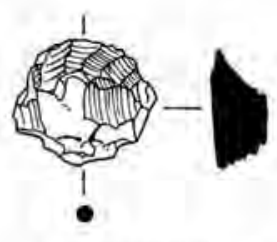

13. (context 102)

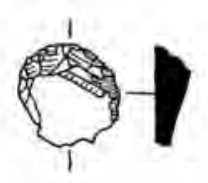

14. (context 110)
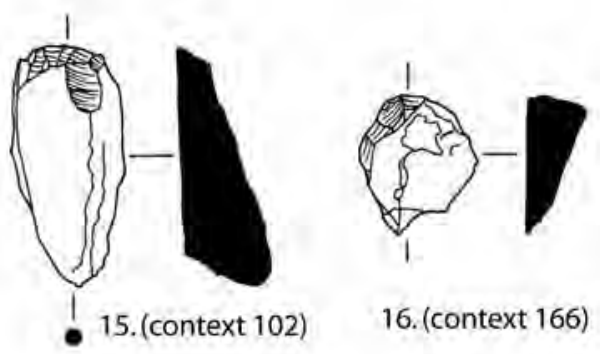

16. (context 166)

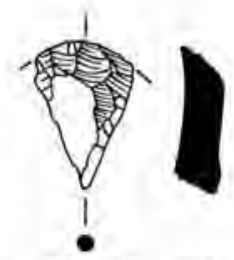

17. (context 102)

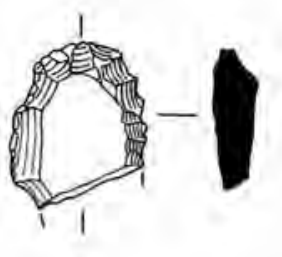

18. (context 102)

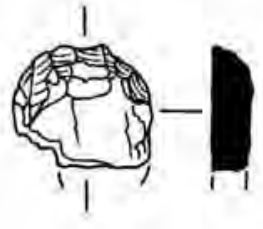

19. (context 154)

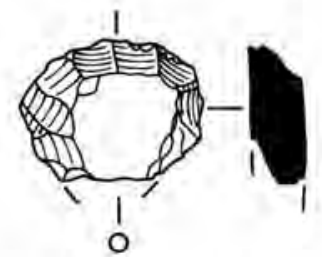

20. (context 154)

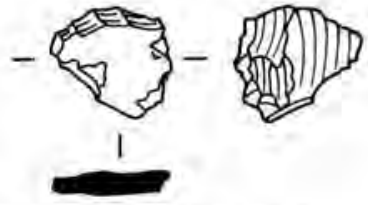

21. (context 102)

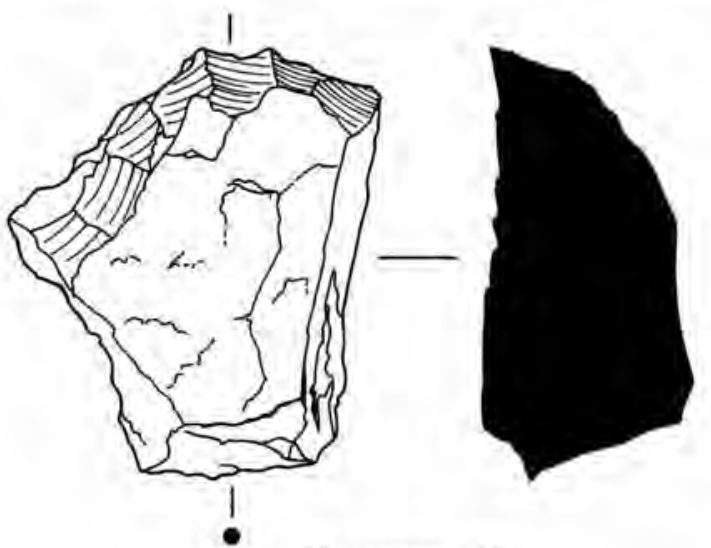

22. (context 102)

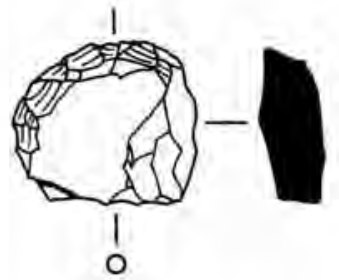

23. (context 154)

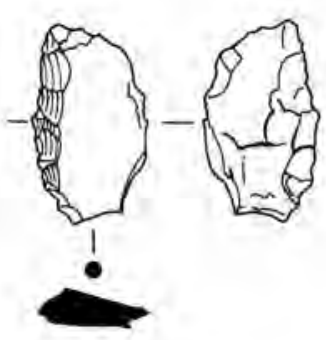

24. (context 154)

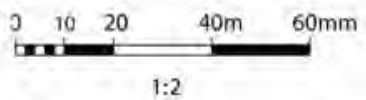

Illus 25 Worked stone. 13, 14, 16-21 and 23: short convex scraper; 15: long convex end scraper; 22: heavy convex scraper; 24: side scraper. All quartz except for 13, 14, 16 and 19 (flint) 


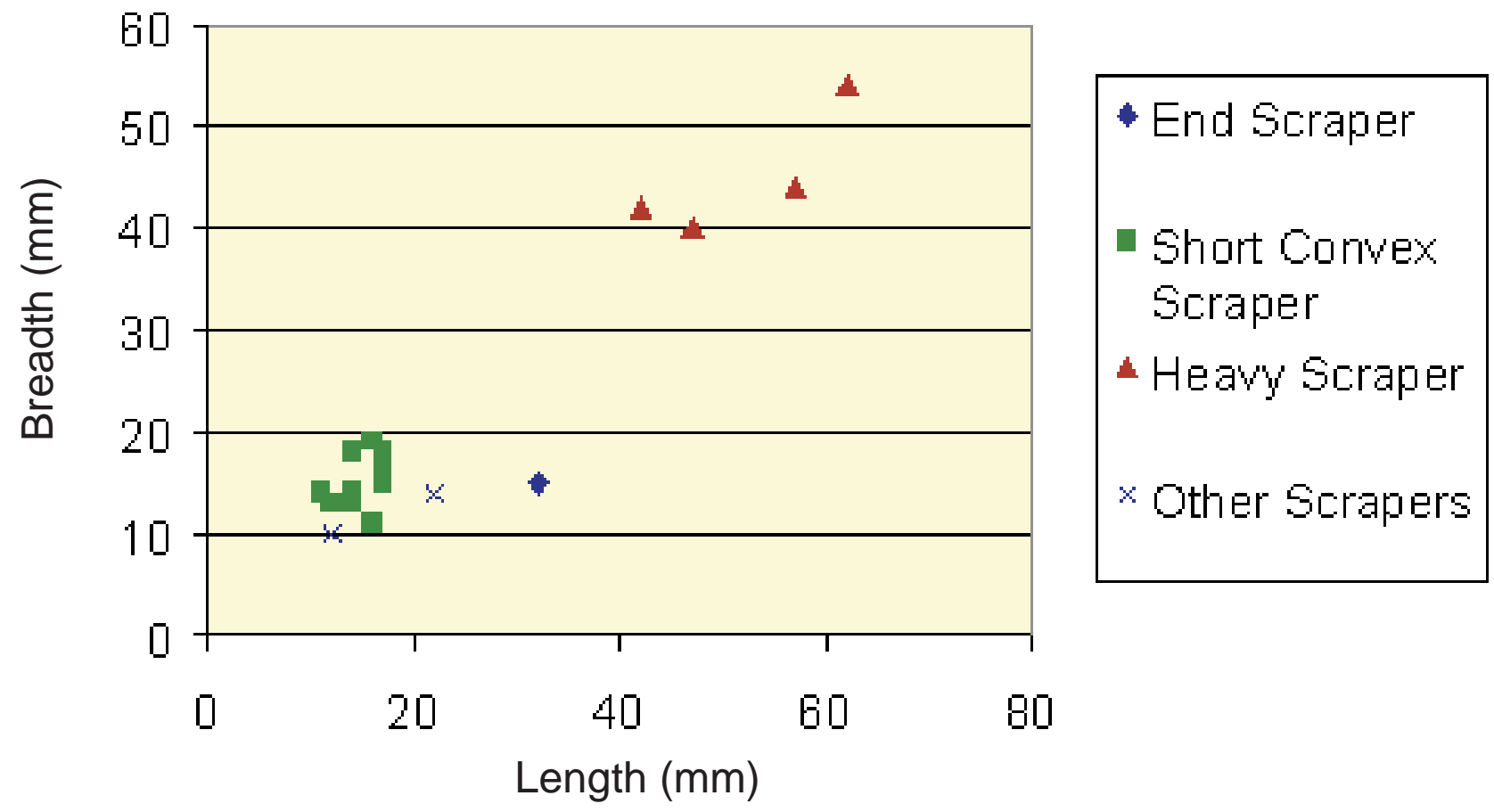

Illus 26 Length:breadth ratios of complete scrapers

scrapers present in the assemblage, comparing only length and breadth.

Three edge-retouched artefacts were also found, including two flint flakes with miscellaneous retouch. Most notable amongst these artefacts is C.154.14, a fine percussion flake of quartz with extensive unifacial retouch (Illus 25, 14). One fragmentary arrowhead and one possible incomplete arrowhead are also present; these are both triangular in shape and neither is diagnostic.

Finally, a fine barbed and tanged arrowhead, manufactured in sedimentary material, was recovered from Test Pit 31, immediately to the south-east of the cairn (Illus 27). It is a small arrowhead measuring $18 \times 16 \times 5 \mathrm{~mm}$ with light damage to the tips and barbs. It has a slightly chunky section and has been formed by semi-invasive retouch. It does not fit easily into any of the categories proposed by Green, its barbs being rather weakly developed (Green 1980, 122).

\subsection{Location of finds}

The location of finds within the main trenches and in the test pits adds focus to the discussion. At the largest scale, worked or possibly worked material was identified in small proportions in 15 test pits but these are mainly from the areas immediately surrounding the cairn. The information in the test pits, in conjunction with the analyses offered below, seem to indicate that knapping activity was focused around the area of the cairn. For example, Test Pits 8 and 9 indicate some knapping to the north of the cairn itself.

\subsubsection{Smalls}

A wide range of very small lithics and natural pieces were recovered by hand and within samples from across the site. These were analysed macroscopically in order to characterize the spatial extent of flint débitage and to see if the quartz debris might also have resulted from human activity. All 'smalls' were attributed to one of two categories: worked or possible/ natural. All flint was assumed to be worked as it does not occur locally. There is a degree of subjectivity involved in attributing quartz items to these categories and, in some ways, the category of worked quartz is limited to fresh-looking quartz fractures. Not every attribution will be correct but a generalized picture 


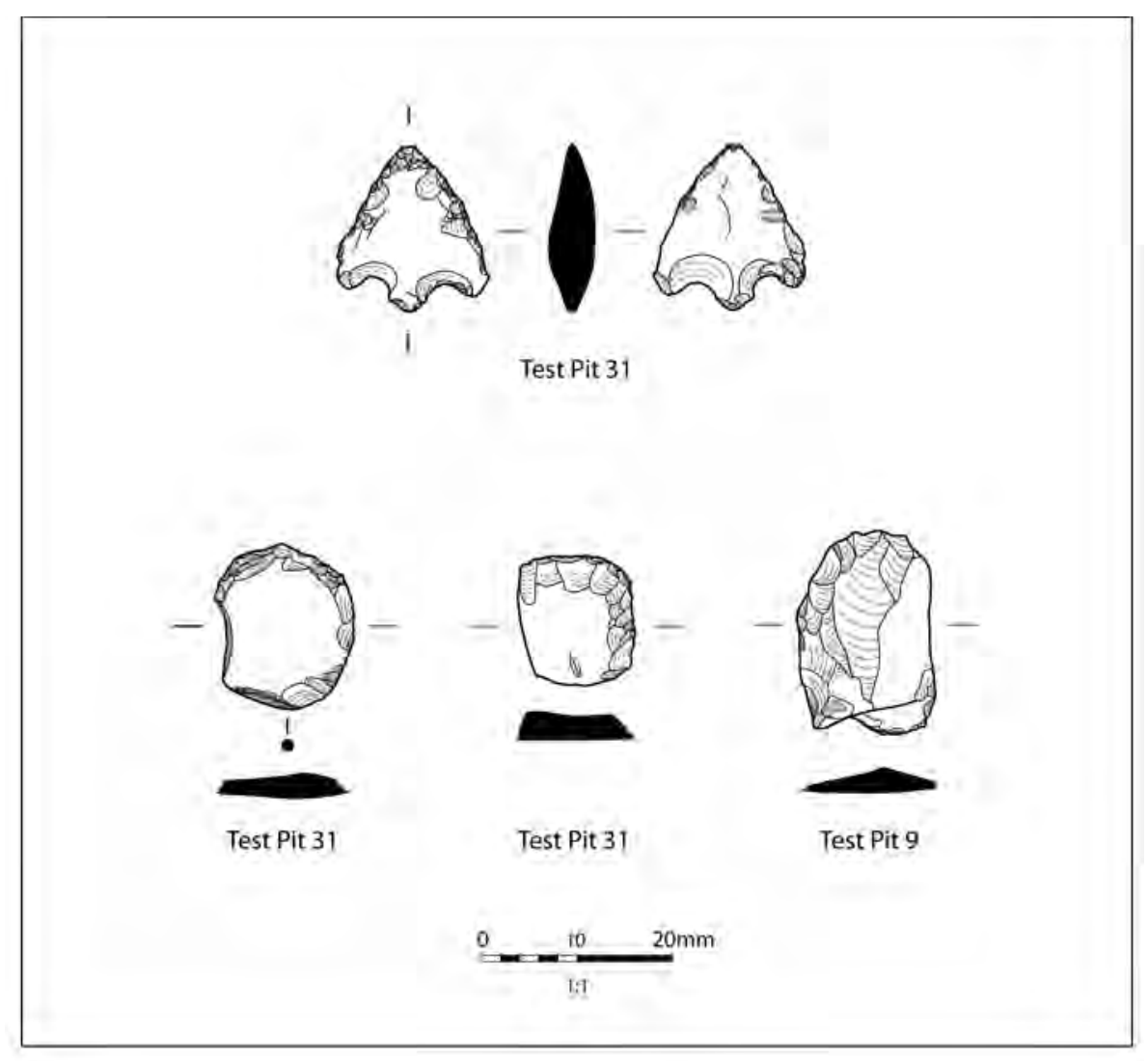

Illus 27 Worked stone from test pits. Top: barbed and tanged arrowhead, banded shale. Bottom (left to right): scrapers, flint, flint, quartz

still emerges, allowing the analysis of differences between regions of the site. Indeed, close similarities between the location of worked quartz and flint smalls indicate that the strategy has validity. Single appearances of smalls are excluded from the discussion that follows.

Flint smalls are present in quantities of greater than one in a range of deposits (Table 12, column 1). These include re-deposited burnt peat or ash deposits $(134,135,153,180,181)$, the central cist (129), pits 124 and 126 and deposits below the cairn $(154,157,159,177)$. Flint made up between $6.3 \%$ (in 129 ) and $30.4 \%$ (in 182) of the worked smalls in these deposits, averaging $16.8 \%$; it comprised $15.7 \%$ of the 'blind' sample of worked smalls from sample residues. Smalls of sedimentary rock were mainly recorded from the grids collected outside the cairn. Only the cremation deposit (129) and the ash (135) contained this material; those in the latter were all natural.

The significance of worked quartz smalls is harder to assess because of a background of natural and possibly worked quartz. On average, $6.1 \%(n=754$, total 12,369) of the quartz smalls are worked but the percentage within any given context ranges from 0 to $100 \%$. For example, the pottery-rich area in the north-west quadrant (121) contained eight flint smalls, 60 worked quartz smalls and 221 possible or natural smalls. The variation across the site as a whole partly reflects genuine spatial variation across the site but has also been influenced by collection strategies: a more controlled understanding emerges by examining quartz recovered from samples. One implication of this is that it is hard to assess the patterning in the areas where samples were not taken. Of the residue materials, $19.2 \%$ ( $n=502$ from a sample of 2542) are worked. This initially suggests that the smallest worked quartz chips were missed during collection by hand. However, this may not be the entire story, as many small natural quartz pieces were recovered. Therefore, the high proportions of quartz in the samples may also therefore reflect the concentration of quartz débitage in the immediate vicinity of the cairn.

The proportions of worked smalls varies widely, from $100 \%$ in a post-hole in the north-east quadrant $(194, n=12)$ and a stone-filled pit to the south-west of the cairn $(172, n=11)$ to none in another post-hole in the north-east quadrant $(195, n=11)$ and a pit in the north-west quadrant $(186, n=8)$. This variety also makes rigorous analysis difficult. However, by considering only samples with more than five worked pieces and a proportion of worked material higher than average ( $>19.2 \%$ ), a simpler picture emerges. Table 12 compares the contexts that contain two or more flint smalls and those containing greater than five quartz smalls, which makeup over $20 \%$ of those present. This demonstrates that the two distributions are closely comparable, the only significant difference being the absence of flint from the post-holes. 
Table 11 Finds from test pits

\begin{tabular}{|c|c|c|c|c|c|c|c|c|c|}
\hline $\begin{array}{l}\text { Test } \\
\text { pit }\end{array}$ & $\begin{array}{l}\text { Depth } \\
\text { (m) }\end{array}$ & $\begin{array}{c}\text { Quartz } \\
\text { worked }\end{array}$ & $\begin{array}{c}\text { Quartz } \\
\text { possible }\end{array}$ & $\begin{array}{c}\text { Total } \\
\text { quartz }\end{array}$ & $\begin{array}{l}\text { Total quartz } \\
\text { per unit } \\
\text { depth }\end{array}$ & $\begin{array}{c}\text { Flint } \\
\text { (smalls) }\end{array}$ & $\begin{array}{c}\text { Sedimentary } \\
\text { (smalls) }\end{array}$ & $\begin{array}{l}\text { Proportion } \\
\text { worked } \\
\text { quartz } \\
\end{array}$ & $\begin{array}{l}\text { Proportion } \\
\text { worked flint }\end{array}$ \\
\hline 1 & 0.1 & 0 & 0 & 33 & 330 & 0 & 0 & & \\
\hline 2 & 0.1 & 6 & 0 & 51 & 500 & 1 & 0 & High & \\
\hline 3 & 0.26 & 11 & 7 & 126 & 485 & 4 & 0 & High & High \\
\hline 4 & 0.04 & 0 & 1 & $>500$ & $>500$ & 2 & 0 & & \\
\hline 5 & 0.2 & 7 & 2 & $>500$ & $>500$ & 0 & 0 & & \\
\hline 6 & 0.2 & 2 & 2 & $>500$ & $>500$ & 0 & 0 & & \\
\hline 7 & 0.1 & 2 & 0 & $>500$ & $>500$ & 0 & 0 & & \\
\hline 8 & 0.1 & 10 & 4 & $>500$ & $>500$ & 1 & 0 & Moderate & \\
\hline 9 & 0.4 & 13 & 6 & $>500$ & $>500$ & 4 & 1 & Moderate & Moderate \\
\hline 10 & 0.52 & 0 & 0 & 1 & 2 & 0 & 0 & & \\
\hline 11 & 0.5 & 0 & 0 & 1 & 2 & 0 & 0 & & \\
\hline 12 & 0.5 & 1 & 0 & $>500$ & $>500$ & 0 & 0 & & \\
\hline 13 & 0.46 & 0 & 0 & 215 & 467 & 0 & 0 & & \\
\hline 14 & 0.28 & 2 & 4 & 67 & 239 & 0 & 0 & High & \\
\hline 15 & 0.15 & 0 & 0 & 0 & 0 & 0 & 0 & & \\
\hline 16 & 0.26 & 0 & 1 & 65 & 250 & 0 & 1 & & \\
\hline 17 & 0.28 & 3 & 1 & 71 & 254 & 1 & 0 & High & \\
\hline 18 & 0.17 & 0 & 0 & 5 & 29 & 0 & 0 & & \\
\hline 19 & 0.22 & 0 & 1 & 16 & 73 & 0 & 0 & & \\
\hline 20 & 0.3 & 1 & 1 & 42 & 140 & 0 & 0 & & \\
\hline 21 & 0.26 & 0 & 0 & 28 & 108 & 0 & 0 & & \\
\hline 22 & 0.17 & 0 & 0 & 83 & 488 & 0 & 0 & & \\
\hline 23 & 0.5 & 0 & 0 & 4 & 8 & 0 & 0 & & \\
\hline 24 & 0.28 & 0 & 0 & 4 & 14 & 0 & 0 & & \\
\hline 25 & 0.6 & 0 & 0 & 46 & 77 & 0 & 0 & & \\
\hline 26 & 0.45 & 0 & 0 & 6 & 13 & 0 & 0 & & \\
\hline 27 & 0.3 & 0 & 0 & 0 & 0 & 0 & 0 & & \\
\hline 28 & 0.28 & 3 & 2 & 22 & 79 & 1 & 0 & High & \\
\hline 29 & 0.18 & 3 & 1 & 54 & 300 & 2 & 0 & High & \\
\hline 30 & 0.25 & 1 & 0 & $>500$ & $>500$ & 0 & 0 & & \\
\hline 31 & 0.28 & 12 & 12 & $>500$ & $>500$ & 5 & 0 & Moderate & Moderate \\
\hline 32 & 0.29 & 0 & 0 & $>500$ & $>500$ & 1 & 0 & & \\
\hline Total & & 77 & & & & & & & \\
\hline
\end{tabular}

The flint and worked quartz smalls result in part from knapping episodes although it is difficult to assess whether this reflects primary tool production or secondary finishing. Although collection strategies may have played a part in the final distribution, general tendencies are apparent and activity seems to focus on the region of the cairn itself. Further affirmation of this argument at a wider scale can be drawn from the comparative absence of worked quartz smalls from the test pits.

\subsubsection{Larger artefacts}

Worked quartz was found throughout the site, generally comprising about $90 \%$ of the worked material in any given area. There was a slight tendency for more material to be found in the north of the site than the south although the general impression is that the cairn and the area immediately around it were covered in quartz debris. This assessment is also borne out by the evidence from the test pits (see above). Quartz was found above and within the cairn and large amounts of material were retrieved from the old ground surface. Large deposits of quartz were also found immediately outside the kerb in the north-west quadrant (110). It is difficult to assess variation within these deposits, not least because of the disturbance the site has suffered.

Flint was found over much of the site, both within the cairn itself and in a notable concentration to its north. This area contained 24 of the artefacts, with perhaps the greatest concentration in the northwest. The distribution of flint artefacts closely matches that of the flint micro-débitage.

There is little meaningful distinction between the 
Table 12 Location of smalls

\begin{tabular}{lll}
\hline Context & Flint & Quartz \\
\hline 121: Pottery-rich north-west quad & $\mathrm{Y}$ & $\mathrm{Y}$ \\
122: Central cist & $\mathrm{Y}$ & $\mathrm{Y}$ \\
123: Pit in south-east quad & $(n=1)$ & $\mathrm{Y}$ \\
124: Pit in south-east quad & $\mathrm{Y}$ & $\mathrm{Y}$ \\
126: Pit fill in north-west quad & $\mathrm{Y}$ & $(n=44,11.2 \%)$ \\
129: Cremation deposit & $\mathrm{Y}$ & $(n=44,10.7 \%)$ \\
134: Red burnt peat (as 180) & $\mathrm{Y}$ & $(n=6,17.1 \%)$ \\
135: Red burnt peat & $\mathrm{Y}$ & $\mathrm{Y}$ \\
153: Red ash & $\mathrm{Y}$ & $\mathrm{Y}$ \\
154: Beneath cairn & $\mathrm{Y}$ & $\mathrm{Y}$ \\
157: Beneath cairn & $\mathrm{Y}$ & $(n=31,10.4 \%)$ \\
159: Peat above OGS under cairn & $\mathrm{Y}$ & $(n=13,18.6 \%)$ \\
177: Central area & $\mathrm{Y}$ & $\mathrm{Y}$ \\
180: North-west quad burnt layer & $\mathrm{Y}$ & $\mathrm{Y}$ \\
181: North-west quad burnt layer & $\mathrm{Y}$ & $\mathrm{Y}$ \\
182: North-west quad & $\mathrm{Y}$ & $\mathrm{Y}$ \\
194: Post-hole in north-east quad & & $\mathrm{Y}$ \\
202: Post-hole in north-east quad sealed by cairn & & $\mathrm{Y}$ \\
Post-hole 90 & & $\mathrm{Y}$
\end{tabular}

artefact types found in different areas of the site. Many of the samples from individual contexts are small, rendering comparison very difficult. One pattern of some interest is that many of the simple split pebbles or anvil splits came from on or near the cairn $(102,103)$. This again seems to indicate that some of these pieces result from little more than deliberately smashing pebbles.

The thumbnail scrapers were found in a variety of locations, many under or on the cairn itself (Table 13), although two were found in the south part of the site. The thick, heavy scrapers were found within and beneath the cairn, as were the edge-retouched tools. The arrowhead was found with two thumbnail scrapers in Test Pit 31 immediately to the south-east of the cairn (Illus 27). A slight concentration of retouched tools was apparent beneath the cairn (154) where they comprised $8.3 \%$ (4/48) of the finds from this deposit; a high proportion of regular flakes $(39.6 \%)$ was also found here. The cairn itself, and the ground surface beneath it, appear to have acted as foci for patterns of deposition.

\subsubsection{Discussion}

Artefacts were found on, within, under and near the cairn. Deposits below the cairn yielded a high proportion of retouched and regular material but no exclusive patterns emerged as activity continued across the site. Knapping deposits extended away from the cairn, and were indistinguishable in character from those close to it. The complex construc- tion of the cairn itself defies easy chronological interpretation although activities on site may have extended over a long period of time. Furthermore, evidence for disturbance of the site is clear.

Given these facts, it would not be appropriate to reconstruct a detailed sequence of lithic deposition on site. However, broad themes that appear to have been important in structuring activity can be identified. The site of the cairn appears to have acted as a focus for varied stone-crafting activities over some time, presumably including the deliberate deposition of retouched artefacts before and during the construction of the cairn. Small thumbnail scrapers were particularly significant there. Lithics were also incorporated into the body of the cairn through the re-deposition of material from elsewhere and had also been added to the cairn after its construction although the timescale is obscure. The site was carpeted with quartz and the seemingly deliberate addition of crudely smashed quartz to the cairn body during and after its construction appears to have been significant. As well as these activities, there was a series of knapping episodes in the immediate vicinity of the cairn. The chronological relationship of these materials to the cairn itself is not clear. They may pre-date the cairn, possibly being associated with structures represented by some of the postholes and with earlier pottery types. The scatters may be contemporary, reflecting the use of the site for funerary purposes; or they may be later. It is difficult to disentangle these themes solely by reference to the site itself and it is necessary to step back from our data. 
Table 13 Location of retouched pieces

\begin{tabular}{|c|c|c|c|c|}
\hline & Scraper: short convex & Scraper: misc & Edge-retouched & Arrowhead \\
\hline Context 101 & & 1 & & \\
\hline Context 102 & & 1 & & \\
\hline Context 103 & & 1 & & $1 ?$ \\
\hline Context 110 & 2 & & & \\
\hline Context 133 & 1 & & & \\
\hline Context 154 & 3 & & 1 & \\
\hline Context 157 & 1 & & 1 & \\
\hline Context 165 & 1 & & & \\
\hline Context 166 & 1 & & & \\
\hline Context 177 & & 1 & & \\
\hline Grid C & & 1 & & \\
\hline Grid F & & 1 & & \\
\hline Grid J & 1 & & & \\
\hline Grid K & 1 & & & \\
\hline Context 102/103 & 6 & 2 & 1 & \\
\hline TP31 & 2 & & & 1 \\
\hline TP9 & 2 & & & \\
\hline Total & 21 & 8 & 3 & 1 \\
\hline
\end{tabular}

\subsection{The assemblage in context}

Good parallels for the Olcote assemblage can be found in both funerary and other contexts. Local comparisons include the main Calanais ritual complex, where quartz, mylonite and flint industries have been recorded (Ballin forthcoming). Further quartz and flint industries have been identified from sub-peat contexts by the Calanais Fields Project (Flitcroft et al. 2001). Although neither assemblage is closely dated, both demonstrate similarities to the reduction techniques noted at Olcote. Lacaille commented on surface quartz and coarse stone industries from Traigh na Beirgh (Lacaille 1937; Lacaille 1954) but the date and associations of these artefacts are unclear.

Other quartz industries have been identified elsewhere in the Western Isles, including several kilograms in midden deposits of Beaker age at Rosinish (Shepherd 1976, 212). Quartz artefacts, few of which are retouched, form part of the assemblage from Northton, alongside pebble flint and banded mylonite (Simpson 1976). Retouched forms include small thumbnail scrapers comparable to those from Olcote and slightly larger irregular scrapers. Dates for the Beaker layers are 1654 $\pm 70 \mathrm{BC}(\mathrm{BM} 707)$ and 1531 $\pm 54 \mathrm{BC}$ (BM707). Flake industries utilizing bipolar and platform techniques to exploit flint and quartz assemblages have been recorded on Barra (Wickham-Jones 1995). The industries are likely to be Neolithic in date and include both barbed and tanged and leaf-shaped points.

Local parallels from funerary contexts are rarer. The beehive-shaped structure at Rosinish contained no lithics (Crawford 1978). An old soil sealed by the kerb cairn at Cnip, and therefore pre-dating it, contained four large, unused quartz artefacts, two of which had been refitted (Close-Brooks 1995). A broader series of associations can be seen by looking further afield. Thumbnail scrapers are often associated with Beakers, sometimes as funerary deposits, and it has been argued that they are a closely defined tool type whose use was surrounded by 'subtle conventions' (Edmonds 1995, 140-1). Early Bronze Age funerary contexts sometimes include a variety of lithics, perhaps intended for use by the dead, or as part of their personal property, or sometimes as a more abstract symbol (Edmonds 1995, 153). In addition, barbed and tanged arrowheads are frequently associated with Beaker burials although their use and manufacture were not necessarily limited to funerary occasions (Edmonds 1995, 143; Edmonds 1998). Local manifestations of these associations are also evident at Calanais and possibly on Barra.

The presence of quartz itself in association with the cairn is very interesting. Quartz pebbles appear to have played an important role in funerary rituals of various kinds in Scottish prehistory. The persistence of quartz and funerary associations on Lewis is demonstrated by the presence of unworked quartz pebbles in Middle Iron Age funerary contexts at An Dunan, c 400$100 \mathrm{BC}$ (S Gilmour, pers comm) and there is a wide range of ethnographic material discussing the possible significance of raw materials (e.g. Taçon 1991). Lebour highlights the properties of quartz (Lebour 1914), a distinctly iridescent material which emits a bright spark if two pebbles are struck together, especially under water. It would not be appropriate to use a direct analogy for the prehistoric inhabitants of Lewis and it is important to note that the relationship of our crude category of quartz, 
including many variations of material type, to complex subdivisions of classification that presumably existed in prehistory could be flawed. Nevertheless, these studies, and the use of quartz in such distinctive contexts at Olcote, demand interpretation.

Although it is difficult to interpret the precise role of quartz at Olcote some interesting associations can be identified (see Warren \& Neighbour 2004). Archaeologists realize that quartz was a poor quality lithic raw material as well as a symbolically charged resource suitable for use in funerary rituals. Rarely do we gain much sense of the interplay between such ways of understanding the material. This is significant because, at Olcote, it has proved impossible to separate its function as a ritual or symbolic medium from its use as part of a mundane tool kit. Instead it appears to have been both, different characteristics of the material being more or less significant in specific contexts. During the construction of the cairn, for example, that particular activity appears to have provided a close structure for the deposition of material, presumably with some funerary associations. Presumably, these were times when the symbolism of quartz was paramount. However, not all activities on site revolved around the cairn, some of the material pre-dating the construction of the cairn itself. The contexts for this behaviour are hard to establish although at such times the symbolic associations of quartz may not have been as important.

\subsection{Conclusions}

In an interpretative sense the assemblage remains a little obscure. A range of deliberate deposits of lithic material can be identified, including the deliberate smashing of quartz pebbles, a raw material that may have had some associations with funerary contexts, during and/or after the construction of the cairn, which appears to have been carpeted with it. Finely made formal artefacts were also deposited into and under the cairn. These included types of objects that often had funerary associations. The area around the cairn included scatters of worked quartz and flint. It is possible that stone-working was attracted to this location by the presence of the cairn itself, or that the cairn was built in an area already significant for stone-working. Whichever was the case, the working of quartz and flint at Olcote was an important process by which people made sense of the feature over a long period of time. 


\section{Sedimentary Analysis of Soil Samples by $M$ Church}

\subsection{Introduction}

A series of routine soil tests were carried out for 49 sub-samples taken from the bulk samples removed during excavation. This section presents the results of those tests and discusses the implications for site formation processes and the preservation and taphonomy of ecofacts and artefacts, with particular reference to plant macrofossils.

\subsection{Research basis}

The samples were processed for doctoral research as part of a regional synthesis on the prehistoric use of plants in Lewis. This research is based on plant macrofossil assemblages recovered from over ten sites excavated by the University of Edinburgh, as part of the wider Calanais Archaeological Research Project (Harding 2000). A number of recurrent research questions were formulated for the sedimentary analysis from each of these sites, including the following:

Can basic sedimentary analysis help interpret differential preservation of ecofact and artefact types between sites?

Can basic sedimentary analysis give insights into generic site formation processes?

Can mineral magnetic analysis of ash components on the site allow taphonomic models for carbonized plant macrofossils to be proposed?

\subsection{Methodology}

\subsubsection{On-site sampling}

A sub-sample of approximately 0.25 litres was removed from the bulk samples prior to wet-sieving. Hence, the sampling strategy reflects that of the bulk samples taken on site in 1995. These were taken when the excavator deemed a context to be worthy of sampling, a strategy known as judgement sampling (Jones 1991). This strategy does not statistically represent the sampled population (ie the archaeological contexts across the site) so the results presented here will be biased in the favour of stratigraphically important contents and those perceived to be rich contexts. However, the 49 sub-samples can present a general picture of preservation systems and site formation processes.

\subsubsection{Laboratory methodology}

Each sub-sample was subjected to the following analyses: organic content, $\mathrm{pH}$ and mineral magnetic analysis. The methods employed for each test are described below.

\section{Organic content (following Hodgson 1976)}

Approximately $20 \mathrm{~g}$ of wet soil was dried at $40^{\circ} \mathrm{C}$ for 24 hours before being dry-sieved through a $2 \mathrm{~mm}$ gauge to remove stones and larger particles. The sieved material was then placed in a weighed crucible and placed in an oven at $100^{\circ} \mathrm{C}$ for 5 minutes to drive off any latent moisture within the soil. The crucible and soil were then weighed before being placed in a furnace for 4 hours at a temperature of $550^{\circ} \mathrm{C}$, to incinerate the organic component. The crucible and material were then weighed and the percentage organic content (by weight) calculated.

\section{2 pH (following Hodgson 1976)}

The $\mathrm{pH}$ of the soil was measured using a Pye Unicam PW 9410 digital $\mathrm{pH}$ meter, calibrated to $7 \mathrm{pH}$ and $4 \mathrm{pH}$ buffer solutions. Approximately $20 \mathrm{~g}$ of wet soil was added to $50 \mathrm{ml}$ of distilled water. The solution was left for 20 minutes and stirred periodically. Then the meter probe was immersed in the solution for 2 minutes and a reading taken. Only one reading was taken from each sample because of time constraints.

\section{Magnetic susceptibility}

The samples were dried at $40^{\circ} \mathrm{C}$ and dry sieved through a $2 \mathrm{~mm}$ gauge to remove stones and larger particles. Volumetric ( $\kappa)$ high and low frequency magnetic susceptibilities were measured with a Bartington MS2 meter and MS2 laboratory coil. Mass specific magnetic susceptibility ( $\chi$ lf) and percentage frequency dependent $(\kappa f d \%)$ were then calculated (following Dearing 1994).

\subsection{Results and discussion}

Table 14 presents the results from the sedimentary analysis. These will be first analysed in terms of ecofact and artefact preservation, then generic site formation processes will be addressed with specific reference to carbonized plant macrofossil taphonomy.

\subsubsection{Site preservation systems}

When analysing artefacts and ecofacts within a site assemblage, consideration must be given to the overall preservation environment of the site. Some material, such as bone, requires specific conditions for its preservation. The soil $\mathrm{pH}$ for all the subsamples ranged from 3.93 to 4.77 , with a mean of 4.4 . 
Table 14 Routine soil test results

\begin{tabular}{|c|c|c|c|c|c|c|c|c|}
\hline Context & Phase & $\begin{array}{l}\text { Context } \\
\text { type }\end{array}$ & $\begin{array}{l}\text { Organic } \\
\text { content } \\
(\%)\end{array}$ & pH & $\begin{array}{c}\text { Magnetic } \\
\text { susceptibility } \\
\text { (HF) }\end{array}$ & $\begin{array}{c}\text { Magnetic } \\
\text { susceptibility } \\
\text { (LF) }\end{array}$ & $\begin{array}{c}\chi \mathbf{l f} \\
\left(\mu \mathbf{m}^{3} \mathbf{k g}{ }^{1}\right)\end{array}$ & $\begin{array}{c}\kappa \mathbf{f d} \\
(\%)\end{array}$ \\
\hline 123 & 1 & Pit fill & 7.70 & 4.32 & 39.5 & 42.5 & 0.70 & 7.06 \\
\hline 124 & 1 & Pit fill & 15.93 & 4.37 & 36 & 37 & 0.55 & 2.70 \\
\hline 126 & 1 & Pit fill & 14.31 & 4.30 & 11 & 11.5 & 0.14 & 4.35 \\
\hline 196 & 1 & Pit fill & 6.81 & 4.42 & 32.5 & 33 & 0.45 & 1.52 \\
\hline 197 & 1 & Pit fill & 9.11 & 4.51 & 57 & 60 & 0.78 & 5.00 \\
\hline 198 & 1 & Pit fill & 5.87 & 4.40 & 58.5 & 60.5 & 0.90 & 3.31 \\
\hline 199 & 1 & Pit fill & 6.40 & 4.60 & 48.5 & 51 & 0.74 & 4.90 \\
\hline 200 & 1 & Pit fill & 10.93 & 4.44 & 129.5 & 139.5 & 1.79 & 7.17 \\
\hline 201 & 1 & Pit fill & 4.85 & 4.55 & 81 & 84 & 0.86 & 3.57 \\
\hline 202 & 1 & Pit fill & 5.27 & 4.51 & 73 & 78.5 & 0.99 & 7.01 \\
\hline 203 & 1 & Pit fill & 6.97 & 4.56 & 30.5 & 33 & 0.46 & 7.58 \\
\hline 204 & 1 & Pit fill & 6.31 & 4.65 & 58.5 & 63 & 0.83 & 7.14 \\
\hline 205 & 1 & Pit fill & 12.34 & 4.61 & 22 & 23.5 & 0.35 & 6.38 \\
\hline 206 & 1 & Pit fill & 7.86 & 4.52 & 22.5 & 23 & 0.26 & 2.17 \\
\hline 207 & 1 & Pit fill & 4.24 & 4.61 & 37.5 & 40 & 0.47 & 6.25 \\
\hline 208 & 1 & Pit fill & 5.70 & 4.33 & 31 & 31 & 0.43 & 0.00 \\
\hline $165 a$ & 1 & Pit fill & 5.81 & 4.59 & 18 & 18 & 0.24 & 0.00 \\
\hline $165 b$ & 1 & Pit fill & 4.37 & 4.66 & 23 & 23 & 0.27 & 0.00 \\
\hline 176 & 2 & Hollow fill & 13.61 & 3.93 & 14 & 14.5 & 0.24 & 3.45 \\
\hline 160 & 2 & Hollow fill with OGS & 5.57 & 4.77 & 86.5 & 91 & 1.30 & 4.95 \\
\hline 161 & 2 & Hollow fill with OGS & 5.25 & 4.65 & 42 & 46 & 0.56 & 8.70 \\
\hline 162 & 2 & Hollow fill with OGS & 5.83 & 4.73 & 50.5 & 52.5 & 0.67 & 3.81 \\
\hline 163 & 2 & Hollow fill with OGS & 6.60 & 4.55 & 29.5 & 32 & 0.38 & 7.81 \\
\hline 170 & 2 & Hollow fill with OGS & 19.01 & 4.42 & 16 & 17 & 0.28 & 5.88 \\
\hline 128 & 2 & OGS & 5.88 & 4.36 & 8 & 8.5 & 0.13 & 5.88 \\
\hline 154 & 3 & OGS & 6.94 & 4.75 & 53.5 & 56.5 & 0.74 & 5.31 \\
\hline 172 & 2 & Pit fill & 8.97 & 4.12 & 14 & 15 & 0.22 & 6.67 \\
\hline 121 & 3 & Ash spread & 14.48 & 4.01 & 528.5 & 570 & 8.35 & 7.28 \\
\hline 134 & 3 & Ash spread & 8.89 & 4.20 & 1012 & 1090.5 & 19.68 & 7.20 \\
\hline 137 & 3 & Ash spread & 11.25 & 4.51 & 462.5 & 498.5 & 8.85 & 7.22 \\
\hline 177 & 3 & Ash spread & 8.50 & 4.31 & 215 & 229.5 & 3.29 & 6.32 \\
\hline 180 & 3 & Ash spread & 10.22 & 4.30 & 169 & 182 & 2.72 & 7.14 \\
\hline 181 & 3 & Ash spread & 7.69 & 4.36 & 248 & 266.5 & 4.14 & 6.94 \\
\hline $135 a$ & 3 & Ash spread & 6.15 & 4.21 & 1366 & 1476 & 26.50 & 7.45 \\
\hline $135 b$ & 3 & Ash spread & 8.54 & 4.30 & 364 & 393 & 5.59 & 7.38 \\
\hline 122 & 3 & Cist fill & 18.20 & 4.18 & 238.5 & 257.5 & 4.36 & 7.38 \\
\hline 125 & 3 & Cist fill & 14.86 & 4.02 & 40 & 42.5 & 0.81 & 5.88 \\
\hline 129 & 3 & Cist fill & 16.89 & 4.22 & 148 & 160.5 & 2.91 & 7.79 \\
\hline 164 & 3 & Hollow fill & 18.17 & 4.23 & 18.5 & 20 & 0.37 & 7.50 \\
\hline 167 & 3 & Pit fill & 11.23 & 4.33 & 417 & 453 & 6.83 & 7.95 \\
\hline 183 & 3 & Pit fill & 5.69 & 4.49 & 274.5 & 294 & 3.63 & 6.63 \\
\hline 184 & 3 & Pit fill & 5.48 & 4.13 & 45 & 48 & 0.63 & 6.25 \\
\hline 186 & 3 & Pit fill & 4.50 & 4.57 & 91 & 97.5 & 1.11 & 6.67 \\
\hline 193 & 4 & Pit fill & 8.55 & 4.26 & 17 & 17 & 0.25 & 0.00 \\
\hline 194 & 4 & Pit fill & 6.34 & 4.36 & 156.5 & 169 & 2.33 & 7.40 \\
\hline 195 & 4 & Pit fill & 6.75 & 4.35 & 54.5 & 59.5 & 0.80 & 8.40 \\
\hline 146 & $\mathrm{U}$ & Hollow fill & 6.96 & 4.54 & 9.5 & 10.5 & 0.13 & 9.52 \\
\hline 147 & $\mathrm{U}$ & Hollow fill & 13.61 & 4.24 & 14 & 14 & 0.23 & 0.00 \\
\hline 149 & $\mathrm{U}$ & Hollow fill & 8.39 & 4.33 & 6.5 & 6.5 & 0.11 & 0.00 \\
\hline
\end{tabular}


The cist fills were very acidic, ranging from 4.02 to 4.22. This aggressively acidic soil environment means that no uncarbonized bone and shell survived on the site. The relatively low organic content of 4.37-19.01 (mean of 8.98), coupled with the comparatively well-drained nature of the site, meant that uncarbonized plant macrofossils and insect remains were not detected. The main classes of material recovered on the site were therefore lithics, pottery, carbonized plant macrofossils and burnt bone.

\subsubsection{Site formation processes}

The samples have been split into five blocks for analysis.

Pit fills from Phase 1: The $\mathrm{pH}$ and organic contents of the fills fall within the range of the overall site variation. In general, the $\chi \mathrm{lf}$ and $\mathrm{\kappa fd} \%$ values are relatively low, with some pits showing slight magnetic enhancement, presumably from the re-deposition and mixing of ash with soils and the other materials resulting from human activity. The low levels of $\mathrm{kfd} \%$ are evidence of the paucity of superparamagnetic grains, which are generally indicative of the input of ash into soil.

Phase 2 relic soil: A coherent layer was identified immediately below the cairn, with evidence of cultivation marks within that layer. Carter (Section 10) has suggested, through soil micromorphology, that the layer is the remnant of a relic soil, perhaps stripped during the construction of the cairn. The routine soil results from the relic soil and various pits and hollows filled with this material supports the presence of a horizon soil, with relatively low organic content (5.25-6.6) and a slightly less acidic $\mathrm{pH}(4.36-4.77)$ than the rest of the site. The $\chi \mathrm{lf}$ is low and the $\mathrm{kfd} \%$ values range from 3.81 to 8.7 , the latter values being difficult to interpret in the context of low $\chi$ lf values (Dearing 1994). The more organic sample from 170 may represent a fragment of the A horizon or degraded turf from the relic soil.

Phase 3 ash spreads: A number of the samples relate to the dumping of burnt, peaty turf within the body of the cairn (Section 10). All of these samples display significant magnetic enhancement, with high $\chi$ lf and $\kappa f d \%$ values, confirming the ashy and burnt nature of much of the material. The organic content and $\mathrm{pH}$ vary throughout the site, the higher organic values presumably incorporating carbonized material incinerated at $550^{\circ} \mathrm{C}$

Pits and cist within the body of the cairn: Some of these features were filled with material with an ashy component, presumably from the ash spreads, whilst others contained little magnetic enhancement and therefore a lack of ash within their soil matrices. The three samples from the cist fill had a relatively high organic component that may suggest a slightly different type of material, such as decomposed organics, comprising a significant proportion of the matrix. Again, two of the three cist fills had evidence of magnetic enhancement stemming from the input of ashy material. This suggests that the ash spreads were incorporated into the body of the cairn immediately after the cist was constructed or that the cist was not lidded when the ash was deposited.

Phase 4 and unphased negative features: Only one of these features, a stone-lined pit (194), displayed magnetic enhancement with the input of some ashy material. The organic content and $\mathrm{pH}$ vary over the site.

\subsubsection{Carbonized plant macrofossil taphonomy}

The presence of ashy material, and therefore the possibility of input of carbonized plant macrofossils, can be gauged through mineral magnetic enhancement of the soil (cf Batt \& Dockrill 1998; Peters et al. 2000). Table 14 displays the $\chi \mathrm{lf}\left(\mu \mathrm{m}^{3} \mathrm{~kg}^{-1}\right)$ and macrofossil concentration (quantifiable components/ litre) for many of the bulk samples that contained plant macrofossils (see Section 9.3.2). The phase and sample type is indicated on the $x$ axis and the values of both parameters on the $y$ axis. This shows that the main magnetic enhancement of the Phase 3 ash spreads (denoted 3AS) correlated with the greatest concentration of carbonized plant macrofossils. Limited magnetic enhancement was seen in most of the other samples, with a concomitant decrease in macrofossil concentration. Negative features, such as the cist fills ( $3 \mathrm{CF}$ ), with higher $\chi \mathrm{lf}$, relate to the incorporation of this ashy material into their soil matrix. The pits from Phase 1 (1PF), Phase 2 relic soil (OGS) and unphased hollow fills (UHF) had little or no magnetic enhancement and so therefore had very low concentrations of plant macrofossils, derived through limited re-deposition or bioturbation.

\subsection{Conclusions}

A number of key points can be extracted from this analysis:

- The acidic nature and relatively low organic and moisture content of the site has precluded the preservation of bone, shell, uncarbonized plant macrofossils and insect remains. Therefore, the main classes of material recovered on the site were lithics, pottery, carbonized plant macrofossils and burnt bone.

- The routine soil tests confirmed the presence of an altered relic soil beneath the cairn, with much of the soil representing the $\mathrm{B}$ horizon and a possible fragment of the A horizon (170).

- The correlation between the enhanced magnetic signal and the high concentration of carbonized plant macrofossils in the ash spreads confirms the taphonomy of the archaeobotanical assemblage from the burning and dumping of ash from peaty 
turves and other incorporated plant material into the main body of the cairn.

- Two of the three fills within the cists displayed magnetic enhancement from the input of ashy material from the ash spreads. Therefore, the ash spreads were incorporated into the body of the cairn immediately after the cist was constructed or the cist was not lidded when the deposit was made. The excavation demonstrated that the ash layer was probably cut to insert the cist. It is likely that the ash was re-deposited in the cist during this process. 


\section{Carbonized Plant Macrofossils by M Church}

\subsection{Introduction}

This section analyses the carbonized plant macrofossils and charcoal recovered from the bulk samples. A total of 30 samples were submitted for analysis, 23 of which produced carbonized remains.

\subsection{Research basis}

The samples were processed as part of doctoral research to produce a regional synthesis on the prehistoric use of plants in Lewis. A number of recurrent research questions were formulated for the archaeobotanical remains from each of these sites including:

Is it possible to propose generic taphonomic models for the origin, preservation and subsequent dispersal of the carbonized plant macrofossils on the site?

What materials were used for fuel?

Can aspects of arable agriculture be seen in the archaeobotanical record, from the crops grown to the crop-processing procedures employed?

What other plants were gathered and for what purpose?

\subsection{Methodology}

\subsubsection{On-site sampling}

The samples were taken when the excavator deemed a context to be worthy of sampling, a strategy known as judgement sampling (Jones 1991). This strategy does not statistically represent the sampled population (ie the archaeological contexts across the site) so the results presented in this section will be biased in favour of stratigraphically important contexts and perceived to be rich. However, the 30 samples processed present a coherent picture of the archaeobotanical assemblage across the site.

\subsubsection{Bulk sample processing}

The bulk samples were processed using a flotation tank (Kenward et al. 1980) with the residue held by a $1.0 \mathrm{~mm}$ net and the flot caught by $1.0-$ and $0.3-\mathrm{mm}$ sieves, respectively. All the flots and residues were dried and sorted using a low-powered stereo/ binocular microscope at 15-80× magnification. All macrofossil identifications were checked against botanical literature and modern reference material from collections in the Department of Archaeology, University of Edinburgh. Nomenclature follows
Stace, with ecological information taken from Clapham et al., Stace and Pankhurst \& Mullin (Clapham et al. 1989; Stace 1991; Pankhurst \& Mullin 1994).

\subsection{Results}

\subsubsection{General}

Table 14 presents the carbonized plant macrofossils recovered from the site, sorted by phase and generic context type.

\subsubsection{Macrofossil preservation}

The preservation of the cereal grains recovered from the site as a whole, follows the preservation classes outlined previously (Hubbard 1990). Experimental work by Boardman \& Jones has shown that varied conditions of carbonization produce varied preservation, in terms of the density, condition and range of plant parts, many of which (chaff, culms and seeds) would be destroyed at higher temperatures (Boardman \& Jones 1990). Cereal grains are the best class of archaeobotanical remains from which to judge the loss of material because their preservation reflects the greatest range of conditions of carbonization. Over $75 \%$ of the assemblage was in the worst two classes of preservation, meaning that only genus identification was possible in general for these remains. However, the material recovered includes fragile plant components, such as culm nodes and seeds, demonstrating both the intensity and variation of temperature and atmospheric conditions within a large fire or funerary pyre (see Section 5.7).

\subsubsection{Summary of the results}

Most of the carbonized plant macrofossils were recovered from the ash spreads across the interior of the cairn. Soil micromorphology (Section 10), pollen analysis (Section 11) and mineral magnetic analysis of this material (Section 8.3.2) have demonstrated that the spreads represent re-deposited ash from burning peaty turves, possibly in a funeral pyre and/ or from a feasting ceremony connected to the closure of the cairn. Peaty turf seems to have been replaced as a fuel source by well-humified, blanket bog peat in later prehistoric periods in Lewis (Church \& Peters 2000; Peters et al. 2004). However, the evidence from this site may represent special activity, such as the deliberate removal of turf, which was then used in 
the funerary pyre, rather than as an everyday fuel. It is, of course, difficult to differentiate between domestic and ritual peat ash residues and the precise events which led to peat ash being deposited within the body of the cairn can only be conjectured.

In general, the archaeobotanical assemblage represents a mix of material relating to the fuel source and other plant material incorporated into the fire. Many of the carbonized plant macrofossils relate to the burning of peaty turf(Dickson 1998; Church \& Peters 2004). They include relatively large quantities of small culm bases, nodes and rhizome fragments, fibrous burnt peat and seeds and other plant components of heathers (Calluna vulgaris L Hull, Erica spp), sedges (Carex spp) and grasses (Poaceae undiff), notably heath-grass (Danthonia decumbens L).

However, there is also a significant proportion of cultivated plants and wild species stemming from cultivated areas. The identifiable cereals are dominated by barley (Hordeum $\mathrm{sp}$ ), with less than $1 \%$ wheat (Triticum sp.) and oat (Avena sp). The latter two species have been interpreted as weeds of the barley crop, rather than crops in their own right. Approximately $44 \%$ of the identifiable cereals was hulled barley with just over $11 \%$ naked. No rachis internodes were recovered, so species identification was based on the ratio between asymmetric to symmetric grains. From this, the hulled barley was likely to be six-row ( $H$. vulgare var vulgare $\mathrm{L})$, with the two- and six-row species possible for the naked barley $(H$. distichum/vulgare var nudum $\mathrm{L})$. The most numerous weeds of cultivation include seeds of goosefoot/orache (Chenopodium/Atriplex spp), common chickweed (Stellaria media L Vill), knotgrass (Polygonum spp), heep's sorrel (Rumex acetosella L), curled dock (Rumex crispus L), cabbage/ mustard (Brassica/Sinapis spp), wild turnip (Brassica cf rapa L) and ribwort plantain (Plantago lanceolata L).
This mixing of material has a number of implications. First, the likely position in the landscape for cultivation cannot be identified because the wild species represent a mix between the peaty turf fuel and the weed community. Also, the incorporation of material relating to arable agriculture into a fire probably associated with the ceremony and closure of the cairn must be explained. This may represent the accidental incorporation of the arable material within the peaty turf fire, or more structured deposition expressing elements of the seasonal and annual economic cycle into the society's system of belief. It is also interesting to note the presence of a few seeds of bilberry (Vaccinium myrtillus L) and cowberry (Vaccinium vitis-idaea L) within the ash spread at the top of the central cist. Both types of berry would have formed component parts of the wild food gathered in late summer or early autumn and may again represent the structured deposition of designated parts of the ash from a presumed ceremonial fire. Plant macrofossil assemblages from Bronze Age funerary deposits in Scotland are rarely sampled. However, though assemblages dominated by culm bases and nodes of cereal/ monocotyledon type were recovered from cremation pits at Seafield, Aberdeenshire (Church 2003), pyre deposits associated with a cist at Cockburnspath, Berwickshire (Church \& Cressey unpublished data) and from ash spreads within a cairn at Sketewan, Perthshire (Dickson 1997), these presumably represent the burning of grasses and weeds from cultivated land or hay during cremation, again either through accidental burning or a form of structured deposition. Hence, evidence of the limited incorporation of material from arable agriculture into Bronze Age funerary pyres is beginning to emerge from Scottish sites and is consistent with the pattern across Britain (Robinson 1988). 


\section{Analysis of Thin Sections from Ash Deposits Within the Cairn by S Carter}

\subsection{Introduction}

The north-west part of the cairn at Olcote contained layers of sediment identified in the field as burnt peat. Deposits of ash have been recorded elsewhere in association with cremation burials and have been interpreted as the product of the cremation pyre itself, together with fires forming part of other related rituals. The sediments at Olcote were sampled using two $250-\mathrm{mm}$ monolith tins, with the intention of undertaking further analysis of the composition, origins and history of the deposits. Thin-sectioning was selected as an appropriate method of analysis.

\subsection{Methodology}

The first monolith tin had been severely distorted during sampling and, as a result, the sediment block within it had been disrupted. Therefore, it was discarded. The second monolith, sampled as a replacement for the damaged tin, was intact and was chosen for sub-sampling. The stratification of Monolith 2 was recorded before sub-sampling and four layers were apparent. The upper three layers, totalling $130 \mathrm{~mm}$ thick, were red-brown ashes with variable concentrations of carbonized inclusions. The lowest layer, a natural soil, occupied the remaining $10 \mathrm{~mm}$ of the monolith. Sub-samples were extracted in three overlapping Kubiena tins from the uppermost $190 \mathrm{~mm}$ of Monolith 2:

\section{Sample 2.1 0-80 $\mathrm{mm}$ (ash) \\ Sample 2.2 45-125 mm (ash) \\ Sample 2.3 110-190 mm (ash and soil)}

Eight 50-mm thin-sections were produced from the Kubiena tin blocks by the Department of Environmental Science, University of Stirling, using standard methods of acetone drying, resin impregnation and thin-sectioning (Murphy 1986). The thin sections were analysed using the methods and termi- nology recommended in the Handbook for Soil Thin-Section Description (Bullock et al. 1985).

\subsection{Results}

Following microscopic examination, it proved possible to divide the thin sections into six distinct horizontal bands of sediment, the upper five corresponding to the ash layers recorded in the field (Table 15).

Detailed descriptions of these layers are given in Table 16 although the characteristics of the sediments are summarized in Table 15. There is little evidence for post-depositional alteration. Modern roots are present in all layers but at low density and they have not radically altered either fabric or structure. They are the cause of the low-porosity channel structures in layers 1,2 and 4 but this barely disrupted the original massive structure. Amorphous iron pedofeatures in layer 2 are post-depositional in origin and reflect gleying conditions in this sediment, probably due to partial waterlogging. Similar features in layer 6 (natural soil) probably developed prior to burial by the ash layers. It may be assumed that, overall, the present appearance of the sediments offers a good guide to their composition, fabric and structure at the time of deposition.

Only layers 1, 2 and 4 can be correctly described as ash layers; they consist entirely of the oxidized or reduced (carbonized) residues of burnt fuel (Courty et al. 1989, 105). Oxidized residues are characterized by very high reflectance in oblique incident light due to heating of iron oxides present in the fuel. No organic materials survived oxidation so the rare mineral components of the fuel have become concentrated, notably the biogenic silicas (phytoliths and diatoms). Combustion with limited oxygen led to the survival of organic residues in a reduced (carbonized) form; carbonized peat fragments are frequent in layers 1 and 4 .

Layers 3 and 5 are similar, narrow bands of

Table 15 Summary of sediment bands

\begin{tabular}{lll}
\hline Layer & Depth $(\mathbf{m m})$ & Description \\
\hline 1 & 21 (minimum) & Ash with frequent fragments of carbonized peat \\
2 & 55 & Ash with very few carbonized fragments \\
3 & 12 & Narrow band dominated by highly humified organic matter \\
4 & 38 & Ash with frequent fragments of carbonized peat \\
5 & 5 & Narrow band dominated by highly humified organic matter \\
6 & 50 (minimum) & Mineral subsoil with lenses of ash in upper $10 \mathrm{~mm}$ \\
\hline
\end{tabular}




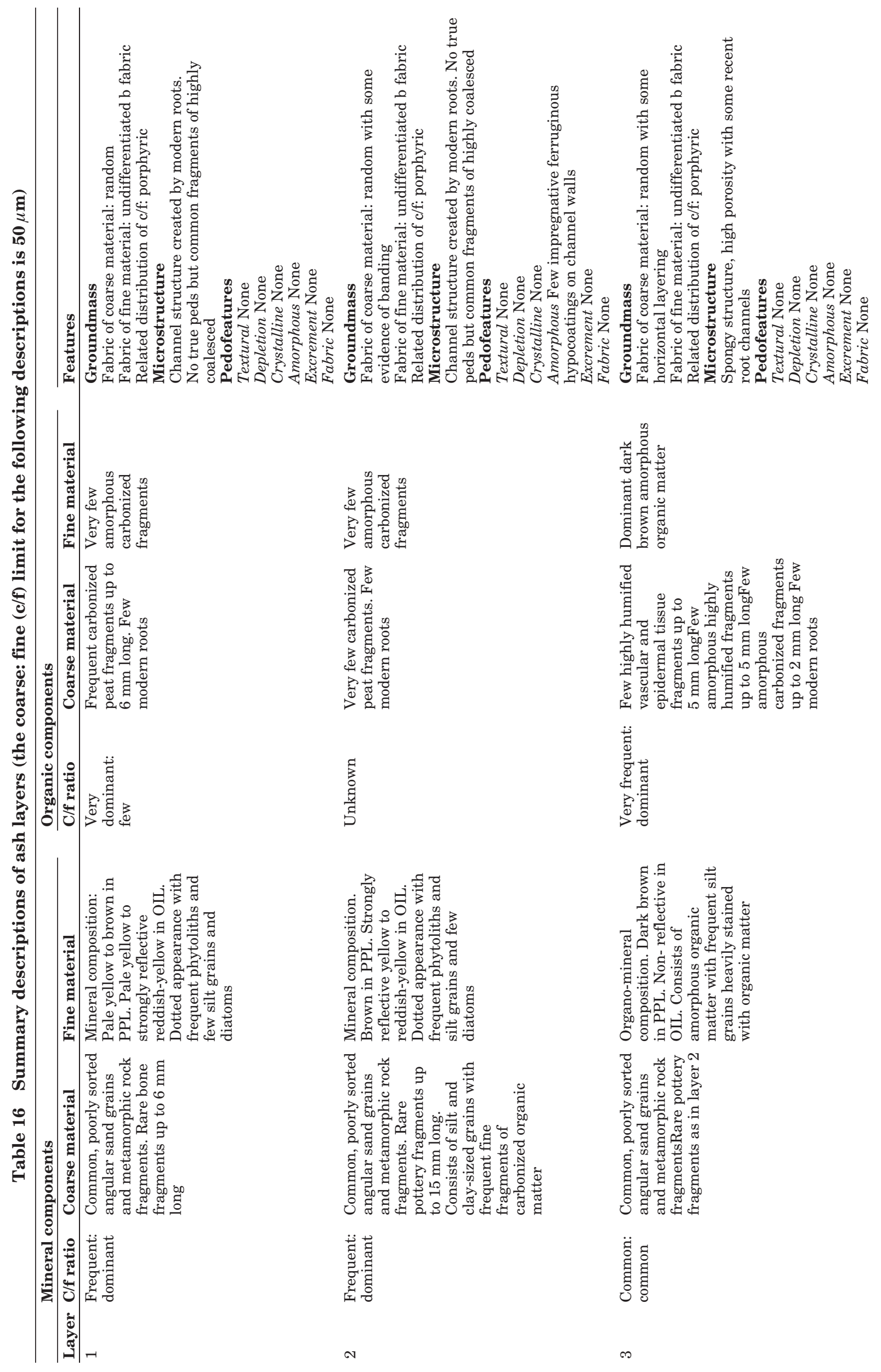




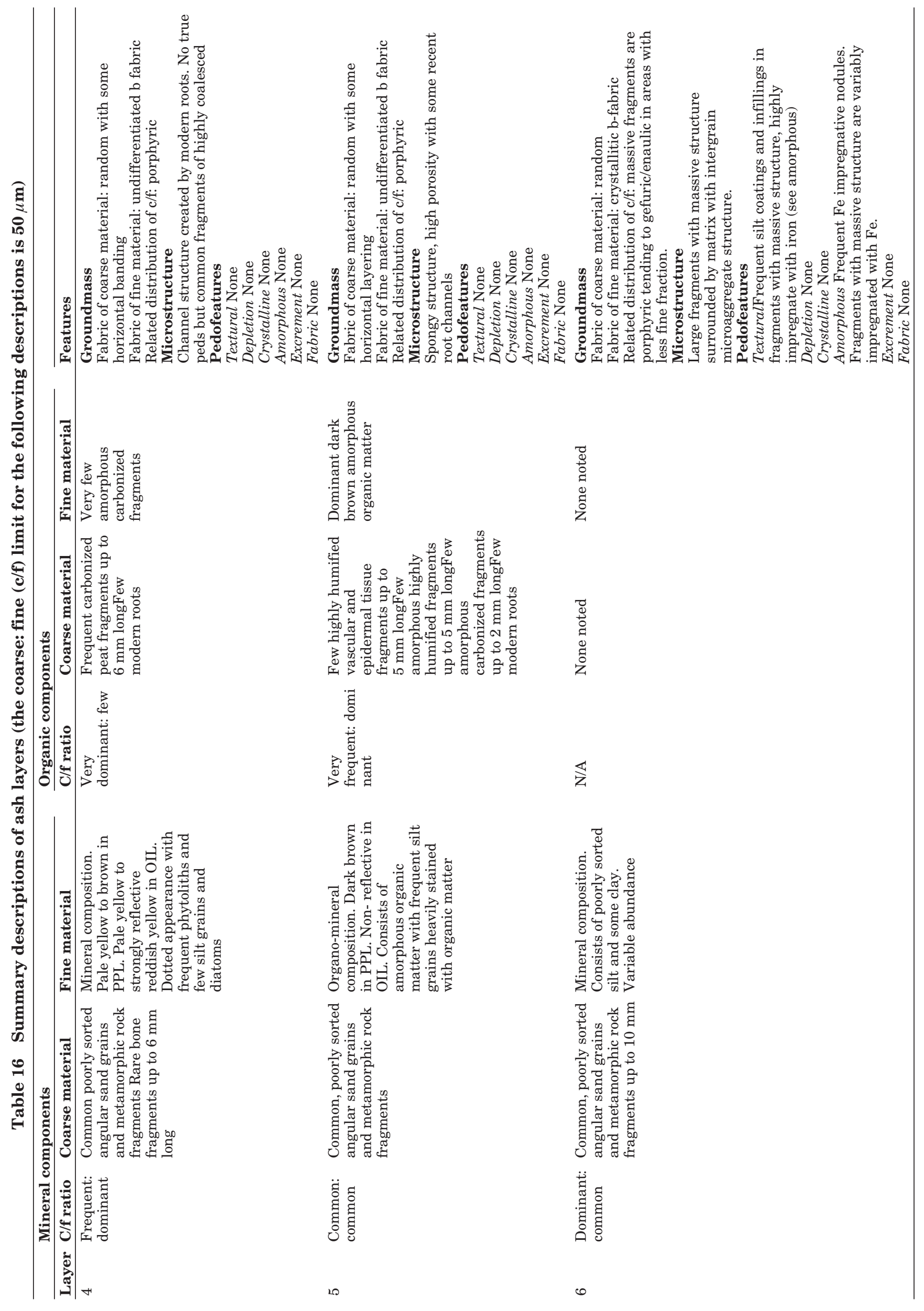


sediment dominated by highly humified, but not burnt, organic residues. Ash (both oxidized and carbonized) residues are present as minor components of these layers. Layer 6, the natural soil beneath the cairn, contrasts strongly with the overlying deposits as it lacks any ash or unburnt organic components. It is purely a mineral sediment.

The presence of two exotic components in these sediments should be noted. Bone is present in layer 1 and pottery in layers 2 and 3 .

\subsection{Discussion}

\subsubsection{Composition and source of the ash layers}

The composition of the three ash layers (1,2 and 4) points to one type of fuel as the source of these deposits - peat. This general term covers a wide variety of organic sediments of terrestrial and aquatic origin and details of the composition may be used to define the nature of the fuel more precisely. Carbonized fragments preserve the original structure and composition of fuel. In these examples it ranges from plant tissue fragments to amorphous, laminated organic matter and amorphous, organomineral sediments. This mixture of residues is typical of peaty turves or shallow blanket peat which contain a significant proportion of mineral sediment and therefore create abundant ash when burnt. Total oxidation of peaty turves yields a mixture of amorphous mineral ash, abundant biogenic silica and mineral grains. This is the mixture recorded in layers 1,2 and 4 .

The only significant difference in composition between the three ash layers is the relative proportions of oxidized to carbonized residues. This simply reflects differences in the conditions of combustion of three essentially similar fuels. Layer 2 ash was created in a strongly oxidizing fire and therefore almost no carbonized residues were created. Total oxidation can normally be achieved simply by the limited tending of a fire and mixing of the ashes as they accumulate. Fuel generally survives in a carbonized condition either if it has fallen out of a fire before total combustion or if it is smothered by accumulating ash which cuts off the supply of oxygen. The variation in composition therefore tells us little about the nature of the fires that created the ashes.

The presence of a few small fragments of bone and pottery could reflect the nature of the source fires if it is assumed that they do not derive from a separate source. Given that there is no other evidence for another source, and the fact that bone will only have survived in a burnt condition, it is safe to assume that the bone and pottery was present in the fires. Given the proximity of an urned cremation in the cairn, it would be reasonable to assume that bone and pottery in the ash points to a source in cremation pyres. This interpretation cannot be supported by the thin-section evidence as the bone fragments are too small to identify as human $(6 \mathrm{~mm}$ maximum length). Support for a cremation pyre source is also lacking in the overall nature of the ash which shows no signs of having been formed at high temperatures. Study of cremation pyres fueled with peaty turves at Linga Fold, Orkney (S Carter unpublished data) identified evidence of high temperatures. Biogenic silica (in particular from diatom frustules) was partially or totally melted and significant quantities of vitrified fuel ash occurred because of the general melting of silicates at temperatures in the range $500-1000^{\circ} \mathrm{C}$. High temperatures were probably achieved in pyres through a combination of careful pyre construction, maintaining the supply of oxygen, a large volume of fuel and long firing time. Therefore, whilst it is an argument based on negative evidence, it may be proposed that there is no reason to believe that the ash layers derive from cremation pyres. A simple cooking fire, using peaty turves, could create ash of a type recorded at Olcote and bone or pottery could easily be incorporated into the ash in this context.

The exact source of the peaty turf burnt in these fires cannot be determined. Shallow, peaty soil horizons would have been widespread in the Bronze Age and provided an important source of fuel at a time when indigenous supplies of wood had effectively ceased in Lewis and the deep blanket peat of the modern landscape had yet to accumulate. Mineralogy of the sand grains and lithology of rock fragments in the oxidized ash do not help, as they represent a soil parent material present over most of the island. However, given the widespread occurrence of peaty soils, a local source for the fuel can be safely assumed.

\subsubsection{Composition and source of the humified organic bands}

Layers 3 and 5 are distinctive because they are dominated by highly humified organic residues that have not been burnt, so they are not fuel ash. The high degree of humification has left little structural information with which to identify the plants originally present. Recognizable remains include epidermal and vascular tissues which are commonly most resistant to decomposition. These derive from herbaceous (non-woody) plants but further identification is not possible. Without more precise identifications for the plants, a source for these layers cannot be proposed.

\subsubsection{Formation of layers 1-5}

Two distinct sources have been identified for sediment layers 1-5: fuel ash from fires burning peaty turves (1,2 and 4) and unidentified herbaceous plants (3 and 5).

The three ash layers contain a mixture of oxidized and carbonized residues in varying proportions. Such 
mixtures can only be created once the ash has cooled because small carbonized fragments would be oxidized if mixed while the ash was still hot. Therefore, these layers represent either fires created in situ and mixed after cooling or dumps of cold ash from fires burnt elsewhere. The presence of uncarbonized organic matter in layers 3 and 5, interstratified with the ash, rules out burning in situ as this would have oxidized or carbonized the plant remains in those layers. Therefore, the ash layers can be confidently interpreted as dumps of cold ashes.

Surviving evidence for horizontal banding in the tissue fragments from layers 3 and 5 indicates that they were deposited in a fresh condition and decomposed in situ. Therefore, layers 3 and 5 were deposited as reasonably fresh herbaceous vegetation. The presence of some fragments of bone and pottery within these two layers probably resulted from infiltration of overlying sediment down into the loose mat of vegetation while still fresh. This suggests that the five layers accumulated over a relatively short period of time, a conclusion supported by the relative lack of evidence for surface soil-forming processes in any of the sediments.

The sediments were deposited onto the surface of a soil represented in thin-section by layer 6 . The characteristics of layer 6 are those of a sub-surface soil horizon with a lack of organic matter, no evidence for biological activity or presence of textural pedofeatures. Therefore, it may be concluded that, at the time of sediment deposition, this soil had been truncated recently, removing its topsoil and exposing subsoil at the surface. The interleaving of lenses of ash and subsoil at the soil surface indicates that this surface itself was disturbed during deposition of the ash and plant layers.

\subsection{Archaeological interpretations}

The analysis of the thin-section evidence presented above offers some guidance to the archaeological interpretation of these deposits. The soil underlying the sediments had been truncated shortly before their deposition; this activity may have been part of the preparation of the site for the cist and cairn. The sediments can be divided into two types: cold fuel ash from fires burning peaty turves and unidentified herbaceous plants. The absence of positive evidence for the ashes originating in cremation pyres has been discussed above although they could have been derived from fires associated with other burial rituals. The role of the layers of plants in any burial activity is obscure but they have been repeatedly interleaved with ash and this suggests more than an accidental presence in the deposits. 


\section{Palynological Analyses by P Milburn}

\subsection{Introduction}

A series of horizontal bands of sediment, identified in the field as burnt peat, were sampled using two 250-mm monolith tins (Section 10.1). Four subsamples of these bands were prepared for pollen analysis (see below) with the aim of determining the composition and origins of the deposits.

\subsection{Methodology}

\subsubsection{Pollen preparation and counts}

Samples selected for pollen analysis were processed using standard chemical methods (Moore et al. 1991) stained with Safranin and mounted in silicon oil. Pollen counts were undertaken using an Olympus BX40 series research microscope at $400 \times$ magnification, with critical features examined at $1000 \times$ under oil and by linear traverses across the slide, in order to avoid biases created by uneven pollen distribution (Brooks \& Thomas 1967). Where possible, a total of 300 land pollen grains was counted per sample. Samples with pollen densities too low for counting to an acceptable sum [a total land pollen (TLP) concentration of less than 600 grains per $\mathrm{cm}^{-3}$ ] were for the purposes of this report defined as non-polleniferous.

Identifications were based primarily on type reference material, with further reference to standard keys (Moore \& Webb 1978; Andrew 1984; Faegri \& Iverson 1989, Moore et al. 1991). Cereal-type pollen grains were categorized (Anderson 1978). Because of the difficulties of differentiating between the pollen of Corylus avellana and Myrica gale, a general Coryloid category was used. Other identifications follow the conventions outlined in The Present and Past Vegetaion of the Isle of Skye: a Paleoecological Study (Birks 1973). The state of preservation of all pollen grains was assessed and the grains placed in non-hierarchical categories (cf Cushing 1967).

Fragments of microscopic charcoal were also counted. A minimum fragment size of $10 \mu \mathrm{m}$ diameter based on graticule estimates was employed. Charcoal counts are expressed as a percentage of charcoal fragments per 300 land pollen. Values in Table 17 are expressed as a percentage of TLP and for non-terrestrial taxa as a percentage of total land pollen plus group/taxon count. Botanical nomenclature follows Flora of the British Isles (Clapham et al. 1989).

\subsection{Results}

Percentage pollen and spore data are presented in Table 17. An absence of exotic Lycopodium in sample 1 prevented an accurate assessment of the paucity of pollen. However, the examination of three slides $(24 \times$ $40 \mathrm{~mm}$ ), 150 traverses, located only two pollen grains and therefore this sample was considered nonpolleniferous. On the basis of the applied criteria (see above), only sample 2 contained sufficient pollen to be classified as polleniferous. In sample 2, 52\% of TLP showed some degree of mechanical or chemical damage, suggesting that pollen may have undergone secondary transportation and been exposed to aerobic conditions prior to burial.

The pollen assemblage from sample 2 is dominated by Gramineae and Ericaceae, forming up to $82 \%$ TLP, and a range of herbaceous pollen taxa associated with open environments, such as Rumex acetosa / sella, Plantago lanceolata and Potentilla.

\subsection{Discussion}

The absence of significant amounts of pollen and/or other microscopic organic remains and the differing amounts of microscopic charcoal recorded in pollen samples 1, 3 and 4 accord with the results of the thin-section analysis. The presence of organic residues in pollen sample 2 corresponds to the presence of significant amounts of relatively well preserved pollen (Table 17; Table 18).

Evidence of horizontal banding in sediment layer 3 (pollen sample 2) led Carter to suggest that this layer had been deposited in a fresh condition and decomposed in situ (Section 10). Although the exact source of the material forming pollen sample 2 cannot be

Table 17 Layers sampled for pollen from monolith samples (see Section 10.2)

\begin{tabular}{lll}
\hline Pollen sample & Sediment layer & Sediment description (Section 10) \\
\hline 1 & 2 & Ash with very few carbonized fragments. No organic materials survive \\
2 & 3 & Highly humified, but not burnt, organic residues \\
3 & 4 & Ash with frequent fragments of carbonized peat. No organic materials \\
4 & 6 & Natural soil. A purely mineral sediment \\
\hline
\end{tabular}


Table 18 Palynological data for four samples from the cairn

\begin{tabular}{|c|c|c|c|c|c|}
\hline Sample no & Counts & $\%$ TLP & Sample no & Counts & $\%$ TLP \\
\hline Sample 1 & & & Charcoal $101+\mu \mathrm{m}$ & 3 & 1 \\
\hline Alnus & $1(\mathrm{Co})$ & & Sample 3 & & \\
\hline Ericaceae undiff. & 1 (De) & & Coryloid & $1(\mathrm{Cr}$ & \\
\hline Exotic Lycopodium & 0 & & Ericaceae & $1(\mathrm{Cr}$ & \\
\hline Charcoal 10-25 $\mu \mathrm{m}$ & 8 & & Gramineae & $8(2 \mathrm{~N}$ & $\mathrm{Cr})$ \\
\hline Charcoal 26-50 $\mu \mathrm{m}$ & 21 & & Plantgo undiff. & $1(\mathrm{~N})$ & \\
\hline Charcoal 51-100 $\mu \mathrm{m}$ & 11 & & Filipendula & $1(\mathrm{~N})$ & \\
\hline Charcoal $101+\mu \mathrm{m}$ & 2 & & Filicales undiff. & $1(\mathrm{~N})$ & \\
\hline Sample 2 & & & Exotic Lycopodium & 301 & \\
\hline Coryloid & 1 & $<1$ & Charcoal 10-25 $\mu \mathrm{m}$ & 59 & \\
\hline Ericaceae & 109 & 35 & Charcoal 26-50 $\mu \mathrm{m}$ & 125 & \\
\hline Gramineae & 148 & 47 & Charcoal 51-100 $\mu \mathrm{m}$ & 55 & \\
\hline Cereal type (Hordeum) & 2 & 1 & Charcoal $101+\mu$ & 28 & \\
\hline Cyperaceae & 2 & 1 & Sample 4 & & \\
\hline Ranunculus type & 4 & 1 & Gramineae & \multicolumn{2}{|c|}{$2(1 \mathrm{~N}, 1 \mathrm{Co})$} \\
\hline Rosaceae undiff. & 2 & 1 & Filicales undiff. & \multicolumn{2}{|c|}{$1(\mathrm{~N})$} \\
\hline Potentilla & 7 & 2 & Exotic Lycopodium & \multicolumn{2}{|l|}{300} \\
\hline Umbelliferae undiff. & 3 & 1 & Charcoal $10-25 \mu \mathrm{m}$ & \multicolumn{2}{|l|}{1} \\
\hline Rumex acetosa/sella & 13 & 4 & Charcoal 26-50 $\mu \mathrm{m}$ & \multicolumn{2}{|l|}{2} \\
\hline Plantago lanceolata & 19 & 6 & Charcoal 51-100 $\mu \mathrm{m}$ & \multicolumn{2}{|l|}{1} \\
\hline Compositae lig. & 2 & 1 & Charcoal $101+\mu \mathrm{m}$ & \multicolumn{2}{|l|}{0} \\
\hline Filicales undiff. & 1 & $<1$ & Preservation data & & \\
\hline Pteridium & 1 & $<1$ & sample 2 & & \\
\hline Sphagnum & 3 & 1 & Normal & 153 & 48 \\
\hline Exotic Lycopodium & 165 & & Corroded & 33 & 11 \\
\hline Charcoal 10-25 $\mu \mathrm{m}$ & 36 & 10 & Degraded & 5 & 2 \\
\hline Charcoal $26-50 \mu \mathrm{m}$ & 49 & 13 & Crumpled & 106 & 33 \\
\hline Charcoal 51-100 $\mu \mathrm{m}$ & 16 & 5 & Split & 17 & 6 \\
\hline
\end{tabular}

Preservation key: N, normal; Co, corroded; De, degraded; Cr, crumpled; Sp, split.

Glossary: Alnus, alder; Ericaceae, heathers; Cyperaceae, sedge family; Rosaceae, rose family; Umbelliferae, wild carrot family; Plantaginaceae, plantain; Filipendula, meadowsweet; Filicales, ferns; Coryloid, hazel/bog myrtle; Gramineae, grasses; Ranunculus, buttercup; Potentilla, cinquefoil; Rumex acetosella/tosa, sorrel/dock; Plantaginaceae, plantain; Plantago lanceolata, ribwort plantain; Compositae, daisy family; Pteridium, bracken.

determined, the environment inferred is open, probably a mixture of damp grassland and heather. It is suggested on the basis of the available data that a likely source for this material would have been an open area of peaty ground.

The presence of two grains of cereal-type pollen in sample 2 may indicate that cereal cultivation was occurring close to the original site of the deposit. However, both of the cereal-type grains identified (after Anderson 1978) fell within the Hordeum-type category. A number of wetland grasses also fall within this size category. It is considered likely that the cereal-type pollen recorded may have come from a naturally occurring wetland grass.

The occurrence of microscopic charcoal in sample 2 may reflect the occurrence of fires in the vicinity of the source area of this deposit. Alternatively, the charcoal could have become incorporated into the sample during the construction of the cairn. 


\section{General Discussion by $T$ Neighbour}

The cairn at Olcote formed the latest recognizably prehistoric component of a site which perhaps developed since the Neolithic. The four broad phases identified were:

Phase 1: Features beneath the cairn (Illus 6; Illus 7; Illus 8)

Phase 2: Cultivation marks and preparation of the ground (Illus 7; Illus 8; Illus 9)

Phase 3: The kerbed cairn, including construction and adaptation (Illus 10-18)

Phase 4: Features cutting the cairn, including post-holes, field drains and stone-robbing (Illus 10).

The first three phases are discussed at length in the following section.

\subsection{Possible Neolithic activity (Phase 1)}

The formless array of pits sealed beneath the cairn almost defies interpretation. Such confused post and pit patterns are common in Neolithic sites of probable domestic character, particularly in the east of Scotland, such as Spurryhillock (Alexander 1997), and it is conceivable that the pits preserved beneath the cairn at Olcote fall into this category (Illus 7). However, many of the Olcote pits seem to have belonged in four- and six-post square, rectangular, triangular and kite-shaped settings (Illus 8, A-Q). Ellison and Drewett have indicated a range of possibilities for such post arrangements (Ellison and Drewett 1971), including raised granaries and exposure platforms for corpses. Although their paper is concerned with two-, four- and six-post structures of Iron Age date, their logic can still be applied to the demonstrably pre-mid-Bronze Age features sealed beneath the cairn at Olcote. Furthermore, there is abundant evidence for the practice of excarnation during the Neolithic in most areas of the British Isles (Scott 1992).

It is conceivable that the features beneath the cairn at Olcote were of Neolithic date, a time when burial took an egalitarian form with bones being collected in communal ossuaries (Barclay \& Russell-White 1993; Ashmore 1996). Typically, similar bones were collected in groups, rather than as discrete individuals, suggesting that burial took place either after the flesh had either been removed from the bones or had fallen off. It is suggested that the small arrangements of pits at Olcote are all that remains of a series of excarnation platforms (see Barclay \& Russell-White 1993,174 , illus 72 , for a graphic image of a putative excarnation enclosure at Balfarg). The rectangular arrangements (Illus 8, A, G and L) were of suitable dimensions to have supported a platform on which a body could be laid prone. The smaller arrangements could have been for platforms for the exposed remains of children or bodies in a crouched or sitting position. Although nothing of the posts survived above ground, there are numerous ethnographic parallels for the 'seemingly bizarre practice of secondary disposal of the corpse' (Metcalf \& Huntington 1991, 35) from North and South America, Central Asia and elsewhere. Transitional rites, such as exposure of the dead, are frequently complex and of long duration, often involving great feasts and elaborate rituals to deflect the hostility of the recently departed soul (van Gennep 1960, 146; Metcalf \& Huntingdon 1991, 34). The absolute minimum duration of the transition rite is the time taken for the bones to be free of decaying flesh:

Documented particularly well in the nineteenth century [amongst the peoples of the north-west of America and Canada] are the huge carved cedar poles that were erected for various reasons, often memorial and sometimes for the physical containment of human remains. Despite the effort that went into producing and shaping these 'totem' poles, and in many cases the supreme quality of the craft and art, they were not maintained but left to decay, physical reminders of the passage of the dead from the world of the living to that of the ancestors (Pitts 2000, 257).

Sadly, any ornate decorated timbers from the presumed excarnation platforms at Olcote are now lost to us. However, their location on the same line as the north avenue of the main site at Calanais (and on the spot chosen for the construction of the cairn some centuries later) lends credence to the excarnation podia hypothesis. It is possible that this was a liminal zone, where bodies were exposed until defleshed, whereafter they were taken up the main avenue at Calanais for interment in the chambered tomb within the circle (Ashmore 1995). This proposed direct journey is at odds with the route along which the dead were escorted from their liminal location at Woodhenge for burial at Stonehenge, as suggested by others (Parker Pearson \& Ramilisonina 1998). This route involved a river journey down a meandering stretch of the River Avon, before processing up to Stonehenge which, it is suggested, was intended to confuse the spirit of the dead (Parker Pearson \& Ramilisonina 1998). The more direct route proposed here for the passage of the dead from Olcote to the Calanais stone circle might indicate a different attitude to the soul of the departed. Perhaps there was less fear of the mali- 
ciousness of the newly dead, or the defleshed corpse now no longer represented a threat. It has been suggested that such rites of passage were commonplace (Pitts 2000). Ceremonial landscapes such as those on Salisbury plain, mainland Orkney and the complex centred on Calanais standing stones must have been extremely important, perhaps literally a matter of 'life and death'.

\subsection{Bronze Age activity (Phases 2 and 3)}

\subsubsection{The cairn}

The cairn at Olcote is of unusual morphology, dating from the mid 2nd millennium BC. Recent excavations in the Hebrides have revealed cairns of strikingly similar morphology to the one at Olcote. In particular, a circular, double-kerbed cairn has been excavated on Cnoc an Tursa, to the south of the main site at Calanais on the alignment of the avenue (Campbell \& Coles 1999). Two circular cairns of similar diameter to the Olcote cairn, both with double kerbs and urned central cremations, have been investigated on Vatersay (Branigan \& Foster 2000, 192-215) and the authors suggest that they discovered many more during survey work. On Lewis, the D-shaped cairn at Cnip also has two kerbs (Close-Brooks 1995). Thus, the double-kerbed cairn appears to have been something of an Hebridean tradition. It is not clear whether the distinctions in this tradition should be given more weight than the similarities to Bronze Age burial customs in the wider context. This mixture of striking similarities and unfathomable differences is a feature of Bronze Age burial rites, which can be broadly characterized as inhumation or cremation within cairns of varying levels of ostentation.

Quartz appears to have been a near ubiquitous accessory in the construction and curation of kerbed cairns (see Section 7.10 for a discussion of the links between quartz and funerary rites). Examples of the varying use of quartz have been found at Logie Newton, Aberdeenshire where blocks were used as kerb stones and at Monzie, Perthshire, where pebbles were placed at the base of a kerb (Ritchie \& MacLaren 1972). At Fowlis Wester, Perthshire, the small central cist was filled with burnt bone and quartz and the kerb itself packed with flakes of quartz (Ritchie \& MacLaren 1972). It is clear that the cairn at Olcote was no exception to the rule because an abundance of quartz was recovered during the excavation (see below). Quantities of worked and unworked quartz were also recovered during the excavation of the nearby cairn at Cnoc an Tursa (Campbell \& Coles 1999). However, quartz was entirely absent from a cairn at Cnip, where quartz might not have contrasted sufficiently with the near-white shell sand (Close-Brooks 1995, 268). More puzzling is the apparent absence of quartz from the kerbed cairns excavated on Vatersay (Brannigan
\& Foster 2000, 192-215). However, small numbers of worked flint and quartz were recovered from the excavation of these two cairns (Brannigan \& Foster 2000) and it is possible that the lack of unworked quartz may simply reflect an excavation retrieval policy rather than a real absence, because quartz was found on the spoil heaps (M Macleod, pers comm).

The cairns at Olcote and Cnoc an Tursa are both colinear with the avenue at the main site at Calanais. The chambered cairn and primary stone ring at Calanais were constructed in the early 4th millennium BC (Ashmore 1995). The cairn at Olcote has been radiocarbon-dated to the mid 2nd millennium BC and, although undated, the cairn at Cnoc an Tursa is likely to be of similar age. Thus a period of over a millennium separates the construction of the main site at Calanias and the cairns which were apparently sited with reference to it. It is suggested that the colinearity of the cairns with the avenue at the main site was a conscious attempt on the part of the cairn builders to construct a link with the past, a past that was probably beyond memory and hence rooted in the realm of legend. The linear link stands in stark contrast to the deliberate destruction of the chambered tomb within the circle at Calanais (Ashmore 1995). This act, which broadly coincided with the construction of the cairns, was sealed by ploughing (Ashmore 1995) and the formation of cultivation marks appears to have preceded the construction of the cairn at Olcote (see below).

The construction of Bronze Age burial sites around Neolithic standing stone monuments and contemporary structural alterations to such monuments is commonplace in Scotland, for example at Temple Wood, Argyll (Scott 1991), Machrie Moor, Arran (Haggarty 1991) and elsewhere in the British Isles, including Stonehenge (Cleal et al. 1995). Several burial cairns have been discovered in the landscape around Calanais (Illus 1), chiefly by Margaret and Ron Curtis. The excavation of the cairns at Olcote and Cnoc an Tursa has provided the first proven evidence for Bronze Age funerary activity in the area. These discoveries make the ceremonial landscape at Calanais more comprehensible within the accepted limits of the development of such Neolithic sites. The problems of archaeology in the peat-bound landscape of Lewis are demonstrated by the relatively recent discovery of a stone circle at Druim Dubh (Curtis \& Curtis 1996). Sites with low relief, such as kerbed cairns, are likely to remain well hidden and it seems safe to assume that yet more Bronze Age burial sites await discovery in the Calanais area.

\subsubsection{Preparing the ground}

The soil micromorphological analysis has demonstrated that the topsoil was stripped from the site of 
the cairn prior to its construction while excavation demonstrated that cultivation marks had been preserved beneath the cairn in the north-east quadrant of the site. Barclay has suggested that prehistoric cultivation marks, which are usually recorded as ard marks, are more often the result of spade work and are the result of cutting and removing turf prior to cultivation (Barclay 1997, 142). The cultivation marks at Olcote were not dissimilar to those discovered at Rosinish (Shepherd \& Tuckwell 1977), where they were not associated with a burial monument at all. However, such a process would have been necessary to remove the turf and prepare the ground for the construction of the cairn at Olcote and it is suggested that the marks here are unlikely to be agricultural traces.

The presence of cultivation marks beneath burial monuments of the Neolithic and Bronze Age has been recorded across Europe (Tarlow 1995). It has been suggested that many of these marks, such as those beneath South Street Long Barrow, have 'a strange vigorousness' (Taylor 1996, 184) and that the act of marking the soil was a deliberate ritual preparation of the ground performed prior to the erection of the cairn.

Ethnography suggests that the idea of the dead fertilizing the landscape is powerful and widespread. Although there are societies, such as the Mambai of East Timor (Metcalf \& Huntington 1991, 105-7), where the fertilizing power of the dead is viewed very literally indeed (the Mambai believe that the bodies of the dead turn into black earth which provides food), generally this idea is metaphorical rather than literal: the potentially dangerous loose soul is transferred to regeneration and growth (van Gennep 1960). Patzold described a rite in India that involved marking out a burial plot with rope, ploughing the plot with a wooden plough, saying a prayer to beseech continued fertility and finally ploughing along the line of the rope (Patzold 1960). The cremated remains of the deceased would then be placed in an urn in the centre of the burial plot. At the end of the ceremony the ground was watered and sown with seed and finally earth heaped upon it. Thus, the ploughing represented a means of preparing the ground for the planting of the dead (Taylor 1996, 184), with attendant implications for future fertility and agricultural output.

While it seems that the cultivation marks at Olcote were the result of the prosaic act of removing topsoil and turf to provide a level subsoil surface for the construction of the cairn, it is suggested that an element of ritual was also attached to the process. Credence is lent to this notion when the destruction of the chambered cairn at the Calanais standing stones is considered (Ashmore 1995). The process of demolition culminated in the ploughing of the site, an action perhaps serving a ritual function (Ashmore 1995), which occurred in broadly the same period as the construction of the cairn at Olcote.

\subsubsection{Construction of the cairn}

The body of the cairn was formed of ash from burnt, peaty turves and peaty soil. Soil micromorphology and magnetic susceptibility analysis (Illus 19) demonstrated that the peaty turves were not burnt on site but were imported for incorporation into the funerary monument. Clues as to the importance of depositing such material are provided by: the layers of vegetation, principally heather (see above), which were deliberately laid between the ash layers; the deposition of smashed sherds of a single vessel within the ash spreads; and the presence of pits within the ash layers, the pits having been dug while the ash was being laid. The fills of the pits provided no clue as to their function although they could have contained organic ritual offerings that did not survive the effects of the acid soil.

Soil micromorphology also provided evidence for the import of soil to a similar cairn at Mousland, Orkney (Downes 1994). The excavator suggests that the ash was from a funeral pyre and that the cremation ceremony took place away from the place of burial. However, burning peaty turves would not have produced the high temperature suggested for the Olcote cremation. Thus, the ash which formed the body of the cairn does not appear to have come from the cremation pyre, but from some other activity. The burnt peaty turves could have been removed from the site of the cairn during the preparation of the ground and provided the fuel for a ceremonial feast. Although the ash was possibly derived from domestic activities, it appears to have been deposited within the body of the cairn in a prescribed manner, layers of heather being interleaved with layers of ash and small hollows in the ash being sealed by further deposits of ash. One of the hollows (167) contained sherds from a single pot. Thus, while the origins of the ash are uncertain, the manner in which it was laid down suggests that its deposition was of ceremonial importance.

The cremated remains were placed within a cist, defined by three orthostats, in the centre of the cairn. A vessel within the cist had been disturbed, probably by the insertion of drains through the cairn and through stone-robbing, and around one third of it was missing. It is suspected that this vessel may have originally covered the cremated remains. A cut (122) indicates that the central cist was constructed following the formation of the low mound that confined by the outer kerb. It is impossible to be precise about the length of time between the construction of the cairn and the insertion of the cist. However, the central position of the cist suggests that the cairn was constructed as a burial monument for the individual(s) within that cist and thus the length of time between the two events was unlikely to have been great (the cremation burial rite is discussed at greater length in Section 12.2.4). A round kerb, built of slabs laid flat, surrounded the low mound. An inner kerb, of uncertain morphology, was laid on top of the mound. The inner kerb was 
apparently very slight along most of its length and laid only on the surface of the soil that formed the body of the cairn. Much of the stone had been robbed from the cairn and much of the remaining stone had been disturbed. Consequently, the exact shape of the inner kerb is not certain, but is most likely to have been designed as a penannular feature (Illus 11), particularly if the presence of a putative satellite inhumation cist is accepted. This putative cist was placed roughly symmetrically between the open arms of the penannular model for the inner kerb. Except for this possible satellite cist, there was no evidence for appreciable stratigraphic depth within the monument. In particular, there was no stratigraphic link between the inner and outer kerbs. It is suggested that, as both features focused on the central cremation cist, the kerbs should be viewed as contemporary. If so, the cairn at Olcote belongs to an Hebridean variation of a more widespread burial tradition, incorporating two kerbs rather than the more typical single kerb (see above).

\subsubsection{Who was buried at Olcote?}

Single burials within Bronze Age cairns contrast with the communal burials of the Neolithic and seem to reflect an increasing individualization of society (Parker Pearson 1993; Bradley 1998). The complex morphology of the cairn and its apparently deliberate relationship with the avenue at Calanias suggest that the burial at Olcote was of some importance. Whether that importance was attached to the individual(s) buried there, or whether the act of burial was important and the individual(s) were merely elements of a wider agenda is fundamental to our full understanding of this monument. This remains unresolved. Questions can be asked and parallels suggested, some of which might appear outlandish.

Inevitably, we have to ask who was buried at Olcote. The cremated remains were of either one or two individuals. It was not possible to establish the sex or cause of death of the incumbent(s). However, it has been possible to ascertain the age at death, either a single 14- to 16-year-old or two individuals, one of whom was over 18 and another represented by only a single tooth from an individual who could have been $3-5,8-10$ or $14-16$ years old. It is considered most likely that two individuals were represented within the cremation. Who were these people? Did they include the young son or daughter of an important person? Were they siblings who died at the same time by accident or illness? Did the nature of their deaths indicate that special treatment of their remains was required to appease their souls after death and ensure the continued fortunes of those left behind? Was one of the individuals a slave, put to death following the departure of their young master/mistress? The presence of two or more individuals in a single urn or burial is not uncommon in the Bronze Age: analysis of the skeletal material recovered from excavations in the Brenig Valley in North Wales revealed that one urn held the bones of two individuals, while a large burial pit contained three individuals who must have been buried at the same time (Lynch 1993, 152).

Downes has highlighted the complexity of the cremation ceremony in Bali (Downes 1999), which involves the corpse being buried for a time, before cremation. A prescribed route from burial location to cremation site to final interment is followed. Similarly, Parker Pearson begins his book, The Archaeology of Death and Burial, with a cautionary tale summarizing an eyewitness account of the rites involved in the cremation of an important Viking in Russia, including the removal of the man's corpse from a temporary grave, reclothing the corpse and the sacrifice of slave girls and animals (Parker Pearson 1999,1-3). This account reminds us that the site of a cremation burial is likely to be the final point on a long literal and metaphorical journey. Recent work on a Bronze Age burial mound in the Iki-Burul region of the Kalmyk Republic (on the steppes between the Don and the Volga) has revealed a startlingly long wait from the preparation of the burial plot to final interment. Pollen analysis demonstrated that the grave was dug in early spring, while the burial was not performed until the beginning of summer, when a 15-year-old girl was interred with a pillow of blooming grasses beneath her head. The excavator suggests that the girl was sacrificed. A low barrow was constructed over the grave immediately following the burial and heightened later, during the winter (N Shishlina, pers comm). Thus, although we know little beyond the age of the cremated individual(s) and the nature of their final resting place at Olcote, it must be acknowledged that this was likely to have been only the final act in a potentially long and ritually prescribed ceremony which could have lasted days, weeks or even months.

Analysis of the plant macrofossils from contexts within the Olcote cairn revealed the presence of bilberry, cowberry and crop plants, all of which are gathered in late summer/early autumn (harvest time). It is, of course, possible that the individual(s) buried at the cairn died at harvest time. However, it is also possible that the deaths occurred earlier in the year (if the cremated remains were of two individuals, not necessarily at the same time), and that the corpse(s) were retained in temporary graves until the prescribed time for burial (Downes 1999). There are numerous rituals recorded in ethnographic and historical studies for harvest time and the possibility that this monument was connected with harvest rituals must be addressed. The timing of the burial at Olcote, coupled with the suggested ritual attached to the preparation of the ground prior to the construction of the cairn, suggests that a link was understood between the dead and continuing agricultural fertility. Although it might seem fanciful, the possibility of sacrifice must at least be considered. Indeed, it is suspected that the adolescent girl buried in the 
cairn in the Kalmyk Republic was sacrificed (see also Tarlow 1995 and Jones-Bley 2000). Fraser provides instances where human sacrifice is linked to agricultural fertility, including an example from Mexico where a chosen sacrificial victim, who resembled the corn goddess, Chicomecohualt, was covered in corn and beheaded, her blood being scattered on the fields to ensure future fertility (Fraser 1911, 589). In India a suttee sacrifice, whereby the wife of a deceased man voluntarily sacrifices herself on her husband's cremation pyre, was reported by The Times as recently as 12 August 2002. The suttee sacrifice is regarded as a cause for celebration: the widow is regarded as a goddess following her death (see Jones-Bley 2000 for a wide-ranging literary and archaeological overview of animal and human sacrifice, including suttee). 


\section{Conclusion by $T$ Neighbour}

The site at Olcote is multi-phase and is suspected to span from the Neolithic to the middle Bronze Age. The earliest features on site were pits of probable Neolithic date. While it is possible that these pits were of domestic origins, the possibility that they were the remains of excarnation platforms has been explored and the link between them and the chambered cairn within the circle at Calanais has been discussed. A kerbed cairn sealed most of the pits. The cairn had two kerbs, in common with a number of other such monuments that have been excavated in the Hebrides and it is suggested that the double kerbed cairn is a specifically Hebridean variant. Despite its complexity, it is suggested that the cairn was a single-phase construction with, at most, one addition, a possible satellite cist of suitable size for an inhumation. The central cist contained the cremated remains of one or two teenage or younger individuals. A vessel within the cist had been disturbed and was suspected to have originally covered the cremated remains. The timing of the burial and the possible rituals attached to the construction of the cairn have also been discussed. 


\section{Acknowledgements}

The project was wholly funded by Historic Scotland, for whom Noel Fojut and Roderick McCullagh advised and assisted at various stages. Bill Finlayson acted as CFA Project Manager. Gordon Barclay provided useful advice on prehistoric cultivation marks, excarnation practices and Neolithic settlement remains. Dr Natalia Ivanova Shishlina, of the Moscow State History Museum, supplied an English language summary of her excavations in the Kalmyk Republic, which have been fully published in Russian. I am grateful to Mike Parker Pearson for joining the dots that became illustration 7 . The illustrations were produced by Kevin Hicks, George Mudie and Alan Braby. Thanks are due to the excavation team of Kirsty Cameron, Alan Braby, Nicola McNee, Jane Fletcher and Kevin Hicks and Mr and Mrs Curtis of Olcote, Calanais. Jim Crawford, Sue Hothersall, Carol Knott, Abdelli Khoudi and Mr Macleod volunteered at various stages of the excavation. The photographic tower was loaned by Jim Crawford.
Julian Cope mentioned the site in his book (Cope 1998, 71-2) with particular reference to its serendipitous discovery; it is hard to disagree.

Paula Milburn thanks Richard Kynoch for producing excellent pollen preparations from difficult sediments. Graeme Warren thanks Torben Ballin, Jane Downes, Mark Edmonds and Simon Gilmour for assisting with varied requests about lithic assemblages and Brian Jackson of the Geology Department of the National Museums of Scotland for his comment on the raw materials. Melanie Johnson thanks Mike Parker Pearson for providing information on the unpublished assemblage from Cladh Hallan.

Comments on earlier drafts of this paper were provided by Roderick McCullagh, Jane Downes, Mark Edmonds, Mike Parker Pearson and Ian Ralston. While the assistance of the above is gratefully acknowledged, responsibility for the report lies with the author and CFA. 


\section{References}

Alexander, D 1997 'Excavation of pits containing decorated Neolithic pottery and early lithic material of possible Mesolithic date at Spurryhillock, Stonehaven, Aberdeenshire', Proc Soc Antiq Scot, 127, 17-28.

Alexander, D \& Armit, I 1993 'Unstratified stratigraphy: methodologies for interpreting and presenting cropmark sites', in Barber, J W (ed) Interpreting Stratigraphy, 37-41. Edinburgh.

Anderson, S T 1978 'Identification of wild grass and cereal pollen', Danm Geol Unders Arbog, 2, 6992.

Andrefsky, W 1998 Lithics: Macroscopic Approaches to Analysis. Cambridge.

Andrew, R 1984 A Practical Pollen Guide to the British Flora. Technical Guide One. Quaternary Research Association, Cambridge.

Armit, I forthcoming 'The Neolithic Settlement of Domhnuill, Loch Olabhat, North Uist'.

Ashmore, P 1995 Calanais: The Standing Stones. London.

Ashmore, P 1996 Neolithic and Bronze Age Scotland. London.

Ballin, T B 2004 The worked quartz vein at Cnoc Dubh, Uig parish, Isles of Lewis, Western Isles: presentation and discussion of a small prehistoric quarry. Edinburgh (= Scottish Archaeological Internet Reports No. 11, www.sair.org.uk.

Ballin, T forthcoming 'Calanais stone circle: the chipped stone tools'.

Barclay, G J 1997 'The Neolithic', in Edwards, K J \& Ralston, I B M (eds) Scotland: environment and archaeology 8000 BC- ad 1000, 127-150. Chichester.

Barclay, G J \& Russell-White, C J 1993 'Excavations in the ceremonial complex of the 4th to 2nd millennium BC at Balfarg/Balbirnie, Glenrothes, Fife', Proc Soc Antiq Scot, 123, 43210.

Bass, W M 1987 Human Osteology: A Laboratory and Field Manual. Missouri.

Batt, C M \& Dockrill, S J 1998 'Magnetic moments in prehistory: integrating magnetic measurements with other archaeological data from Scatness multiperiod settlement', Archaeo Prospection, 5(4), 217-28.

van Beek, G C 1983 Dental Morphology: An Illustrated Guide. Bristol.

Birks, H J B 1973 The Present and Past Vegetation of the Isle of Skye-A Palaeo-ecological Study. Cambridge.

Boardman, S J \& Jones, G E M 1990 'Experiments on the effects of charring on cereal plant components', J Archaeol Sci, 17, 1-11.
Bradley, R 1995 'Fieldwalking without flints: worked quartz as a clue to the character of prehistoric settlement', Oxford J Archaeol, 14, 13-22.

Bradley, R 1998 The Significance of Monuments: On the Shaping of Human Experience in Neolithic and Bronze Age Europe. London.

Branigan, K \& Foster, P 2000 From Barra to Berneray: Archaeological Survey and Excavation in the Southern Isles of the Outer Hebrides. ( = Sheffield Environmental and Archaeological Research Campaign in the Hebrides 5). Sheffield.

Breathnach, A S, 1965 Frazer's Anatomy of the Human Skeleton, 6th edn. London.

Brooks, D \& Thomas, K W 1967 'The distribution of pollen grains on microscope slides. I: The non-randomness of the distribution', Pollen et Spores, 9, 621-9.

Brothwell, D R 1981 Digging up Bones. Oxford.

Brown, N forthcoming Eilean Domhnuill Loch Olabhat Pottery.

Bullock, P, Federoff, N, Jongerius, A, Stoops, G \& Tursina, T 1985 Handbook for Soil Thin-Section Description. Wolverhampton.

Burgess, C 1976 'An early Bronze Age settlement at Kilellan Farm, Islay, Argyll', in Burgess, C \& Miket, R (eds) Settlement and Economy in the $3 r d$ and 2 nd millennia $B C$ ( = BAR, Brit Ser 33). Oxford.

Campbell, S \& Coles, G 1999 Excavation of a Kerb Cairn at Cnoc an Tursa, Calanais, Isle of Lewis. University of Edinburgh, Department of Archaeology, unpublished report.

Church, M J 2003 'The carbonized plant macrofossils', in Cressey, M \& Sheridan, A (eds) A Bronze Age Cemetery, Seafield West, Inverness, Highland region. Proc Soc Antiq Scot, 133, 47-84.

Church, M J \& Cressey, M unpublished 'Plant macrofossils and charcoal from Cockburnspath, Berwickshire', Unpublished Technical Report for CFA Archaeology Ltd.

Church, M J \& Peters, C 2004 'Application of mineral magnetism in Atlantic Scotland archaeology 2: Archaeobotanical taphonomy in Atlantic Scotland', in Housley, R \& Coles, G M (eds) Atlantic connections and adaptations: economies, environments and subsistence in lands bordering the North Atlantic, Oxford: Oxbow, 99-115.

Clapham, A R, Tutin, T G \& Moore, D M 1989 Flora of the British Isles, 3rd edn. Cambridge.

Cleal, R, Walker, K \& Montague, R 1995 Stonehenge in its Landscape: 
Twentieth-Century Excavations. English Heritage Archaeological Report 10. London.

Close-Brooks, J 1995 'Excavation of a cairn at Cnip, Uig, Isle of Lewis', Proc Soc Antiq Scot, 125, 253-77.

Cope, J 1998 The Modern Antiquarian: A Pre-Millennial Odyssey Through Megalithic Britain. London.

Courty, M A, Goldberg, P \& Macphail, R 1989 Soils and Micromorphology in Archaeology. Cambridge.

Crawford, I A 1978 'A corbelled Bronze Age burial chamber and Beaker evidence from the Rosinish machair, Benbecula', Proc Soc Antiq Scot, 108, 94-107.

Crawford, I A 1996 'The Udal', Curr Archaeol, 147, 84-94.

Crawford, I A \& Switsur, R 1977 'Sandscaping and C14: the Udal, North Uist', Antiquity, 51, 124-36.

Crawford, J 1997 'Archaeological collections from sandhill sites in the Isle of Coll, Argyll \& Bute', Proc Soc Antiq Scot, 127, 467-511.

Curtis, M \& Curtis R 1990a 'Crulivig (Uig parish): possible kerb cairn', Disc Excav Scot, 1990, 49.

Curtis, M \& Curtis R 1990b 'Gearaidh Geoidaster (Uig parish): cairn, fieldwall and quartz flakes', Disc Excav Scot, 1990, 49.

Curtis, M \& Curtis R 1990c 'Totarol, Kirkibost, Great Bernera (Uig parish): kerb cairn', Disc Excav Scot, 1990, 49.

Curtis, M \& Curtis R 1991a 'Upper Breasclete (Uig parish): small kerb cairn', Disc Excav Scot, 1991, 76.

Curtis, M \& Curtis R 1991b 'Beannan Mor (Tolsta Chaolais) (Uig parish): probable burial cairn', Disc Excav Scot, 1991, 76.

Curtis, M \& Curtis R 1991c 'Crulivig Island (Uig parish): possible burial cairn or platform with stone setting', Disc Excav Scot, 1991, 76.

Curtis, M \& Curtis R 1991d 'Totarol, Kirkibost, Great Bernera (Uig parish): burial cairn', Disc Excav Scot, 1991, 76.

Curtis, M \& Curtis R 1991e 'Upper Breasclete (Uig parish): possible kerb cairn or hut circle', Disc Excav Scot, 1991, 76.

Curtis, M \& Curtis R 1992a 'Faing Mhor, Hacklete, Great Bernera (Uig parish): probable burial cairn', Disc Excav Scot, 1992, 86.

Curtis, M \& Curtis R 1992b 'Creag Ruadh, Hacklete, Great Bernera (Uig parish): possible burial cairn', Disc Excav Scot, 1992, 86.

Curtis, M \& Curtis R 1992c 'Tob Ceann a'Sgrulain, Beinn Hulavig (Uig parish): probable kerb cairn and possible burial cairn', Discovery Excav Scot 1992, 86.

Curtis, M \& Curtis R 1992d 'Cnoc na h-Inghinna Ruaidha, Breasclete (Uig parish): possible grave and cairn', Discovery Excav Scot 1992, 86.

Curtis, M \& Curtis R 1992e 'Feadan Loch Geal (Uig parish): possible burial cairn', Disc Excav Scot, 1992, 86.

Curtis, M \& Curtis R 1994 'Keava Island, East
Loch Roag (Uig parish): prehistoric burial cairn', Disc Excav Scot, 1994, 97.

Curtis, M \& Curtis R 1995 'Airigh na Beinne Bige (Callanish Site 11) (Uig parish): two kerb cairns', Disc Excav Scot, 1995, 110.

Curtis, M \& Curtis R 1996 'Druim Dubh', Curr Archaeol 147, 98-9.

Curtis, M \& Curtis R 1997 'Loch Bharavat, Callanish (Uig parish): burial cairn or dun?', Disc Excav Scot, 1997, 86.

Cushing, E J 1967 'Evidence for differential pollen preservation in late Quaternary sediments in Minnesota', Rev Palaeobot Palynol 4, 87-101.

Dearing, J 1994 Environmental Magnetic Susceptibility. Kenilworth.

Dickson, C A 1997 'Plant remains', in Mercer, R J \& Midgley, M S 'The early Bronze Age cairn at Sketewan, Balnaguard, Perth and Kinross', Proc Soc Antiq Scot, 127, 318-22.

Dickson, C A 1998 'Past uses of turf in the Northern Isles', in Mills, C \& Coles, G M (eds), Life on the Edge: Settlement in Marginal Areas, 105-9. Oxford.

Downes, J 1994 'Excavation of a Bronze Age burial at Mousland, Stromness, Orkney', Proc Soc Antiq Scot, 124, 141-54.

Downes, J 1999 'Cremation: a spectacle and a journey', in Downes, J \& Pollard, T (eds) The Loved Body's Corruption: Archaeological Contributions to the Study of Human Mortality, 19-29. Glasgow.

Dunwell, A J, Neighbour, T \& Cowie, T G 1995 ‘A cist burial adjacent to the Bronze Age cairn at Cnip, Uig, Isle of Lewis', Proc Soc Antiq Scot, 125, 279-88.

Edmonds, M 1995 Stone Tools and Society. London.

Edmonds, M 1998 'Sermons in stone: identity value and stone tools in Later Neolithic Britain', in Edmonds, M \& Richards, C (eds) Understanding the Neolithic of North-Western Europe, 248-76. Glasgow.

Ellison, A \& Drewitt, P L 1971 'Pits and post-holes in the British early Iron Age: some alternative explanations' Proc Prehist Soc, 37, 183-94.

Faegri, K \& Iverson, J 1989 Textbook of Pollen Analysis, 4th edn. Chicester.

Flitcroft, C, Johnson, M, \& Coles, G 2001 The Calanais Field Project: Second Interim Report 1999-2000. Department of Archaeology, University of Edinburgh, unpublished interim report.

Fraser, J G 1911 The Golden Bough: a Study in Magic and Religion. London.

van Gennep, A 1960 The Rites of Passage. Chicago.

Gibson, A M 1995 'The Neolithic pottery from Allt Chrisal', in Branigan, K \& Foster, P (eds) Barra: Archaeological Research on the Tangaval Peninsula. Sheffield Academic Press (SEARCH), 1, 100-15.

Gibson, A M forthcoming 'Northton, Harris: the Beaker pottery assemblage'. 
Green, S H 1980 The Flint Arrowheads of the British Isles ( = BAR, Brit Ser 75). Oxford.

Haggarty, A 1991 'Machrie Moor, Arran: recent excavations at two stone circles', Proc Soc Antiq Scot, 121, 51-94.

Harding, D W 2000 The Hebridean Iron Age: 20 years research. Department of Archaeology, University of Edinburgh, Occasional Paper 20. Edinburgh.

Henshall, A S 1972 The Chambered Tombs of Scotland, 2. Edinburgh.

Henshall, A \& Johnson, M in prep 'Calanais stone circle: the pottery'.

Hodgson, J M (ed) 1976 Soil Survey Field Handbook, Soil Survey of England and Wales Technical Monograph 5. London.

Holm, L \& Knutsson, K (eds) 1998 Proceedings from the Third Flint Alternatives Conference at Uppsala, Sweden, October 18-20, 1996.

Department of Archaeology and Ancient History, Uppsala University, Occasional Papers in Archaeology 16.

Hubbard, R N L B 1990 'Quantifying preservation and distortion in carbonized seeds, and investigating the history of friké production', $J$ Archaeol Sci, 16, 103-6.

Johnson, M forthcoming a 'Northton Harris: the Bronze Age and later pottery assemblage', in Simpson, D D A, Murphy, E M \& Gregory, R A forthcoming Excavations at Northton, Isle of Harris.

Johnson, M forthcoming b 'Northton Harris: the Neolithic pottery assemblage', , in Simpson, D D A, Murphy, E M \& Gregory, R A forthcoming Excavations at Northton, Isle of Harris.

Jones, M 1991 'Sampling in palaeoethnobotany', in Zeist, W, van, Wasylikowa, K \& Behre, K E (eds) Progress in Old World Palaeoethnobotany, 53-62. Rotterdam.

Jones-Bley, K 2000 'Sintashta burials and their Western European counterparts' in Davis-Kimball, J, Murphy, E M, Koryakova, L \& Yablonsky, L T (eds) Kurgans, Ritual Sites, and Settlements: Eurasian Bronze and Iron Age. Oxford (= British Archaeological Reports International Series No. 890), 126-133.

Kenward, H K, Hall, A R \& Jones, A K G 1980 ‘A tested set of techniques for the extraction of plant and animal macrofossils from waterlogged archaeological deposits', Science and Archaeology, 22, 3-15.

Knutsson, K 1998 'Convention and lithic analysis', in Holm, L \& Knutsson, $\mathrm{K}$ (eds) Proceedings from the Third Flint Alternatives Conference at Uppsala, Sweden, October 18-20, 1996.

Department of Archaeology and Ancient History, Uppsala University, Occasional Papers in Archaeology 16, 71-94.

Lacaille, A D 1937 'A stone industry, potsherds and a bronze pin from Valtos, Uig, Lewis', Proc Soc Antiq Scot, 71, 279-96.
Lacaille, A D 1954 The Stone Age in Scotland. Oxford.

Lebour, N 1914 'White quartz pebbles and their archaeological signficance', Trans Dumfriesshire \& Galloway Natur Hist Soc, 2, 121-34.

Lynch, F 1993 Excavations in the Brenig Valley: A Mesolithic and Bronze Age Landscape in North Wales. The Cambrian Archaeological Association. Aberystwyth.

McKinley, J I 1993 'Bone fragment size and weights of bone from modern British cremations and the implications for the interpretation of archaeological cremations', Intl J Osteoarchaeol, 3, 283-7.

Marshall, P, Parker Pearson, M, Mulville, J \& Smith, H 1999 The Late Bronze Age and Early Iron Age Community at Cladh Hallan, South Uist, Excavations in 1999. University of Sheffield, unpublished report.

Megaw, J V S \& Simpson, D D A 1961 'A short cist burial on North Uist and some notes on the prehistory of the Outer Isles in the 2nd millennium BC', Proc Soc Antiq Scot, 91, 62- 78.

Mercer, J 1971 'A regression-time stone-workers' camp, 33ft OD, Lussa River, Isle of Jura', Proc Soc Antiq Scot, 103, 1-33.

Metcalf, P \& Huntington, R 1991 Celebrations of Death: the Anthropology of Mortuary Ritual. Cambridge.

Moore, P D \& Webb, J A 1978 An Illustrated Guide to Pollen Analysis. London.

Moore, P D, Webb, J A \& Collinson, M E 1991 Pollen Analysis, 2nd edn. Oxford.

Murphy, C P 1986 Thin-Section Preparation of Soils and Sediments. Berkhamsted.

Neighbour, T 1996a 'A new cairn at Callanish', Curr Archaeol 147, 116-17.

Neighbour, T 1996b Excavation of a Kerb Cairn near Calanais, Isle of Lewis: Data Structure Report. CFA Report no 266.

Pankhurst, R J \& Mullin, J M 1994 Flora of the Outer Hebrides. London.

Parker Pearson, M 1993 Bronze Age Britain. London.

Parker Pearson, M 1999 The Archaeology of Death and Burial. Sutton.

Parker Pearson, M \& Ramilisonin A 1998 'Stonehenge for the ancestors: the stones pass on the message' Antiquity, 72, 308-26.

Parker Pearson, M, Marshall, P, Mulville, J, Smith, H \& Ingrem, C 2000 Cladh Hallan: Excavation of a Late Bronze Age to Early Iron Age Settlement, August-September 2000. University of Sheffield, unpublished report.

Patzold, J 1960 'Rituelles Pflugen beim vorgeschichtlichen Totenkult - ein alter indo-germanischer Bestattungsbrauch?', Prähistoriche Zeitschrift, 38, 189-240.

Peters, C, Church, M J \& Batt, C 2004 'Application of mineral magnetism in Atlantic Scotland archaeology 1: techniques, magnetic enhancement and the identification of fuel sources', in Housley, R \& Coles, G M (eds), Atlantic Connections and 
Adaptations: Economies, Environments and

Subsistence in Lands Bordering the North

Atlantic, Oxford, 86-95.

Peters, C, Church, M J \& Coles, G M 2000 'Mineral magnetism and archaeology at Galson on the Isle of Lewis, Scotland', Physics and Chemistry of the Earth (A), 25(5), 455-60.

Pitts, M 2000 Hengeworld. London.

Ponting, M, Ponting, G \& Curtis, R 1976 'Callanish IV and Ceann Thulabeg', Disc Excav Scot, 1976, 57.

Ritchie, J N G \& Crawford, J 1978 'Excavations at Sorisdale and Killunaig, Coll', Proc Soc Antiq Scot, 109, 75-84.

Ritchie, J N G \& MacLaren, A 1972 'Ring-cairns and related monuments in Scotland', Scot Archaeol Forum, 4, 1-17.

Ritchie, J N G \& Stevenson, J B 1982 'Cists at Traigh Bhan, Islay, Argyll', Proc Soc Antiq Scot, 112, 550-59.

Ritchie, J N G, Thornber, I, Lynch, F \& Marshall, D N 1975 'Small cairns in Argyll: some recent work', Proc Soc Antiq Scot, 106, 15-38.

Robinson, M 1988 'The significance of the tubers of Arrheanatherum elatius (L) Beauv, from Site 4, Cremation 15,11', in Lambrick, G et al. (eds) The Rollright Stones, 102. English Heritage Archaeological Report 6. London.

Saville, A \& Ballin, T B 2001 'Quartz technology in Scottish prehistory', Lithics, 21, 45-51.

Scott, J G 1991 'The stone circles at Temple Wood, Kilmartin, Argyll', Glasgow Archaeol J, 15, 53124.

Scott, J G 1992 'Mortuary structures and megaliths', in Sharples, N \& Sherdan, A (eds) Vessels for the Ancestors: Essays on the Neolithic of Britain and Ireland, 104-19. Edinburgh.

Scott, W L 1935 'The chambered cairn of Clettraval, North Uist', Proc Soc Antiq Scot, 69, 480-536.

Scott, W L 1948 'The chamber tomb of Unival, North Uist', Proc Soc Antiq Scot, 82, 1-49.

Scott, W L 1951 'Eilean an Tighe: a pottery workshop of the 2nd millennium BC', Proc Soc Antiq Scot, 85, 1-37.

Shepherd, I A G 1976 'Preliminary results from the Beaker settlement at Rosinish, Benbecula', in Burgess, C \& Miket, R (eds) Settlement and Economy in the $3 r d$ and 2 nd millennia $B C$ ( = BAR, Brit Ser 33), 209-16. Oxford.
Shepherd, I A G \& Tuckwell, A N 1977 'Traces of beaker-period cultivation at Rosinish, Benbecula', Proc Soc Antiq Scot, 108, 108-13.

Simpson, D D A 1976 'The later Neolithic and Beaker settlement site at Northton, Isle of Harris', in Burgess, C \& Miket, R (eds) Settlement and Economy in the $3 r d$ and 2 nd millennia $B C$ ( = BAR, Brit Ser 33), 221-26. Oxford.

Stace, C 1991 New Flora of the British Isles. Cambridge.

Taçon, P S C 1991 'The power of stone: symbolic aspects of stone use and tool development in western Arnhem Land, Australia', Antiquity, $65,192-207$.

Tarlow, S 1995 'Scraping the bottom of the barrow: an argricultural metaphor in Neolithic/Bronze Age European burial practice', J Theoretical Arch, 3/4, 123-45.

Taylor, T 1996 The Prehistory of Sex: Four Million Years of Human Sexual Culture. London.

Ubelaker, D H 1978 Human Skeletal Remains. Washington.

University of Glasgow, Department of Geography 1978 Callanish: a Map of the Standing Stones and Circles at Callanish, Isle of Lewis, with a Detailed Plan of Each Site. Glasgow.

Warren, G M \& Neighbour, T 2004 'Quality quartz: working stone at Olcote Kerbed Cairn, Calanais, Lewis', Norwegian Archaeology Review, 37(2).

Wells, C 1960 'A study of cremation', Antiquity, 34, 29.

Whittaker, J C 1994 Flintknapping: Making and Understanding Stone Tools. Austin.

Wickham-Jones, C R 1986 'The procurement and use of stone for flaked tools in prehistoric Scotland', Proc Soc Antiq Scot, 116, 1-10.

Wickham-Jones, C R 1990 Rhum: Mesolithic and Later Sites at Kinloch. Excavations 1984-86. ( = Society of Antiquaries of Scotland Monogr 7). Edinburgh.

Wickham-Jones, C R 1995 'The flaked stone tools', in Brannigan, $\mathrm{K} \&$ Foster, $\mathrm{P}$ (eds) Barra: Archaeological Research on Ben Tangaval. Sheffield Environmental and Archaeological Research Campaign in the Hebrides, 1, 120-39. Sheffield. 


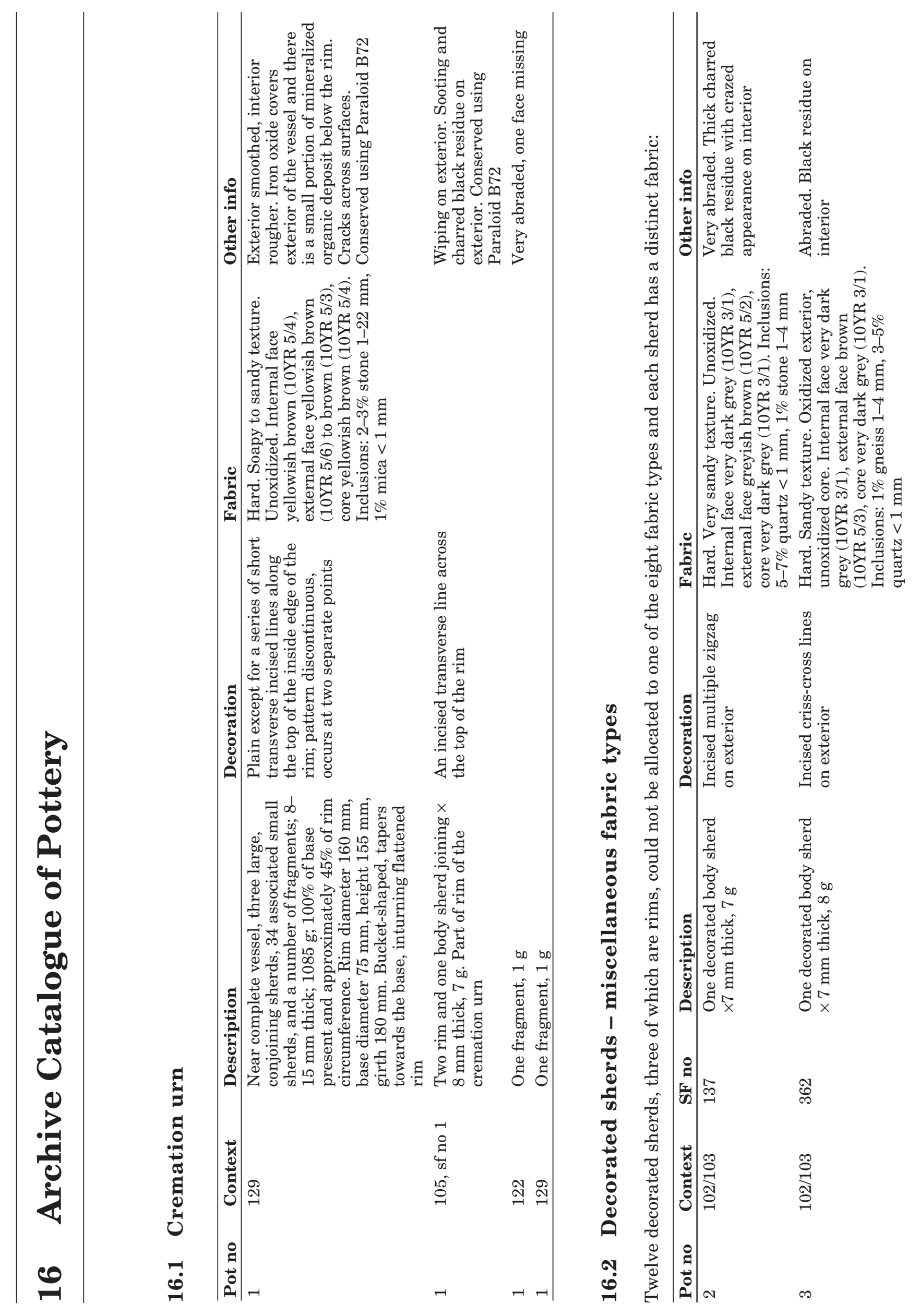




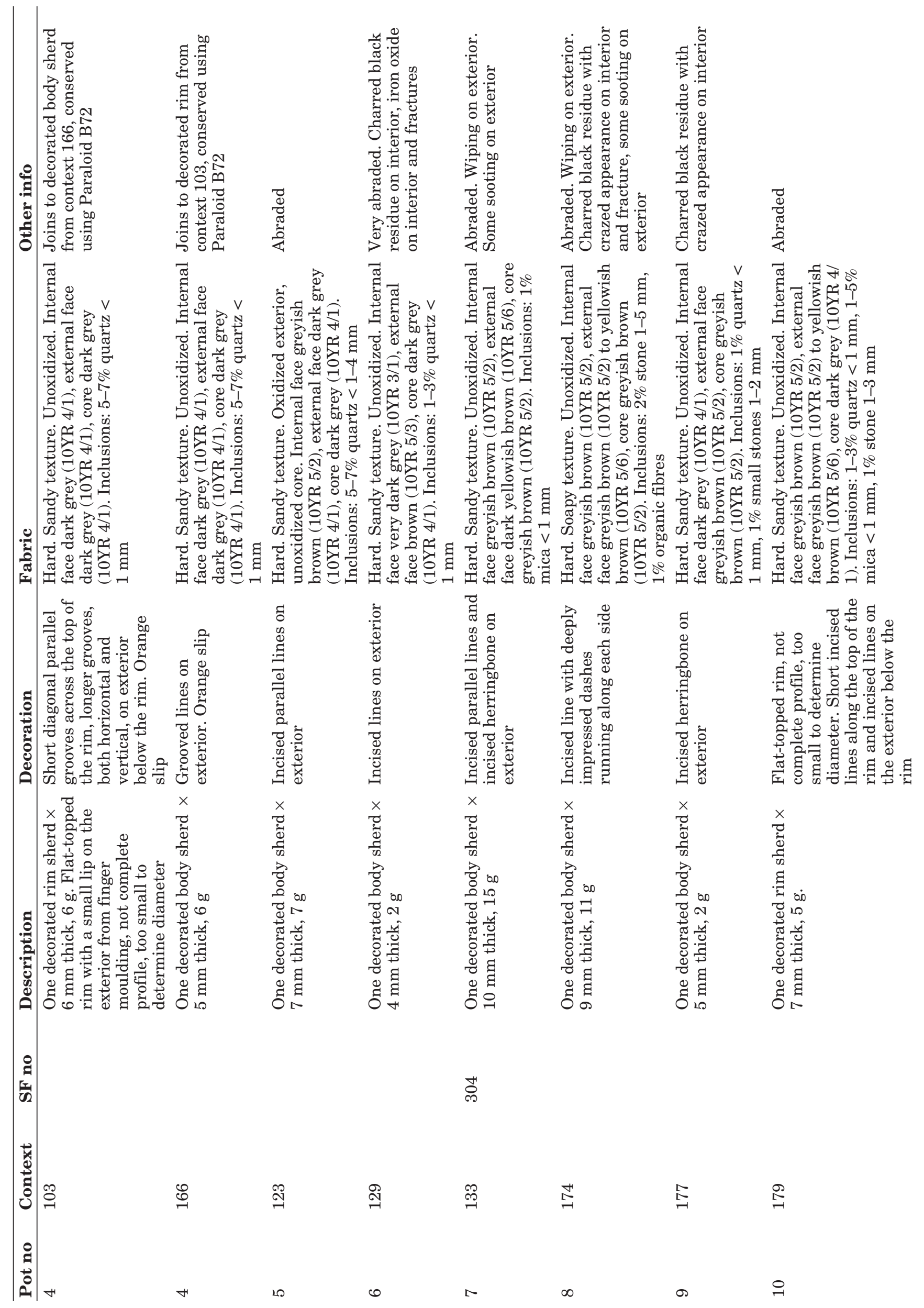




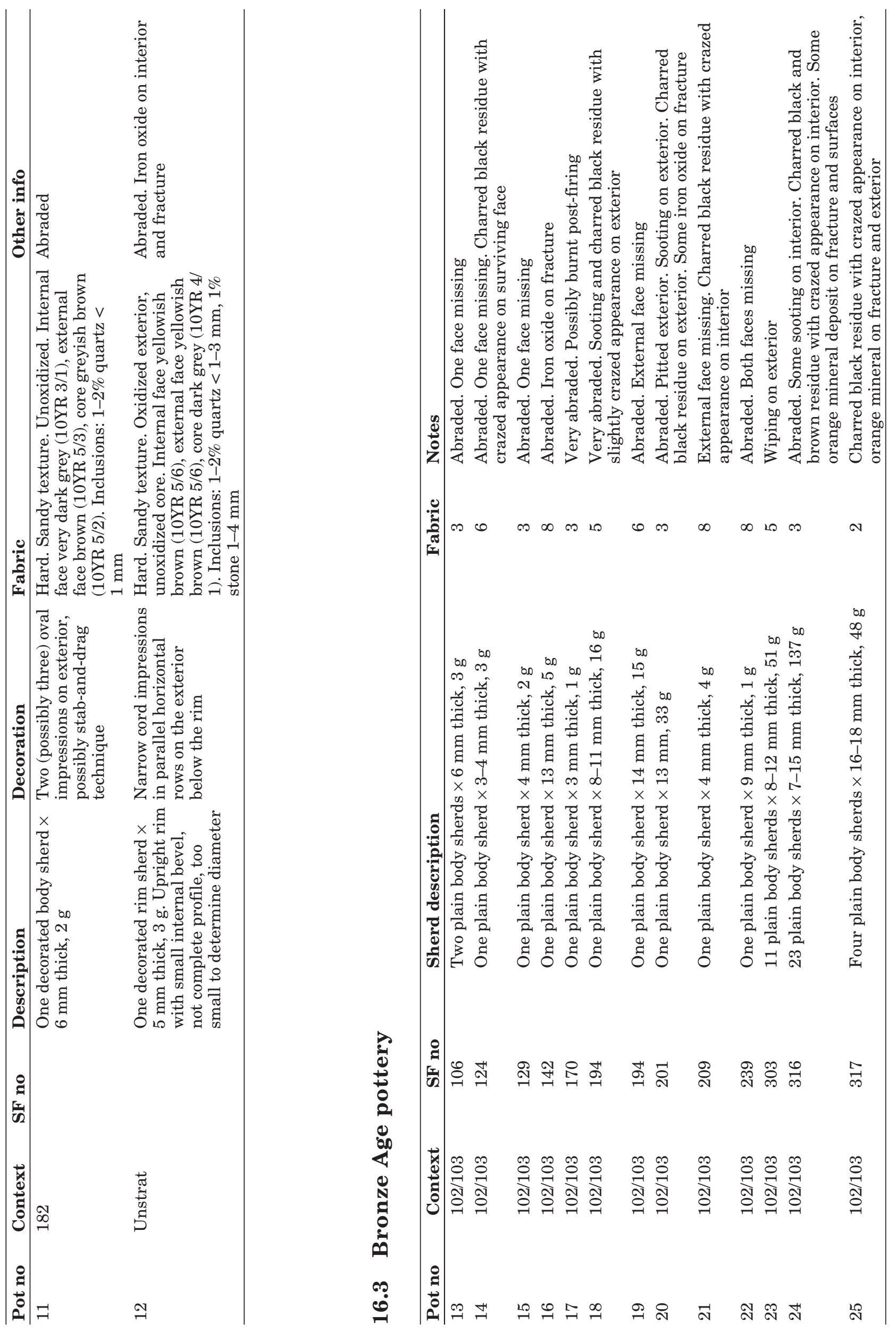




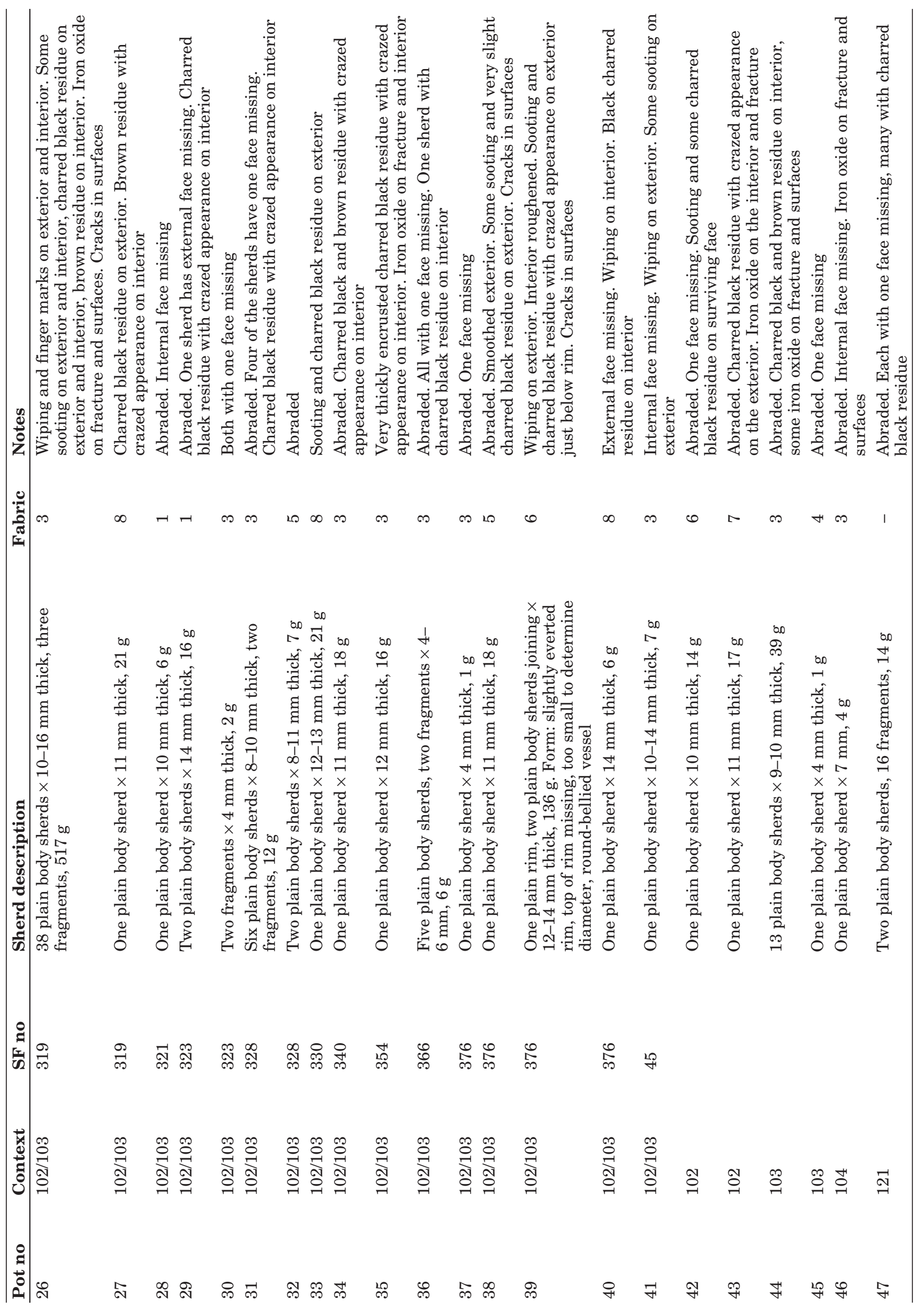




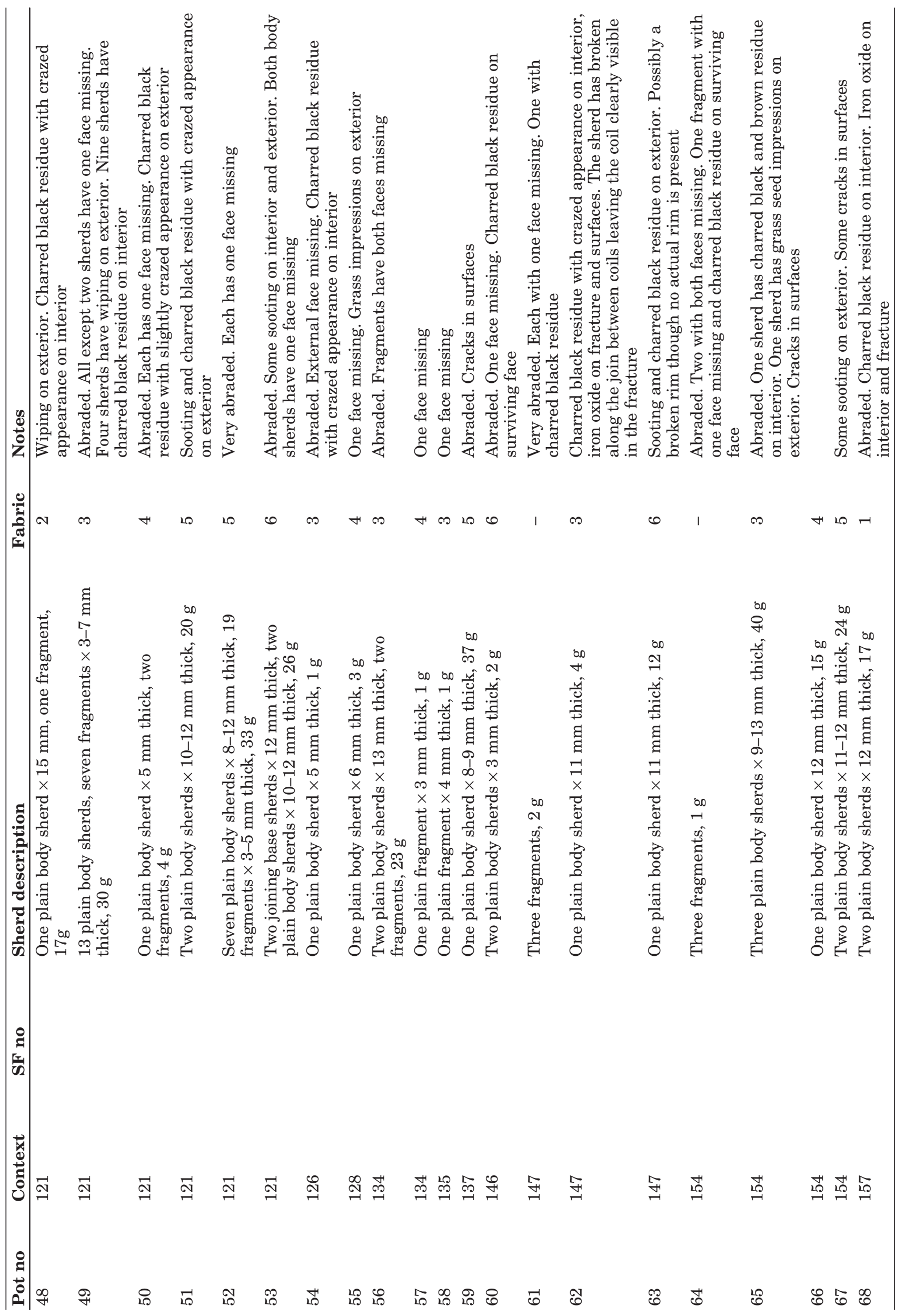




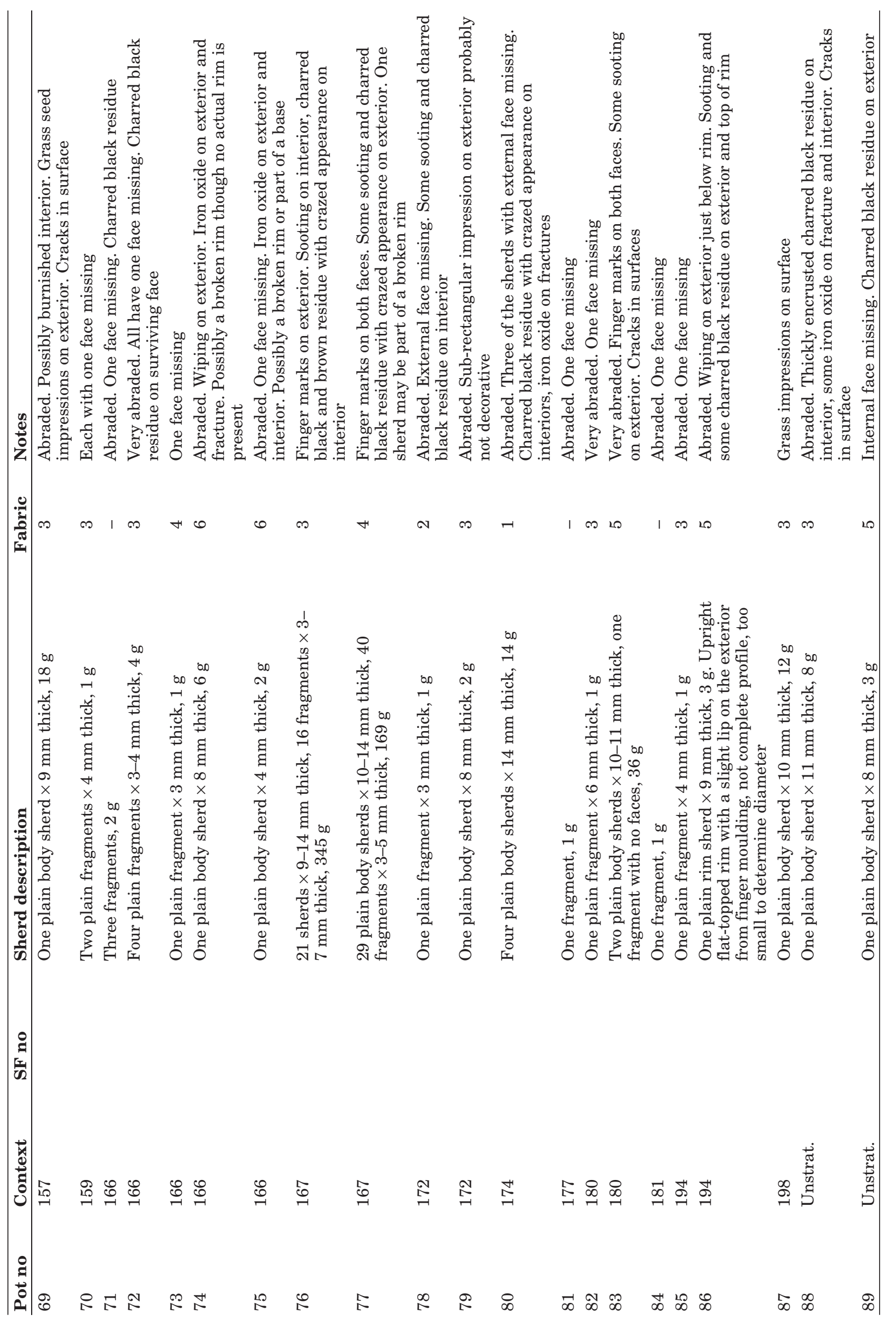



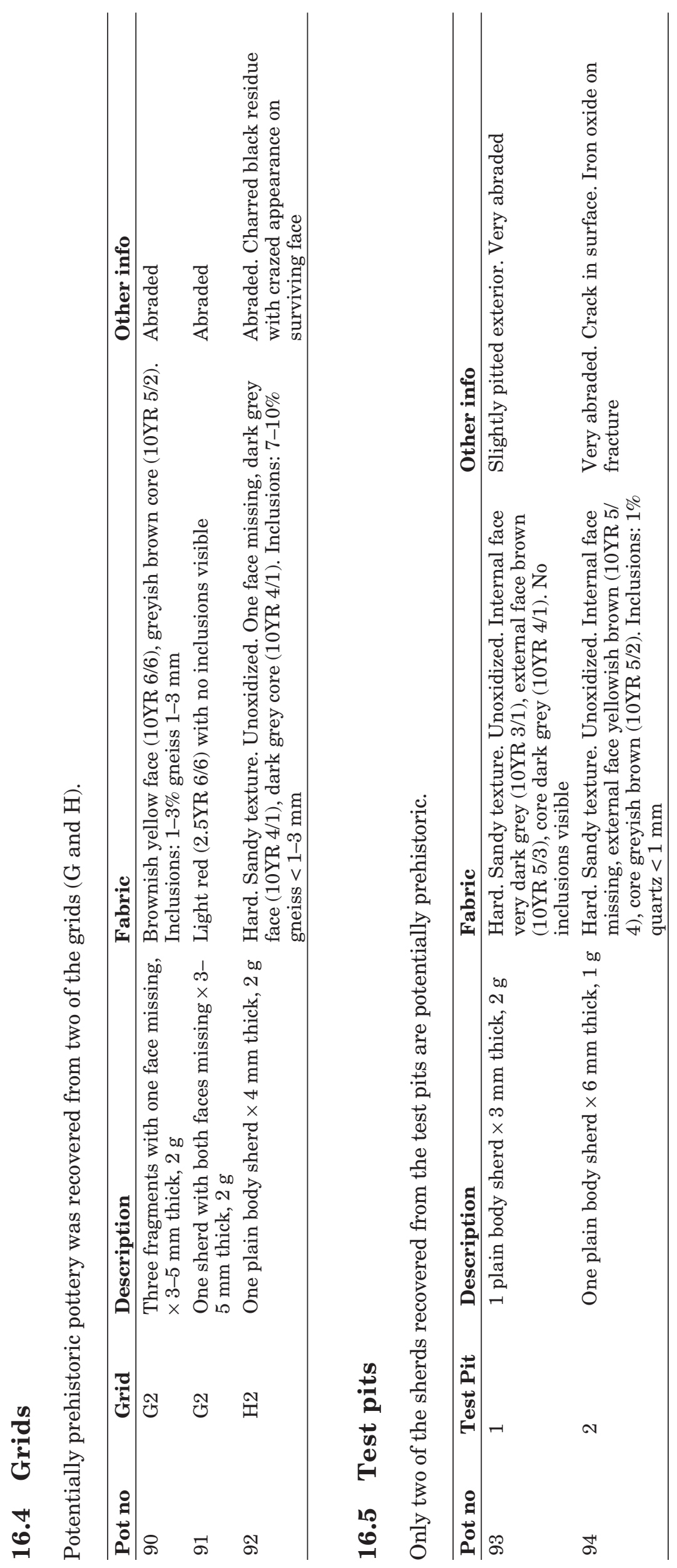